\title{
Microgrid Energy Management System Integration with Advanced Distribution Management System
}

Energy Systems Division 


\begin{abstract}
About Argonne National Laboratory
Argonne is a U.S. Department of Energy laboratory managed by UChicago Argonne, LLC under contract DE-AC02-06CH11357. The Laboratory's main facility is outside Chicago, at 9700 South Cass Avenue, Lemont, Illinois 60439. For information about Argonne and its pioneering science and technology programs, see www.anl.gov.
\end{abstract}

\title{
DOCUMENT AVAILABILITY
}

Online Access: U.S. Department of Energy (DOE) reports produced after 1991 and a growing number of pre-1991 documents are available free at OSTI.GOV (http://www.osti.gov/),

a service of the US Dept. of Energy's Office of Scientific and Technical Information.

Reports not in digital format may be purchased by the public from the National Technical Information Service (NTIS):

U.S. Department of Commerce

National Technical Information Service

5301 Shawnee Road

Alexandria, VA 22312

www.ntis.gov

Phone: (800) 553-NTIS (6847) or (703) 605-6000

Fax: (703) 605-6900

Email: orders@ntis.gov

Reports not in digital format are available to DOE and DOE contractors from the Office of Scientific and Technical Information (OSTI):

U.S. Department of Energy

Office of Scientific and Technical Information

P.O. Box 62

Oak Ridge, TN 37831-0062

www.osti.gov

Phone: (865) 576-8401

Fax: (865) 576-5728

Email: reports@osti.gov

\section{Disclaimer}

This report was prepared as an account of work sponsored by an agency of the United States Government. Neither the United States Government nor any agency thereof, nor UChicago Argonne, LLC, nor any of their employees or officers, makes any warranty, express or implied, or assumes any legal liability or responsibility for the accuracy, completeness, or usefulness of any information, apparatus, product, or process disclosed, or represents that its use would not infringe privately owned rights. Reference herein to any specific commercial product, process, or service by trade name, trademark, manufacturer, or otherwise, does not necessarily constitute or imply its endorsement, recommendation, or favoring by the United States Government or any agency thereof. The views and opinions of document authors expressed herein do not necessarily state or reflect those of the United States Government or any agency thereof, Argonne National Laboratory, or UChicago Argonne, LLC. 
ANL/ESD-20/10

\section{Microgrid Energy Management System Integration with Advanced Distribution Management System}

by

Ravindra Singh, ${ }^{1}$ Jim Reilly, ${ }^{2}$ Albert Phan, ${ }^{3}$ Eric Stein, ${ }^{3}$ Dimitrije Kotur, ${ }^{4}$ Mladen Petrovic, ${ }^{4}$ Will Allen, ${ }^{5}$ and Monica Smith ${ }^{5}$

${ }^{1}$ Energy Systems Division, Argonne National Laboratory

${ }^{2}$ Reilly Associates

${ }^{3}$ PECO, an Exelon Company

${ }^{4}$ Schneider Electric

${ }^{5}$ Schweitzer Engineering Laboratories, Inc.

for

U.S. Department of Energy, Office of Electricity

September 2020 
This page intentionally left blank 


\section{CONTENTS}

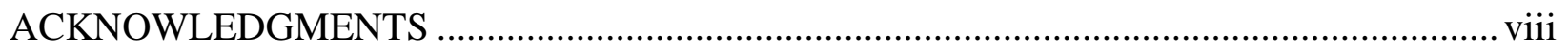

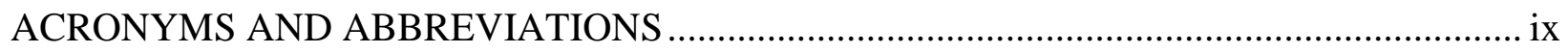

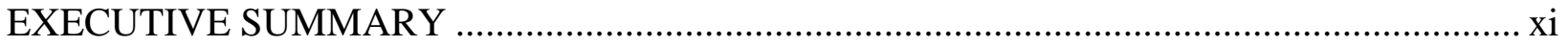

INTEGRATION OF THE ADMS/DERMS AND MICROGRID CONTROLLER .................. xi

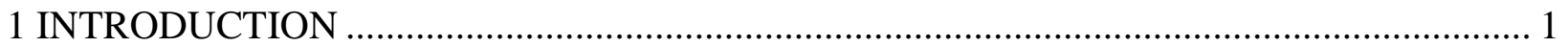

1.1 DOE/OE MICROGRID PROGRAM — INTEGRATED DISTRIBUTION

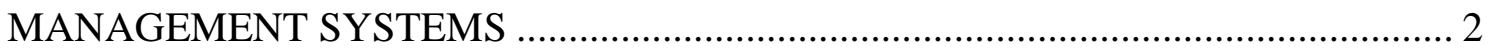

1.2 UTILITY MICROGRID MODEL INTEGRATION WITH THE DISTRIBUTION

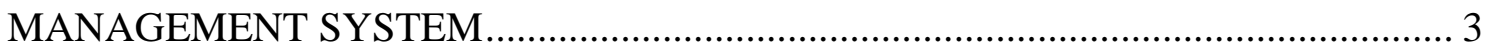

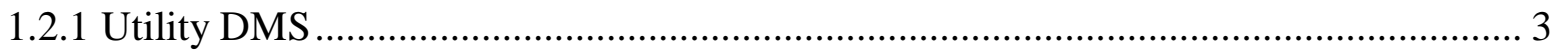

1.2.2 Microgrid Controller …………………………..................................................... 3

1.2.3 DER Modeled for Microgrid Site................................................................................... 4

1.2.4 Significance of the Project for PECO....................................................................... 4

1.3 TEAM ORGANIZATION AND COMMUNICATION STRATEGY ………………......... 5

1.4 IDMS PROJECT IMPLEMENTATION …………………………………………….... 5

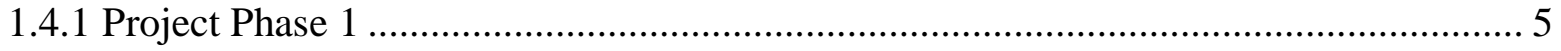

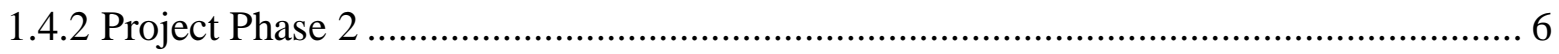

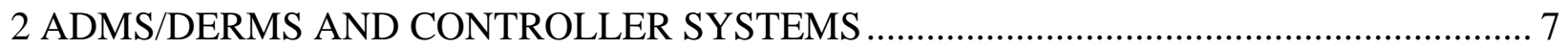

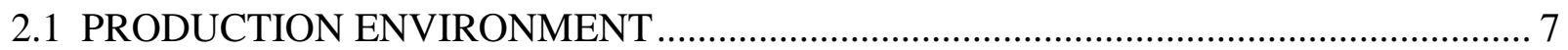

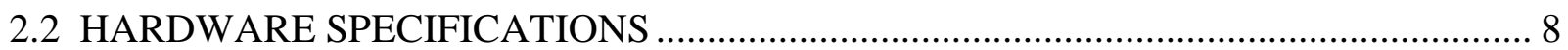

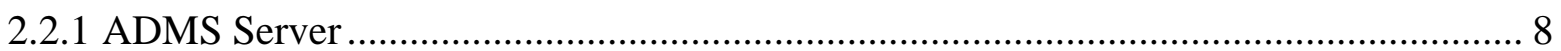

2.2.2 Virtual Machine Specifications .............................................................................. 8

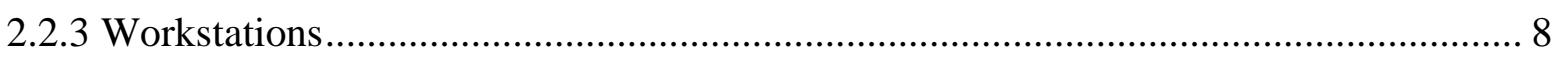

2.3 ADMS POWER APPLICATION INFRASTRUCTURE ............................................. 9

2.3.1 ADMS Power Application Modules .......................................................................... 10

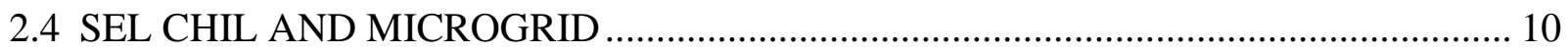

2.4.1 SEL POWERMAX Microgrid Control System Functions............................................. 12

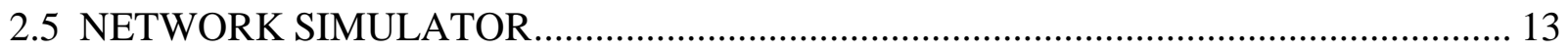

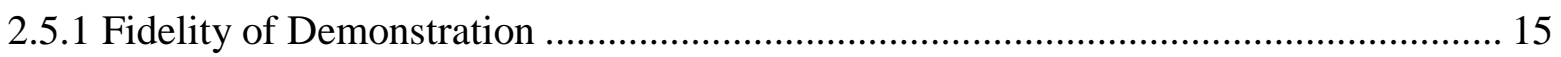

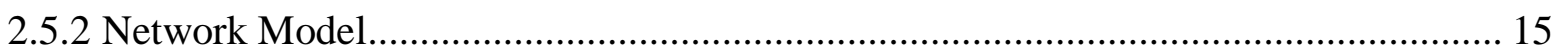

3 COMMUNICATION BETWEEN SE ADMS WITH DERMS AND SEL CHIL .................... 17

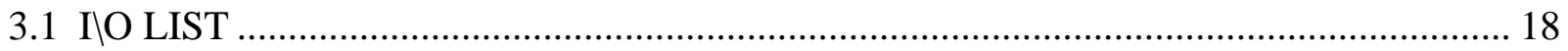




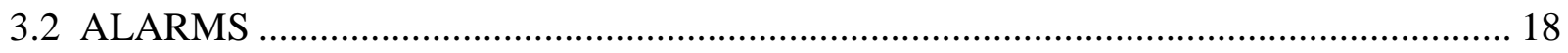

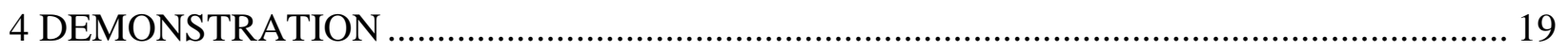

4.1 MICROGRID CONTROLLER DASHBOARD …………………………................... 19

4.2 USE CASES FOR MICROGRID FUNCTIONS AND UTILITY INTERACTION TO

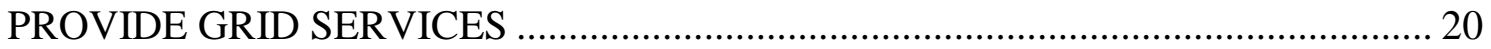

4.2.1 Use Case 1 - Microgrid Islanding and Reconnection from ADMS ............................ 20

4.2.2 Use Case 2 - DMS Visibility and Monitoring of Microgrid....................................... 21

4.2.3 Use Case 3 - Capacity Management by DMS Using Microgrid .............................. 21

4.2.4 Use Case 4 - Utility Voltage Support by ADMS Using Microgrid............................. 22

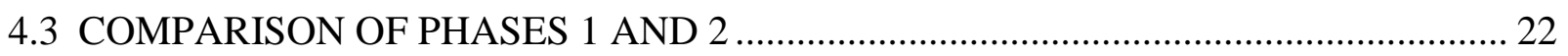

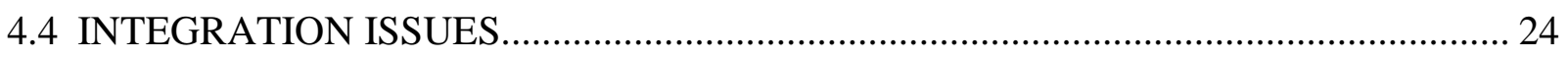

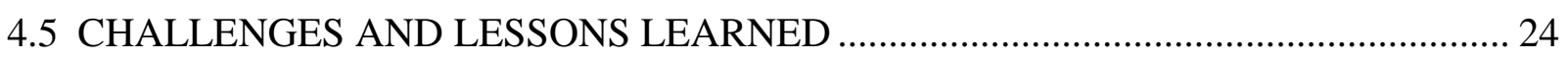

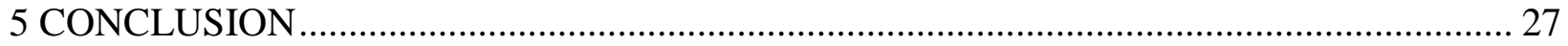

5.1 SUMMARY OF USE CASE DEMONSTRATIONS .................................................... 27

5.1.1 Use Case 1 - Microgrid Islanding and Reconnection from ADMS ............................ 27

5.1.2 Use Case 2 - DMS Visibility and Monitoring of Microgrid......................................... 28

5.1.3 Use Case 3- Capacity Management by DMS Using Microgrid .................................. 28

5.1.4 Use Case 4 - Utility Voltage Support by ADMS Using Microgrid............................ 28

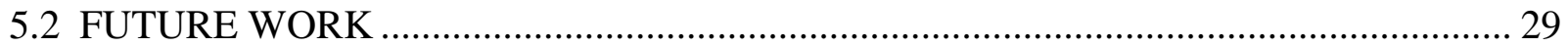

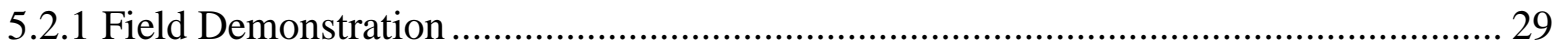

5.2.2 IDMS with Multiple Microgrids and Virtual Power Plants .......................................... 29

APPENDIX A: SEL POWERMAX MICROGRID CONTROL SYSTEM ……………............ 31

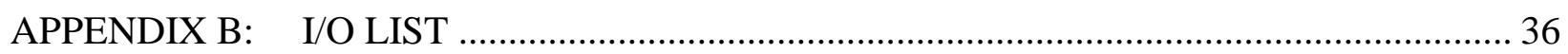

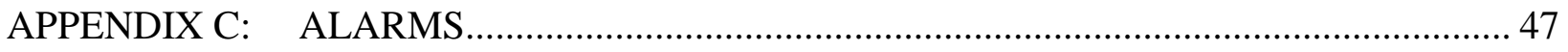

APPENDIX D: MGC DASHBOARD DESCRIPTION …………………………………..... 53

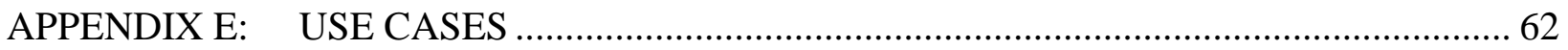

\section{FIGURES}

FIGURE 1 High level architecture of the integrated DMS project system .................................. 2

FIGURE 2 Integration of DMS and microgrid controller at the modeled utility microgrid.......... 4

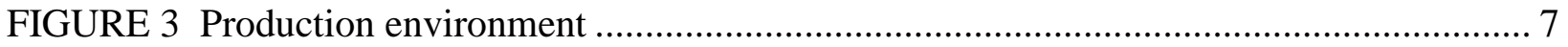




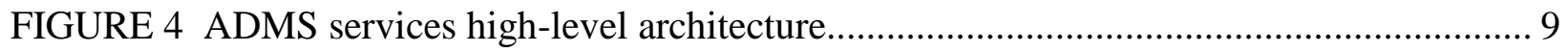

FIGURE 5 EcoStruxure ADMS used in Phase 1 and Phase 2................................................ 10

FIGURE 6 SEL POWERMAX MGC architecture................................................................. 11

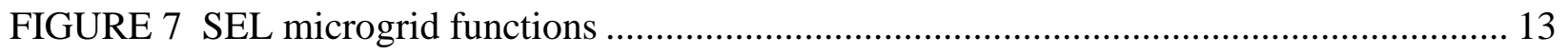

FIGURE 8 Two simulators: ADMS network simulator and SEL microgrid controller .............. 14

FIGURE 9 Network simulator components and data flows ............................................. 14

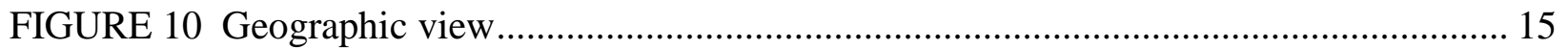

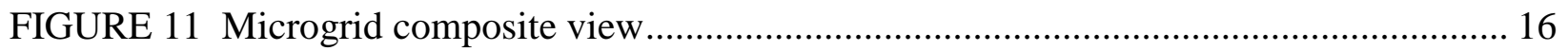

FIGURE 12 Network simulator components and data flows ........................................... 17

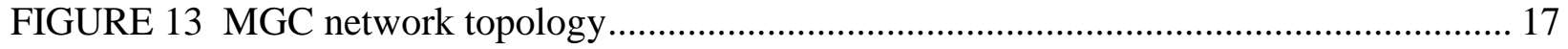

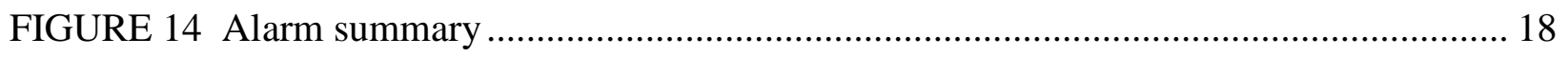

FIGURE 15 MGC dashboard DERMS user interface ........................................................ 19

FIGURE 16 MGC dashboard user interface ............................................................................. 19

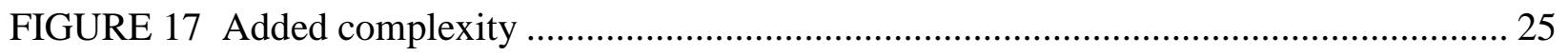

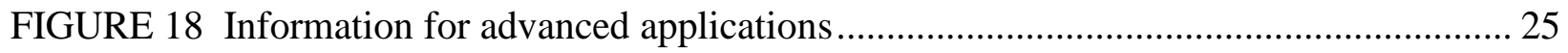

FIGURE 19 Distribution bus with multiple microgrids, VPPs and aggregators ....................... 30

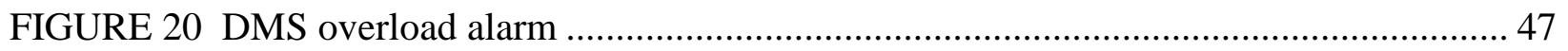

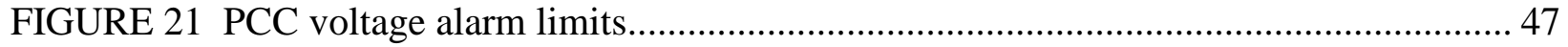

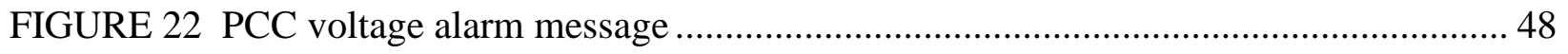

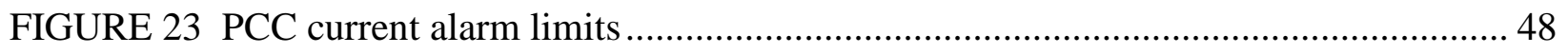

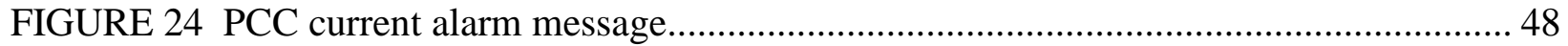

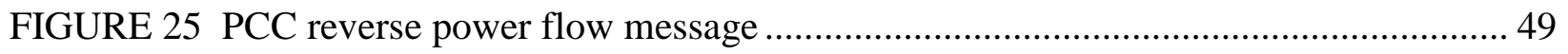

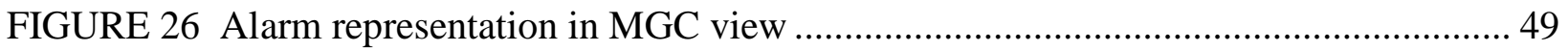

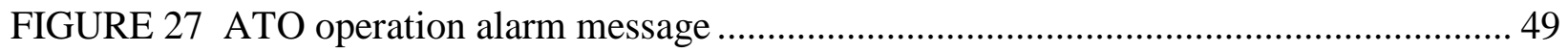

FIGURE 28 Breaker protection trip alarm message ......................................................... 49

FIGURE 29 Breaker change of state alarm message ...................................................... 50

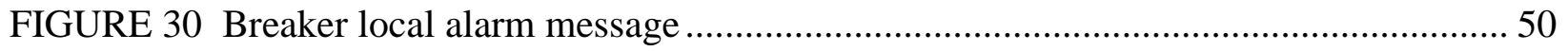

FIGURE 31 Breaker general alarm message .................................................................. 50

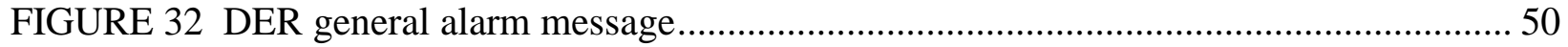

FIGURE 33 DER availability alarm message .............................................................. 51

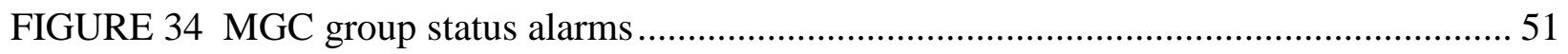


FIGURE 35 ADMS control mode alarm ………………................................................. 51

FIGURE 36 Master MGC controller disabled alarm................................................................. 51

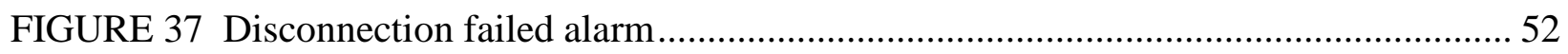

FIGURE 38 Reconnection failed alarm ............................................................................ 52

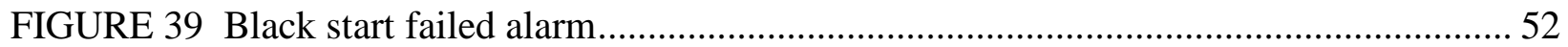

FIGURE 40 MGC any communication alarm message............................................................... 52

FIGURE 41 a.) PCC information on the MGC dashboard, b.) PCC information in the MGC

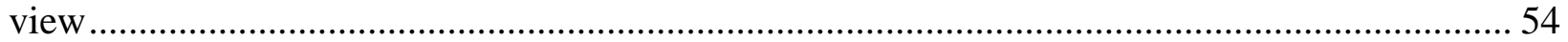

FIGURE 42 a.) MGC dashboard when microgrid is connected to the second feeder, b.) MGC view when microgrid is connected to the second feeder .............................................................. 54

FIGURE 43 a.) MGC dashboard when microgrid is in island operation, b.) MGC view when microgrid is in island operation ............................................................................................. 55

FIGURE 44 MGC dashboard in blackout event .................................................................... 55

FIGURE 45 Alarm and status summary for different combinations of breaker status................. 56

FIGURE 46 Indication of the MGC transition and PCC relay trip................................................ 57

FIGURE 47 Production share and building share section of MGC dashboard ............................ 57

FIGURE 48 Production and consumption as seen on the MGC view ......................................... 58

FIGURE 49 MGC Dashboard with available generation parameters............................................ 59

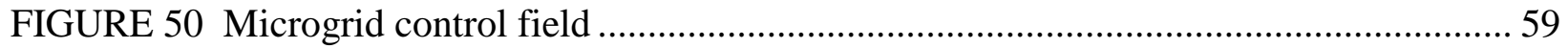

FIGURE 51 Sending a request for island mode operation ............................................................ 60

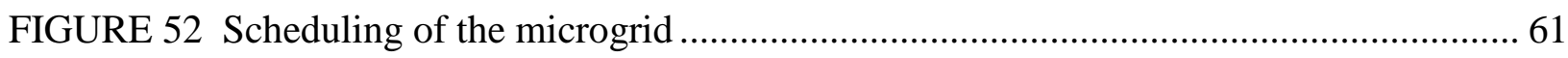

FIGURE 53 Microgrid view in initial state ………................................................................. 67

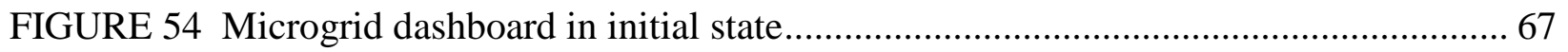

FIGURE 55 Request for planned disconnection..................................................................... 68

FIGURE 56 Operation of the microgrid in island .................................................................. 68

FIGURE 57 Microgrid dashboard in island operation.............................................................. 69

FIGURE 58 Request for grid-connected operation of the microgrid ........................................... 69

FIGURE 59 Microgrid operation in grid-connected mode after reconnection .............................. 70

FIGURE 60 SCADA alarms (control window and alarm limits) ............................................. 71

FIGURE 61 DMS alarms (right clicked to show overload limits) ............................................... 72

FIGURE 62 Monitoring of key power system parameters ........................................................... 73

FIGURE 63 State estimation report (core apps and state estimation report)................................ 74 


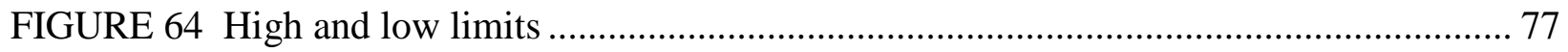

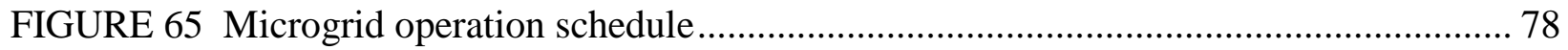

FIGURE 66 Alarm summary when LR is triggered (summary and alarm summary).................. 79

FIGURE 67 LR is triggered and calculates optimal setpoint (core apps and LR closed loop) ... 79

FIGURE 68 LR execution is successful (core apps and LR closed loop) ................................... 79

FIGURE 69 Microgrid view after execution of VVWO ............................................................ 81

\section{TABLES}

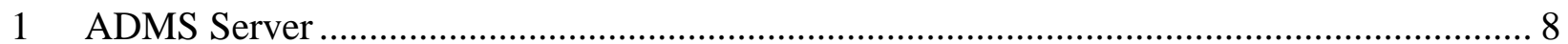

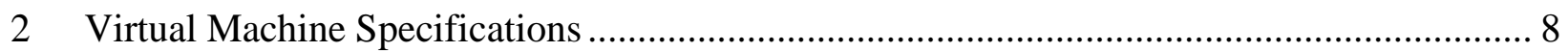

3 Phase 1 and Phase 2 Microgrid Controller Simulators............................................................ 23

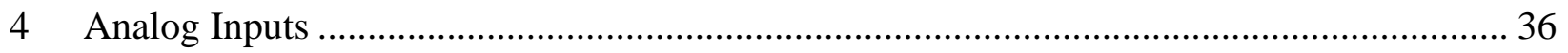

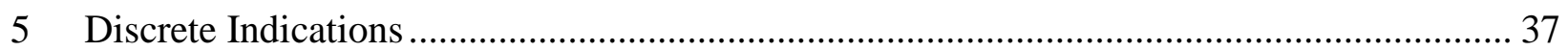

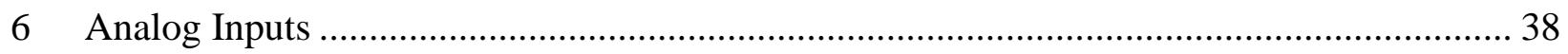

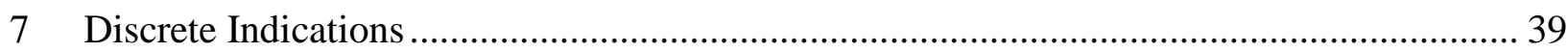

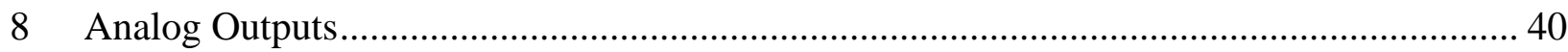

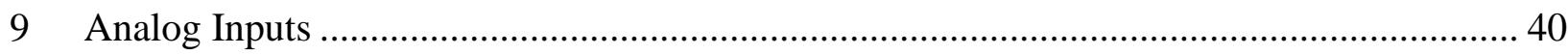

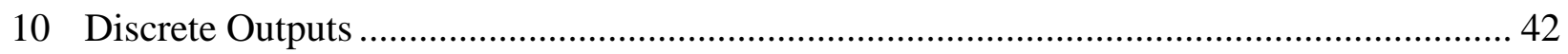

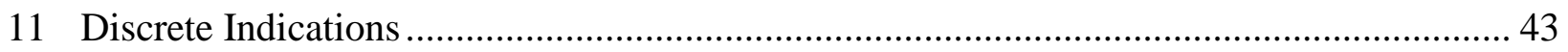

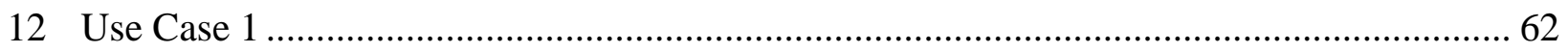

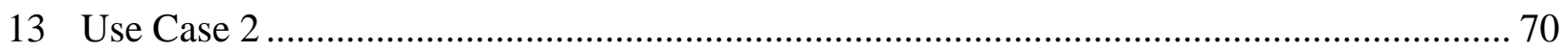

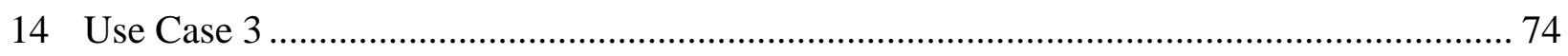

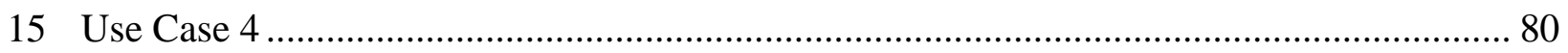




\section{ACKNOWLEDGMENTS}

This report was prepared by UChicago Argonne, LLC, operator of Argonne National Laboratory. Argonne's work was supported by the U.S. Department of Energy (DOE) under contract DE-AC02-06CH11357.

The authors wish to acknowledge the sponsorship and guidance provided by Dan Ton, Office of Electricity, Department of Energy.

We would also like to extend our special appreciation to Linda Davis-Flinn (PECO), Brent Melson (PECO), George Sey Jr. (PECO), Scott Koehler (Schneider Electric), Brandon Horne (Schneider Electric), the Schneider Electric DMS team, and SEL Engineering Services team for their contributions. 


\section{ACRONYMS AND ABBREVIATIONS}

ADMS Advanced distribution management system

ATO Automatic throw over

$\mu \mathrm{GMS} \quad$ Microgrid management system

BESS Battery energy storage system

CE Calculation engine

CFS Core function service

CHIL Controller hardware in the loop

CMS Command management service

DER Distributed energy resource(s)

DERMS Distributed energy resources management system

DG Distributed generator

DMD Dynamic mimic diagram

DMS Distribution management system

DR Demand response

ESS Energy storage systems

GMS Generation management system

IDMS Integrated Distribution Management System project (Argonne National Laboratory)

LR Load relief

MGC Microgrid control system

MTS Model topology service

NDS Network dynamics service

NMS Network model service

PCC Point of common coupling

RTDS Real-time digital simulator

SE $\quad$ Schneider Electric

SEL Schweitzer Engineering Laboratories, Inc.

SCADA Supervisory control and data acquisition

SMMS Smart meter management service

VVO Volt/VAR optimization

VVWO Volt/VAR watt optimization 
This page intentionally left blank. 


\section{EXECUTIVE SUMMARY}

The Integrated Distribution Management System (IDMS) project was initiated to demonstrate the interactive operation of microgrid systems and the distribution systems with which they interconnect. The key technologies for this are the microgrid management system and the utility distribution management system.

The IDMS project successfully demonstrated that a utility's advanced distribution management system/distributed energy resources management system (ADMS/DERMS) could effectively manage microgrids to provide visibility and control functionalities as well as use the microgrid as a dispatchable resource to support the utility grid. The DERMS accomplishes this by determining active and reactive power needs at the point of common coupling (PCC) using advanced applications like volt/VAR watt optimization (VVWO) and load relief (LR) with the underlying core applications state estimation (SE) and load flow (LF). The ADMS/DERMS can use the microgrid as a resource to resolve and prevent violations in the grid and to optimize the operational working state of the grid.

The IDMS project demonstrated that a utility-operated ADMS with embedded DERMS functionality can flexibly manage a variety of microgrids and other aggregated distributed energy resources (DER) in concert with the wider distribution grid. Microgrids can provide grid services in any number of different ways to meet the operational needs of the distribution utility. The manner of aggregation - microgrid or virtual power plant — is not necessarily relevant to the utility as long as the grid services from the aggregated DER are available and can be managed by its ADMS/DERMS for the stability and reliability of the grid.

The IDMS project demonstrated this integrated ADMS concept by combining hardware/software-in-the-loop testing with commercial products from different vendors and a utility's network model.

The project integrated the Schneider Electric EcoStruxure ${ }^{\mathrm{TM}}$ ADMS with DERMS with the Schweitzer Engineering Laboratories (SEL) POWERMAX ${ }^{\circledR}$ Microgrid Control System, and the simulated resources with energy company PECO's model of a utility-owned microgrid, establishing an operational relationship in which the utility manages the operational functionality of a microgrid at the PCC and that provides the utility with the capability to control the comprehensive power system, inclusive of the macrogrid and microgrid.

\section{INTEGRATION OF THE ADMS/DERMS AND MICROGRID CONTROLLER}

\section{Use Case 1 - Microgrid Islanding and Reconnection by ADMS}

Use Case 1 demonstrated that the ADMS/DERMS could be used by distribution system operators to manage planned and unplanned islanding of the microgrid from the utility grid. This showed compliance with the requirements of IEEE Std 2030. $7^{\mathrm{TM}}$ for connecting/disconnecting (and transitions) at the point of interconnection. 


\section{Use Case 2 -Visibility and Monitoring of Microgrid by ADMS}

Use Case 2 demonstrated that the ADMS/DERMS could give distribution system operators visibility of the microgrid, and the DER within the microgrid, to manage the impacts of DER on their systems and the ability to provide information to transmission system operators.

\section{Use Case 3 - Capacity Management Using Microgrid by ADMS}

Use Case 3 defined scenarios for operators to manage system capacity constraints and control active power flows at the PCC using ADMS/DERMS. The load relief function was used as a resource to provide flexible grid services (real power and frequency support) to the utility grid. This function could be further extended to utilize other customer, utility, and third party owned resources, such as utility owned and operated DERs, to provide capacity service.

\section{Use Case 4 -Voltage Support Using Microgrid by ADMS}

Use Case 4 defined scenarios for how ADMS/DERMS could be used by the system operator to manage the reactive power of the microgrid and resolve voltage and reactive power violations at the PCC. The ADMS/DERMS demonstrated the VVWO function using the microgrid as a resource in providing flexible grid services (voltage support).

Whether the microgrid is owned by the customer, utility, or a third party, or whether the microgrid controller is developed by the same vendor as that of the ADMS/DERMS, an integrated system that provides interactive control is essential. An integrated DMS requires complex combinations of input/output points and command logic for decision-making for both the utility ADMS/DERMS and the microgrid controller. Specifying these I/O points, resolving these complexities, and bringing them together in a microgrid controller dashboard with alarms necessary for the operation of the microgrid from the ADMS/DERMS, for use by DSO and microgrid operators, are all major achievements of this project.

The report is organized according to the project plan and deliverables to the DOE Microgrid Program. Details on the use cases, I/O points for the DMS, and microgrid controller interface and communications are included in the Appendices.

\section{Terminology}

This report includes references to ADMS, DMS and DERMS, which are terms of varying definitions and interpretations in the industry. For purposes of this report, the usage of these terms is as follows:

- ADMS refers to Schneider Electric's ADMS solution.

- PECO is using DMS and SCADA as modules of Schneider Electric's ADMS in their existing production implementation.

- $\quad$ PECO uses the term DMS when it refers to their deployment of Schneider Electric's ADMS.

For the IDMS project, in addition to DMS and SCADA, PECO is using Schneider's DERMS as a module of ADMS. 


\section{INTRODUCTION}

Microgrids are a special configuration of distributed energy resources (DERs) — a group of interconnected loads and distributed energy resources within a clearly defined electrical boundary that acts as a single controllable entity with respect to the grid. The microgrid controller is the technology that defines the microgrid's functionality with respect to the resources within its boundaries and at the point of interconnection with the grid. It provides local control and intelligence over the microgrid's DERs and can thus be viewed as a form of distributed energy resources management system (DERMS) itself. As microgrids are deployed further on utility distribution networks, there will be impacts on the grid itself and services to mitigate them, as well as services that enhance the value of the DERs.

Microgrids, as well as virtual power plants (VPPs) and other aggregations of DERs, are linked to distribution networks at a point of interconnection. The utility is responsible for managing microgrids (and other interconnected entities) in order to maintain grid stability and reliability and provide grid services. This is done by integrating the distribution management system (DMS) for the network with the controller for the microgrid. An advanced DMS (ADMS) has a component to accomplish the integration of the microgrid controller and is referred to as an integrated distribution management system (IDMS).

This project, titled IDMS, demonstrates a utility-operated ADMS with embedded DERMS functionality that can flexibly manage a variety of microgrids and other aggregated DERs in concert with the wider distribution grid. With this conceptual approach, the owner of a microgrid can provide grid services in any number of different ways to meet the operational objectives set by the utility. The manner of aggregation - microgrid or virtual power plant should not necessarily be important to the utility as long as the grid services from the aggregated DER are available. Effectively delegating the complexity of managing these resources directly to the microgrid owner is an efficient way to satisfy the utility's needs. Meanwhile, the microgrid owner is free to innovate solutions that make sense for its specific operation. This architecture matches the high-speed control decisions needed for the microgrid's operations with a local controller specifically engineered for and able to perform such control.

The control architecture is structured with the utility's ADMS managing the distribution network with a DERMS component to manage the DER and aggregated DERs. One type of possible aggregation is a microgrid. The microgrid controller (MGC) interfaces with the ADMS/DERMS, thus linking the microgrid owner to the utility, which is described in this project as an integrated distribution management system.

Whether the microgrid is owned by the utility or a third party, or whether or not the microgrid controller is developed by the same vendor as that of the ADMS, an integrated system that can accommodate these various situations is essential. These interfaces require complex combinations of input/output points and command logic for decision making. Resolving these complexities is a major achievement of this project. 
Besides providing visibility and control functionalities, the ADMS/DERMS can use the microgrid as a dispatchable resource to support the utility grid at the point of common coupling (PCC). The DERMS accomplishes this by determining active and reactive power needs at the PCC using advanced applications like volt/VAR watt optimization (VVWO) and load relief (LR) with the underlying core applications state estimation (SE) and load flow (LF). Advanced optimization determines the ideal grid settings for the immediate needs, and ADMS/DERMS dispatches the local microgrid controller accordingly. These commands include active power and reactive power setpoints as well as disconnect (island) and reconnect commands. In this way, the DERMS can use the microgrid as a resource to resolve and prevent violations in the grid and to optimize the operational working state of the grid. The high-level architecture is shown in Figure 1.

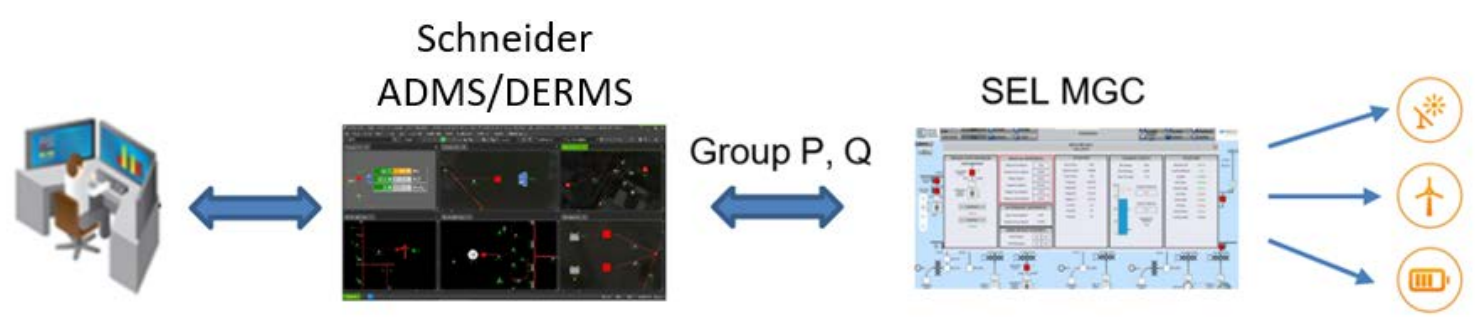

FIGURE 1 High level architecture of the integrated DMS project system

This project demonstrates the IDMS concept as realistically as possible by combining hardware/software-in-the-loop testing with actual commercial products from different vendors and a utility's network model. The project integrates the Schneider Electric EcoStruxure ADMS/DERMS with the Schweitzer Engineering Laboratories (SEL) microgrid controller and demonstrates its operation in a simulation based on proposed generation and loads in a modeled utility-owned microgrid. In this way an operational relationship is established in which the utility manages the operational functionality of the microgrid at the PCC and manages the operational relationship with the distribution network, inclusive of the macrogrid and microgrid.

\subsection{DOE/OE MICROGRID PROGRAM — INTEGRATED DISTRIBUTION MANAGEMENT SYSTEMS}

On July 20, 2017, Argonne National Laboratory released Integrated Distribution Management Systems, Monitoring and Control of Distributed Energy Resources and Microgrid Energy Management Systems. That report was based on the findings of the DOE/OE Structuring DMS Project, Phase 1. That project in turn built on the findings of two previous studies, also funded by the DOE/OE, the results of which were reported in Guidelines for Implementing Advanced DMS: Requirements for DMS Integration with DERMS and Microgrids (2015) and Foundational Report Series: Advanced Distribution Management Systems for Grid Modernization; Importance of DMS for Distribution Grid Modernization (2015-2017).

Integrated Distribution Management Systems set forth a comprehensive structure for an integrated system (including functions, communication, control, and interoperability), principles 
for interactive relationships among the various components of the distribution system and DERs, and gaps with respect to the integration of DMSs, DERs, and microgrids. It identified the needs of a wide range of stakeholders, including utilities, DMS and DER technology vendors, aggregators, and microgrid owners/operators.

The report addressed significant issues regarding the integration of an ADMS with a microgrid energy management system (controller) and, most importantly, the operational rules for interaction of the DMS and controller. It defined the operational functions and information exchanges between a DMS and microgrid controller for the management of microgrids connected to distribution utility networks. The report proposed a proof-of-concept and hardwarein-the-loop simulation as a step towards establishing the technical and implementation requirements for a field site/demonstration project.

The time for operational implementation and field validation of integrated microgrid/utility interaction has arrived: The project Interaction of Micro-EMS and DMS via Field Verification of a proposed utility microgrid was launched in FY 2018. The IDMS project delivers the anticipated demonstration for an existing ADMS on the distribution network and microgrid controller, although the DER and storage were simulated.

PECO is focused on reliability and resiliency benefits and how microgrids and utility grids can complement each other. Economic analysis is of secondary interest. PECO is also interested in building a business case for the benefits of the microgrid in economic terms as well as quantified benefits in terms of resiliency as the rationale for future utility-connected microgrids.

\subsection{UTILITY MICROGRID MODEL INTEGRATION WITH THE DISTRIBUTION MANAGEMENT SYSTEM}

\subsubsection{Utility DMS}

PECO is utilizes an ADMS with functions beyond outage management. The ADMS is being upgraded, with support from Schneider Electric, to include additional functionality as part a larger IT-led project. The component of the ADMS that is required for integration with the microgrid controller - DERMS — is being tested as part of the DOE/PECO project. PECO is continuing to add to its capabilities, ADMS, DERMS, interfaces with DER, and microgrids (Figure 2).

\subsubsection{Microgrid Controller}

The microgrid controller will be provided by Schweitzer Engineering Laboratories. The controller complies with IEEE 2030.7 and IEEE 2030.8 and meets the functional requirements specific to microgrid sites. This controller is capable of interacting with a DMS solutions from multiple vendors (interoperability). 


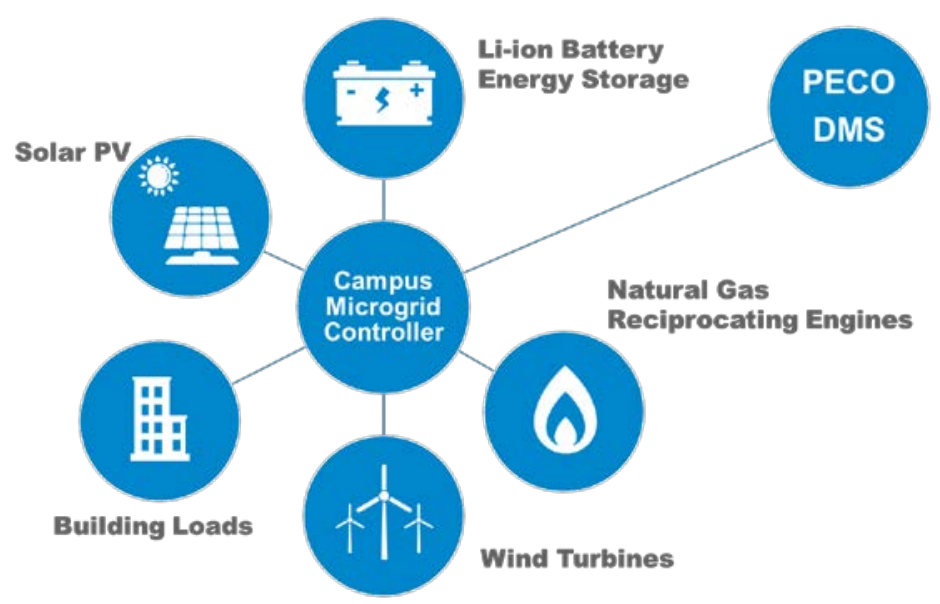

FIGURE 2 Integration of DMS and microgrid controller at the modeled utility microgrid

\subsubsection{DER Modeled for Microgrid Site}

The DERs at the modeled location include:

- $800 \mathrm{~kW}$ natural gas engine

- $1 \mathrm{MW}$ primary connected battery energy storage system (BESS)

- $250 \mathrm{~kW}$ secondary connected BESS

- $20 \mathrm{~kW}$ wind turbine (WT)

- Approximately $350 \mathrm{~kW}$ photovoltaic system (PV)

\subsubsection{Significance of the Project for PECO}

- Demonstrate feasibility of an integrated management system

o Reduce risk of future integrations using project experience and learnings

o Prove that it is possible to integrate new microgrid controller technology with already known and accepted software tool (DMS)

o Show exactly what "monitoring and control" means

o Further understand the capability of two major technology vendors to help enable PECO's vision

- Leverage PECO’s scale and centralized operations center

o Bolster safety and grid operations by integrating situational awareness

o Mitigate adverse grid impacts due to microgrid actions

- Understand DERs as a dispatchable tool to improve grid operations

o Take advantage of active/reactive power flexibility of microgrids 
o Exploit inevitable trend of increasing DERs and microgrids

0 Begin understanding grid services that DERs could provide if properly harnessed

\subsection{TEAM ORGANIZATION AND COMMUNICATION STRATEGY}

The field demonstration at PECO involves many project participants, including vendors, the utility, and Argonne. Coordination among all parties is important, requiring a project management and coordination plan. The project is being executed consistent with existing and future Grid Modernization Laboratory Consortium (GMLC) projects related to DMS. The project team, led by Argonne, is sharing ideas and outcomes with DOE and leveraging best practices and lessons learned for efficient execution of the project.

The project team members include Argonne National Laboratory, PECO, Schneider Electric, and Schweitzer Engineering Laboratories (SEL). Argonne leads the project and is responsible for project management, on-site performance criteria, definition of operational requirements, use cases with the corresponding interactive functions and messages to be tested, and verification of results. PECO is supporting these activities in collaboration with Schneider Electric and SEL.

\subsection{IDMS PROJECT IMPLEMENTATION}

- Start Date: 01/01/2018

- Duration: 30 months. (Eight months on contract negotiations and administrative matters)

The IDMS project was implemented in two phases.

\subsubsection{Project Phase 1}

Phase 1 is a virtual machine simulation of the DERMS/MGC interface. The simulation was based on:

- ADMS with DERMS solution

- Utility grid topology/power system model

- Simulated microgrid controller

- Simulated microgrid power system

Phase 1 used the Schneider Electric EcoStruxure ADMS with DERMS in a network model of a PECO substation with associated feeders connected to a computer-simulated microgrid with an associated controller and power system including DER assets. This simulation environment provided PECO and the project team with valuable insights that will be leveraged for future system-wide production implementation of these ADMS/DERMS capabilities, including microgrids and DER interconnections on the distribution network. 
During the first phase, a network model was developed using the modeled microgrid system configuration and actual PECO power system topology and equipment data for an actual substation and its associated feeders. In addition, the model was tuned to validate the network model using ADMS power system modeling tools. The following use cases demonstrated how a microgrid can be remotely monitored and dispatched, manually and automatically, to resolve utility grid constraints by integrating a centralized ADMS with a local microgrid controller:

- Use Case 1 - Microgrid islanding and reconnection by ADMS

- Use Case 2 - Visibility and monitoring of microgrid by ADMS

- Use Case 3 - Capacity management using microgrid by ADMS

- Use Case 4 - Voltage support using microgrid by ADMS

\subsubsection{Project Phase 2}

In Phase 2, the computer-simulated microgrid was replaced with an SEL controller hardware-in-the-loop (CHIL) system residing in a testbed environment. Using an actual microgrid controller, especially that of another vendor's, increases the fidelity of the demonstration and helps prove the concept's feasibility. This phase demonstrated the interoperability of the two vendor systems for management of the distribution network and a local microgrid. The same four use cases from Phase 1 were demonstrated in Phase 2, with the following changes:

- The simulated microgrid controller from Phase 1 was replaced with a microgrid controller (MGC) CHIL system installed at SEL's test facility in Pullman, Washington.

- A VPN communication network was established between the SEL CHIL system and the SE virtual simulator in Houston, Texas.

The intent of Phase 2 was to more closely replicate a production system and to identify and address any interoperability challenges associated with communications and multivendor system integration. 


\section{ADMS/DERMS AND CONTROLLER SYSTEMS}

The ADMS/DERMS solution for the project is single system and single environment. The ADMS/DERMS platform was set up in Houston, Texas, and the SEL microcontroller was set up in Pullman, Washington (one of the SEL facilities). Communication between the two physical locations used a virtual private network (VPN).

\subsection{PRODUCTION ENVIRONMENT}

The PECO microgrid ADMS architecture consists of a single environment hosting a single system. The design includes the following critical services:

- Front-end processor (FEP) services

- Distribution applications (DMS) and rich communications services (RCS)

- Information archive and historical service (historian)

For the purposes of this project, all the services are installed and configured as standalone; failover capabilities are not available. The production environment layout, with detailed server and workstation boxes, is shown in Figure 3.

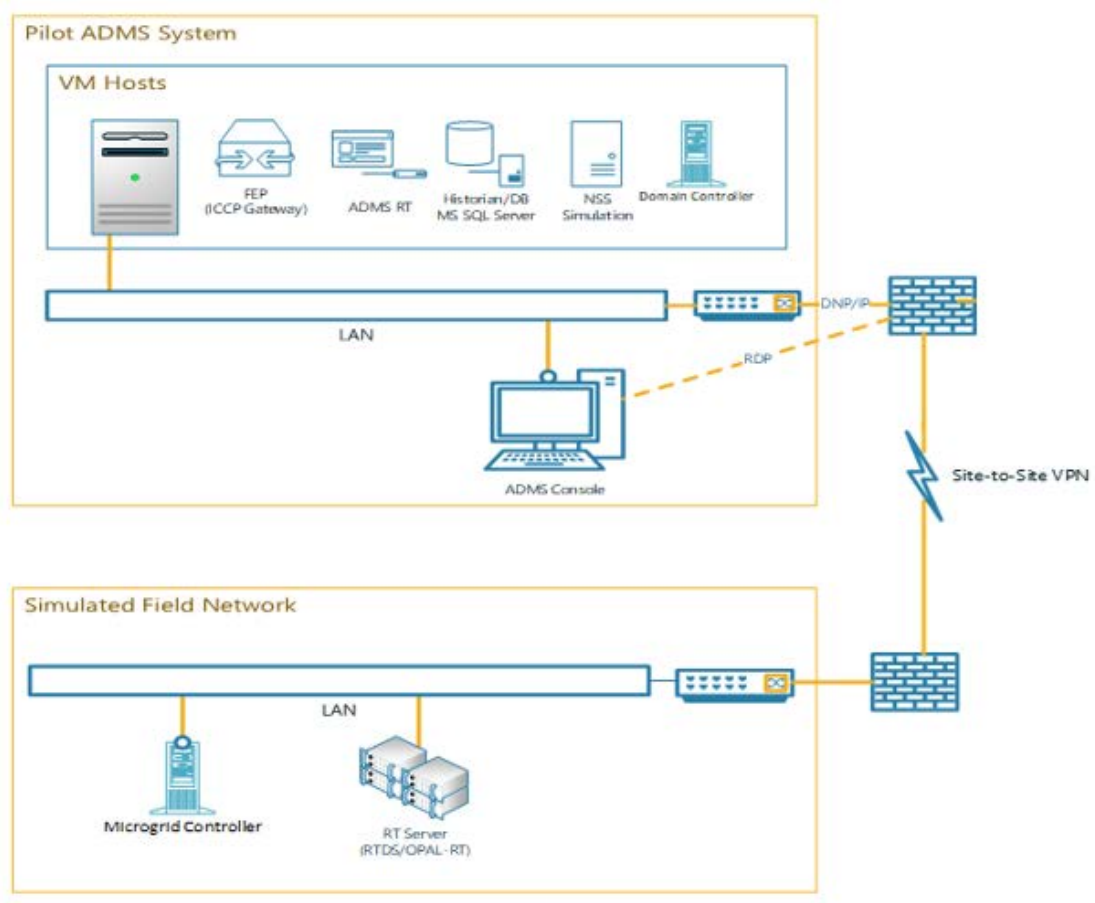

FIGURE 3 Production environment 


\subsection{HARDWARE SPECIFICATIONS}

The following sections describe the physical characteristics of the PECO microgrid ADMS architecture.

\subsubsection{ADMS Server}

The environment is completely virtualized. The host server has the following characteristics:

TABLE 1 ADMS Server

\begin{tabular}{c|c|c|c|c|c|c} 
QTY & CPU & Threads & $\begin{array}{c}\text { RAM } \\
\text { (GB) }\end{array}$ & $\begin{array}{c}\text { Disk (Effective } \\
\text { Capacity) }\end{array}$ & RAID & Host OS \\
\hline 1 & $\begin{array}{c}2 x 10 \text { with Hyper- } \\
\text { Threading } \\
(\geq 2.6 \mathrm{GHz})\end{array}$ & 34 & 256 & $2500 \mathrm{~GB}$ & 1 & $\begin{array}{c}\text { VMware or } \\
\text { Hyper-V }\end{array}$ \\
\hline
\end{tabular}

\subsubsection{Virtual Machine Specifications}

The following table describes the specifications for the virtual machines that host the ADMS services:

TABLE 2 Virtual Machine Specifications

\begin{tabular}{l|c|c|c|c|c|l}
\multicolumn{1}{c|}{ Limited PROD } & Threads & vRAM & vDisk & DB Data & $\begin{array}{l}\text { SQL } \\
\text { Srv. }\end{array}$ & \multicolumn{1}{|c}{ MS Windows } \\
\hline ADMS RT \& FEP & 10 & 64 & 250 & & & $\begin{array}{l}\text { Windows server 2016 Std } \\
\text { LTSC (build 1607) }\end{array}$ \\
\hline Historian RT/NSS & 12 & 64 & 200 & 1000 GB & 2016 Std & $\begin{array}{l}\text { Windows server 2016 Std } \\
\text { LTSC (build 1607) }\end{array}$ \\
\hline Simulation \& RCS & 10 & 96 & 200 & & & $\begin{array}{l}\text { Windows server 2016 Std } \\
\text { LTSC (build 1607) }\end{array}$ \\
\hline DC & 2 & 8 & 80 & & & $\begin{array}{l}\text { Windows server 2016 Std } \\
\text { LTSC (build 1607) }\end{array}$ \\
\hline TOTAL & $\mathbf{3 4}$ & $\mathbf{2 3 2}$ & $\mathbf{7 3 0}$ & & & \\
\hline
\end{tabular}

\subsubsection{Workstations}

The environment includes two (or more) workstations with the following characteristics:

- CPU: Intel Core i7 3.6+ GHz

- Memory: 16 GB DDR4 nECC RAM

- HD: 500GB 
- Video card: 2GB GPU

- OS: Windows 10 Enterprise 2016 LTSC (64-bit)

\subsection{ADMS POWER APPLICATION INFRASTRUCTURE}

The ADMS power application infrastructure is a subsystem of the ADMS used for scheduling, starting, running, and managing the results of the ADMS power applications. It is composed of a number of independent software services that interact and respond to various user inputs, field device changes, or time intervals. Figure 4 illustrates communication between different ADMS services as well as the communication between the SE DERMS and the SEL controller. The communication is established using the DNP3 protocol.

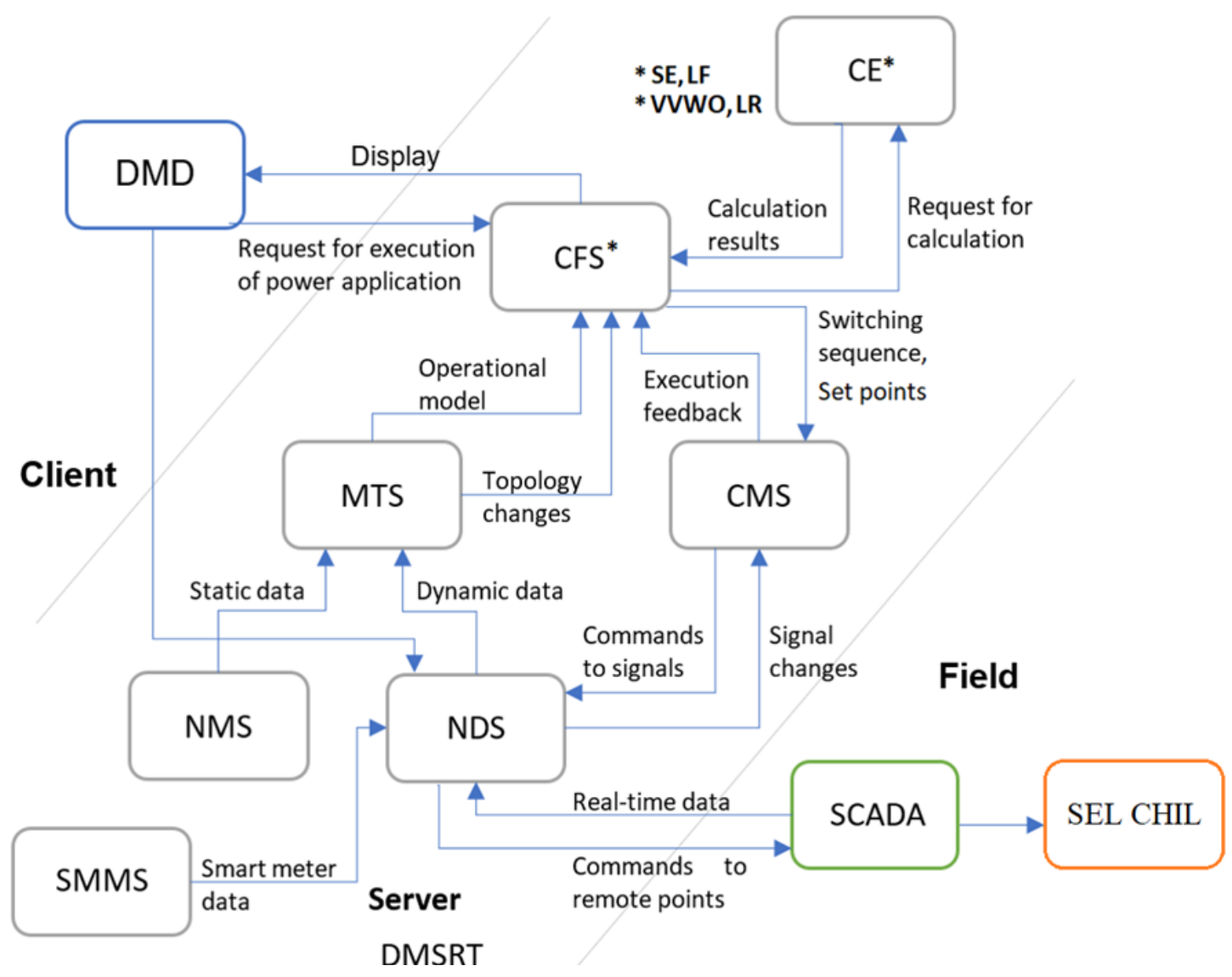

FIGURE 4 ADMS services high-level architecture ${ }^{1}$

\footnotetext{
1 Services that are responsible for the calculation of state estimation, load flow, volt/VAR watt optimization, load
} relief and microgrid management system are marked with an asterisk $\left(^{*}\right)$. 


\subsubsection{ADMS Power Application Modules}

The EcoStruxure ADMS consists of several modules that can be included in the final solution delivered to the client. Figure 4 illustrates how different modules are integrated in an ADMS solution and how communication between ADMS and external systems were established during Phase 1 and Phase 2. Figure 5 shows how different modules are integrated in an ADMS solution and how communication between the ADMS and external systems can be established. Elements and modules that are not part of the solution for this project are shown in gray, parts of the ADMS are green, and external systems integrated with the ADMS are blue.

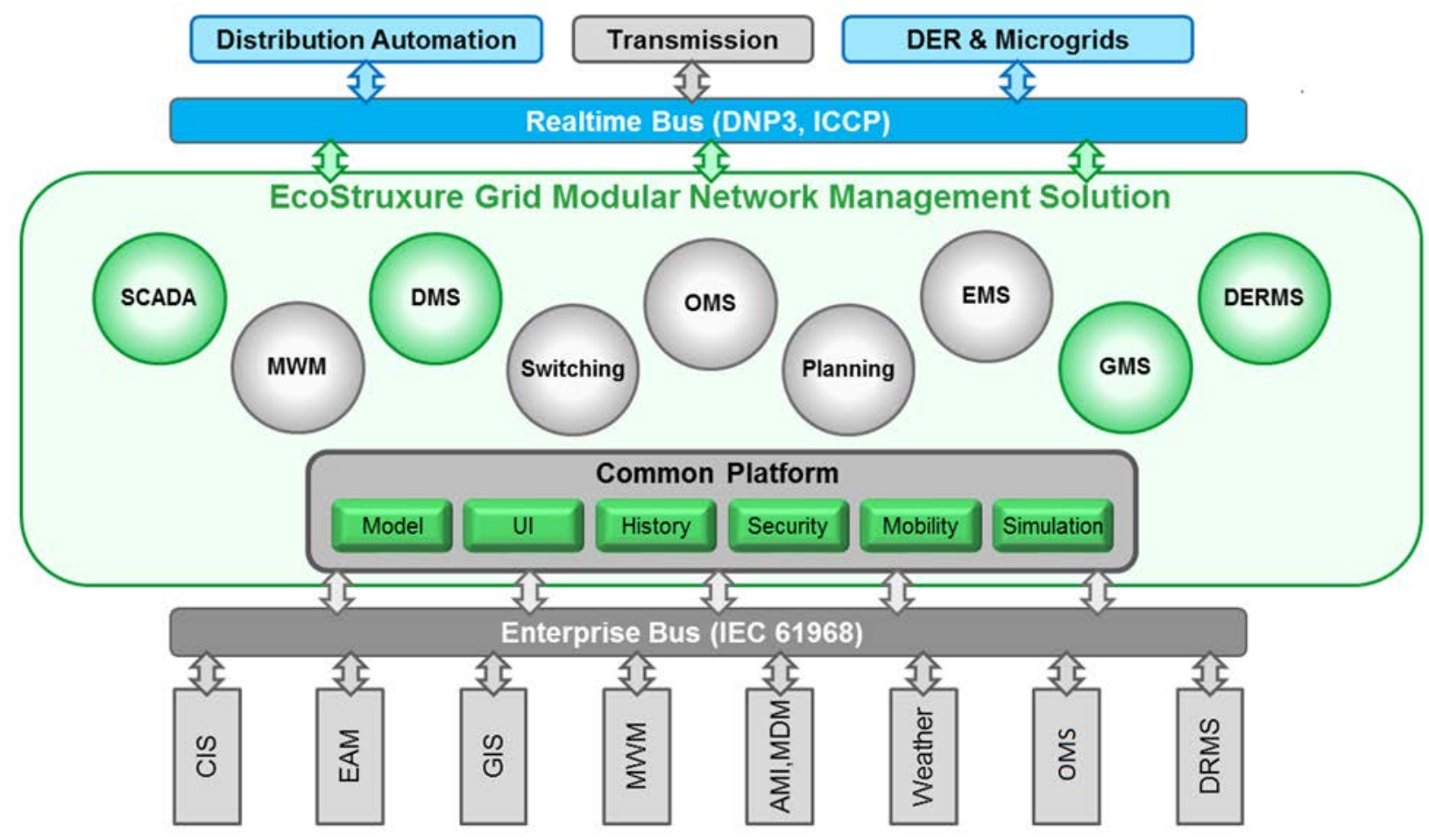

FIGURE 5 EcoStruxure ADMS used in Phase 1 and Phase 2

\subsection{SEL CHIL AND MICROGRID}

In this section, the key components of the SEL CHIL architecture are described. The PECO demonstration project uses a simplified MGC architecture, as shown in Figure 6. 

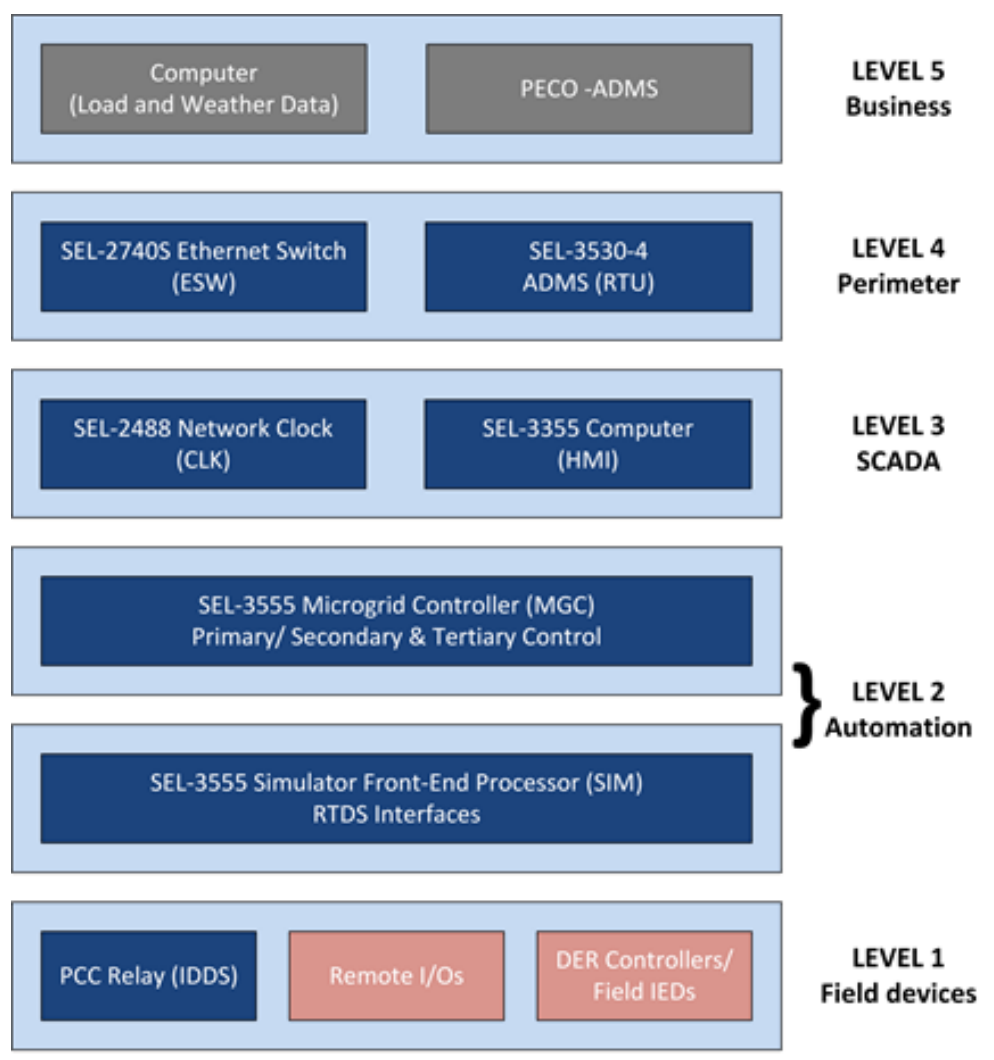

LEVEL 1

Field devices

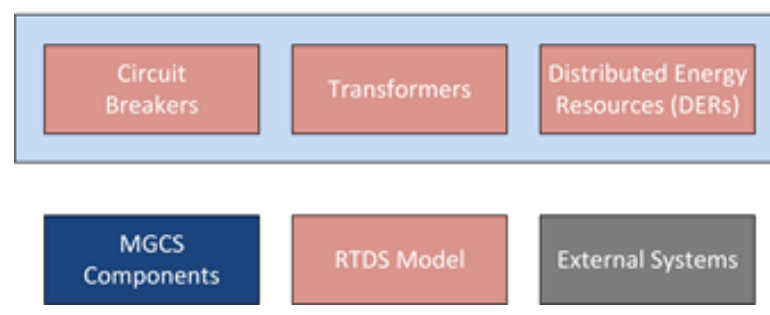

LEVEL 0

Physical

FIGURE 6 SEL POWERMAX MGC architecture

The most important components of this system are the following:

Microgrid controller (MGC) — One SEL-3555 real-time automation controller (RTAC) is used as the MGC for the demonstration project. It is the main decision maker and controls commands to the microgrid's DERs. As part of the SEL POWERMAX microgrid control system, it runs powerful algorithms to maintain voltage and frequency stability in island mode, active and reactive power sharing, peak shaving, load shedding, and the black-start sequence. The MGC also controls the DERs, where required, during grid-connected mode and when islanded, based on the mode selections. 
SEL 3355 computer - One SEL-3355 RTAC is used as the local human-machine interface (HMI) for the demonstration project. This computer hosts COPA-DATA Zenon HMI software with DNP3 device drivers. It will monitor and control real-time data, manage alarms, and track critical parameter trends.

Simulator front-end processor (SIM) - One SEL-3555 RTAC is used as the SIM for the demonstration project, simulating the front-end processors (FEPs) that will be used in the deployed system. It communicates with the real-time digital simulator (RTDS), using DNP3 and GOOSE protocols, and provides channels to the MGC with high-speed and low-speed data traffic segregation.

Remote terminal unit (RTU) - One SEL-3530-4 RTAC is used as the ADMS RTU for the demonstration project, providing the interface with the external ADMS. This RTAC gathers all necessary data from the MGC and SIM for the ADMS to monitor and forwards all necessary commands from the ADMS to the MGC.

Ethernet switch - The SEL-2740S switch is a field-hardened software defined networking (SDN)-enabled switch that is designed to improve Ethernet performance in missioncritical applications. By providing centralized traffic engineering, the SEL-2740S and the SEL5056 SDN flow controller provide path- and packet-level control of communications flows.

Network clock - The SEL-2488 satellite-synchronized network clock receives global navigation satellite system (GNSS) time signals and distributes precise time via multiple output protocols, including IRIG-B time codes and the network time protocol (NTP). One SEL-2488 is used as the network clock (CLK) in the demonstration project. All MGC components in the demonstration rack will be time-synchronized by this clock.

Feeder protection relay - The SEL-751 feeder protection relay provides feeder protection, including overcurrent, overvoltage, undervoltage, directional power, IEC cable/line thermal, vector shift, sensitive earth fault (SEF), load encroachment, and frequency elements. One SEL-751 was used as the PCC breaker relay in the demonstration project. It serves as the island detection and decoupling system (IDDS) relay and also provides synchronism-check functions across the main PCC breaker.

\subsubsection{SEL POWERMAX Microgrid Control System Functions}

The MGC is a collection of hardware and software components configured to maintain a microgrid's power system health over a full range of foreseeable operating conditions. The MGC automatically adjusts system parameters to account for operational changes made within the system and provides fast-acting load shedding to recover the system after a major instability, such as a sudden loss of generation. The MGC provides control strategies for three states of the microgrid:

- Grid-connected

- Island 
- Blacked out

The MGC manages seven transitions between these states:

- Planned seamless disconnect

- Unplanned seamless disconnect

- Non-seamless disconnect

- Blackout event

- Reconnect live microgrid

- Reconnect dead microgrid

- Black start microgrid

These are illustrated in Figure 7. The details of these functions are given in Appendix A.

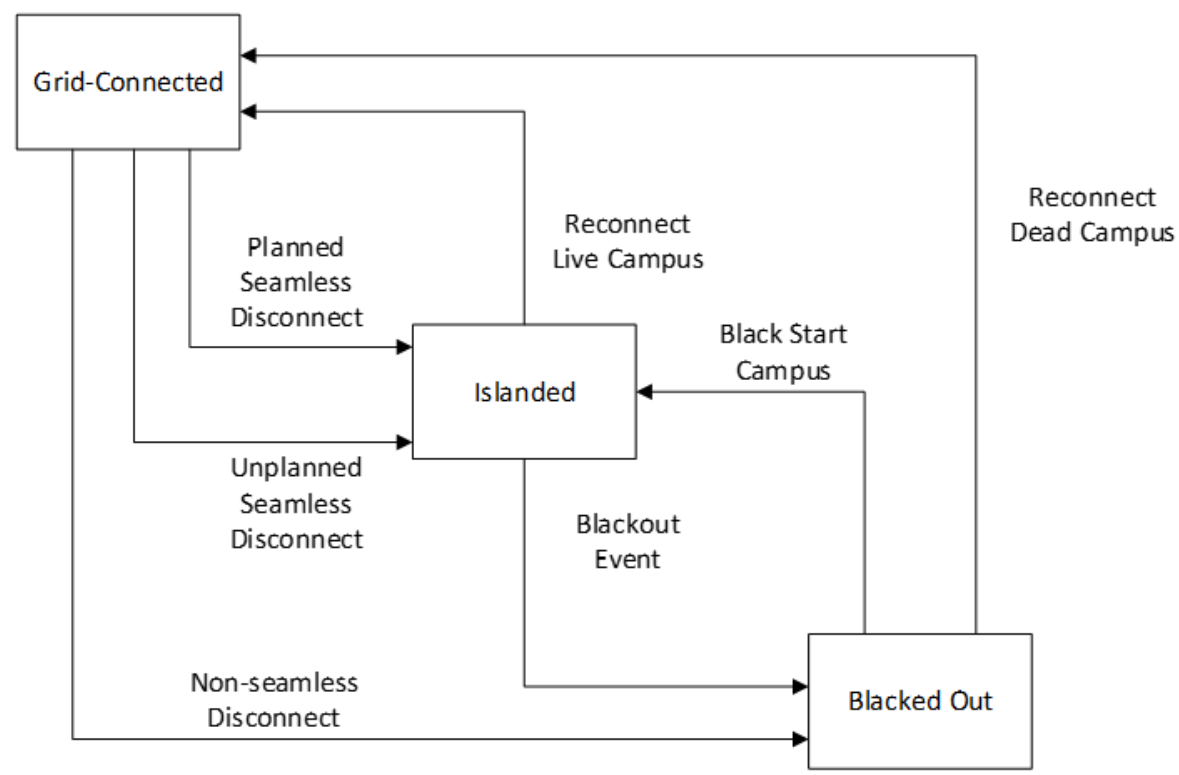

FIGURE 7 SEL microgrid functions

\subsection{NETWORK SIMULATOR}

In the second phase of the project, the ADMS network simulator was used to simulate measurement changes in the field when the ADMS controls the MGC. In the first phase, the ADMS simulated both the response and operations of the MGC along with the rest of the grid. In other words, the whole system was simulated within the ADMS. In the second phase, the SEL CHIL platform simulated the response and operations of the microgrid, and the ADMS received appropriate measurements through SCADA. In this phase, there were actually two simulators that simulated the response of the whole system: The SEL CHIL simulates the response within the microgrid, and the ADMS network simulator simulates the response outside of the microgrid, as shown in Figure 8. 


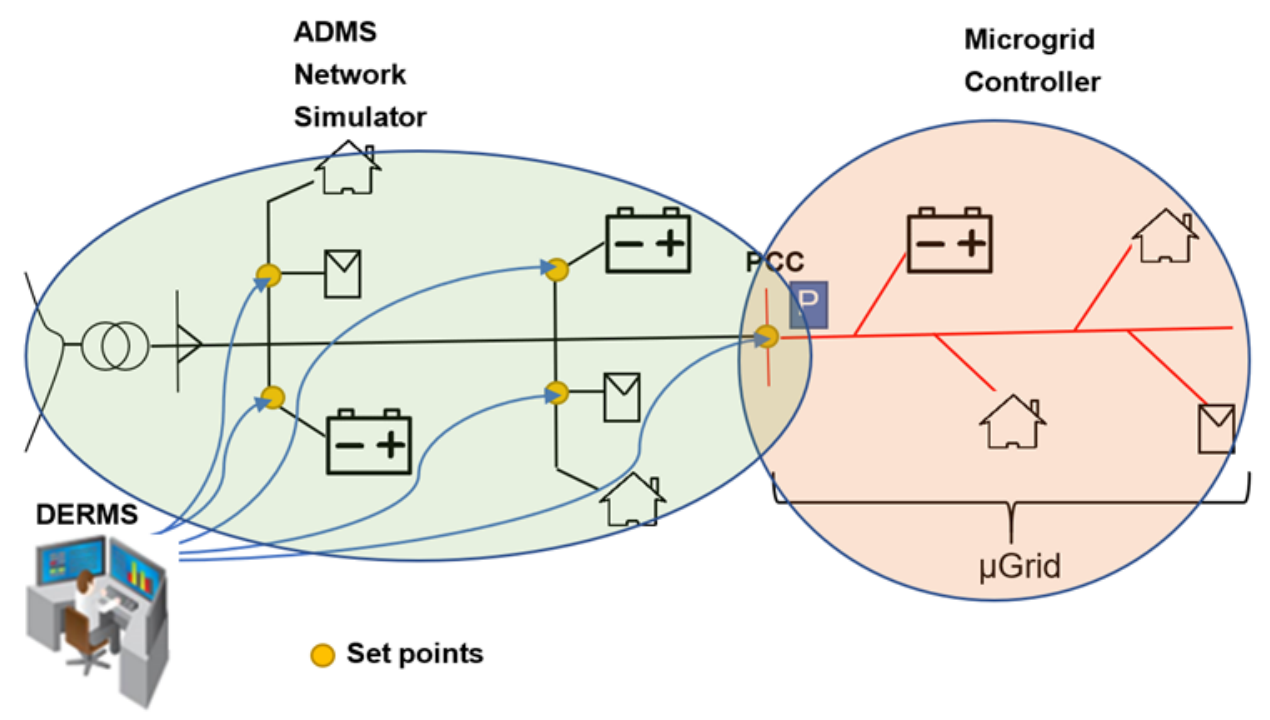

FIGURE 8 Two simulators: ADMS network simulator and SEL microgrid controller

Since these two simulators emulate the behavior of the independent parts that need to interact, it is necessary to align them. To accomplish this, the ADMS transmits received measurements from the SEL CHIL system to the network simulator in order to obtain the expected influence of the microgrid response on the rest of the system. Figure 9 illustrates the communication among the ADMS, network simulator and SEL CHIL (represented by the box labeled SEL MGC).

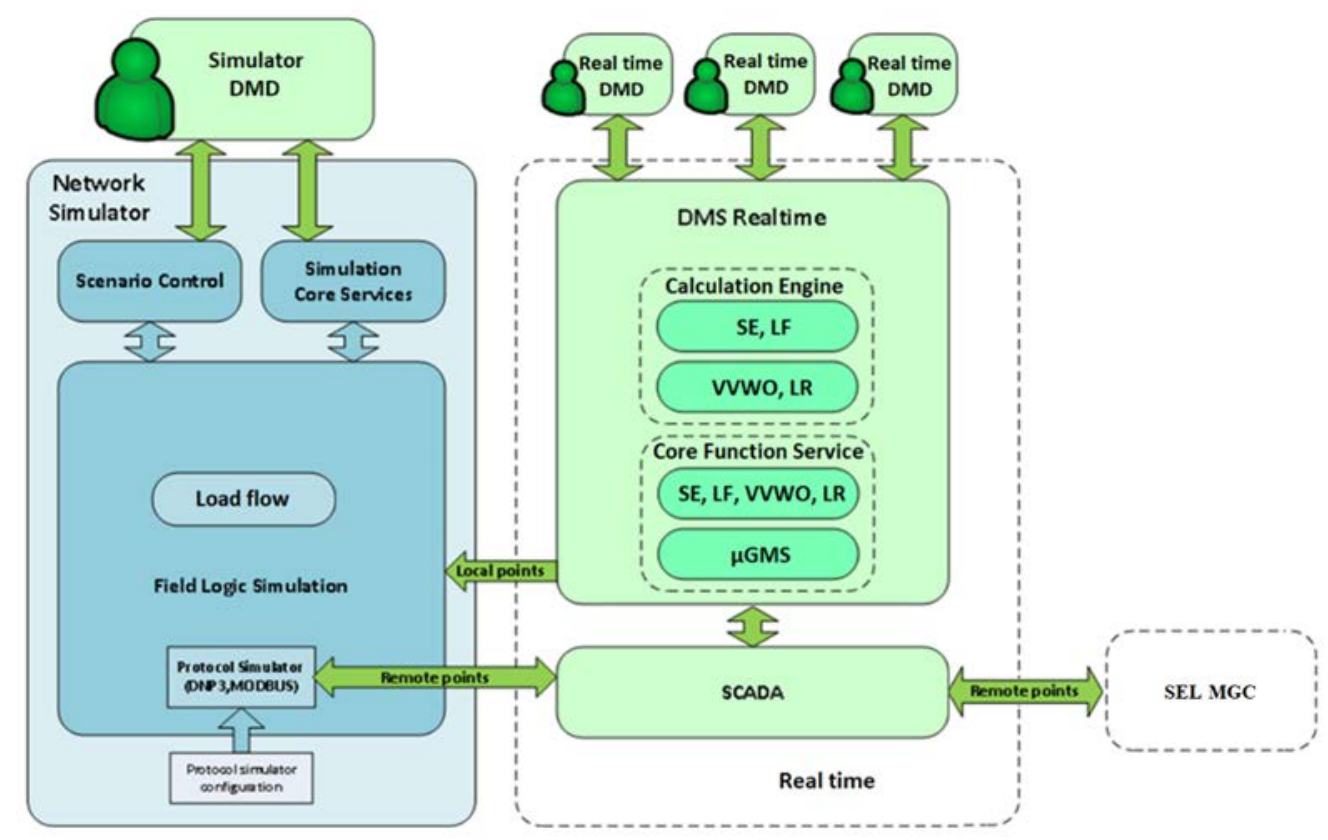

FIGURE 9 Network simulator components and data flows 


\subsubsection{Fidelity of Demonstration}

The overall fidelity of the demonstration was enhanced by the simulation loop having the actual MGC hardware and communication links that are included in the SEL CHIL platform. Note that these were simulations of actual topologies using a MGC and ADMS programmed for the actual functions that would be deployed by the utility and involved an interface of over 1,000 $\mathrm{I} / \mathrm{O}$ points. This demonstrates the high level of detail that is required in order to realize the communications and control needed to achieve integrated operations between the microgrid and the utility. Further, Phase 2 of the project successfully demonstrated the interoperability between the technology of two different vendors: one for the controller, the other for the ADMS to achieve the interactive execution of the use cases.

\subsubsection{Network Model}

In this project, one of PECO's $13 \mathrm{kV}$ feeders where a microgrid would be connected was modeled to enable navigation and visualization of the microgrid. Figure 10 shows the geographic view of the network with microgrid.

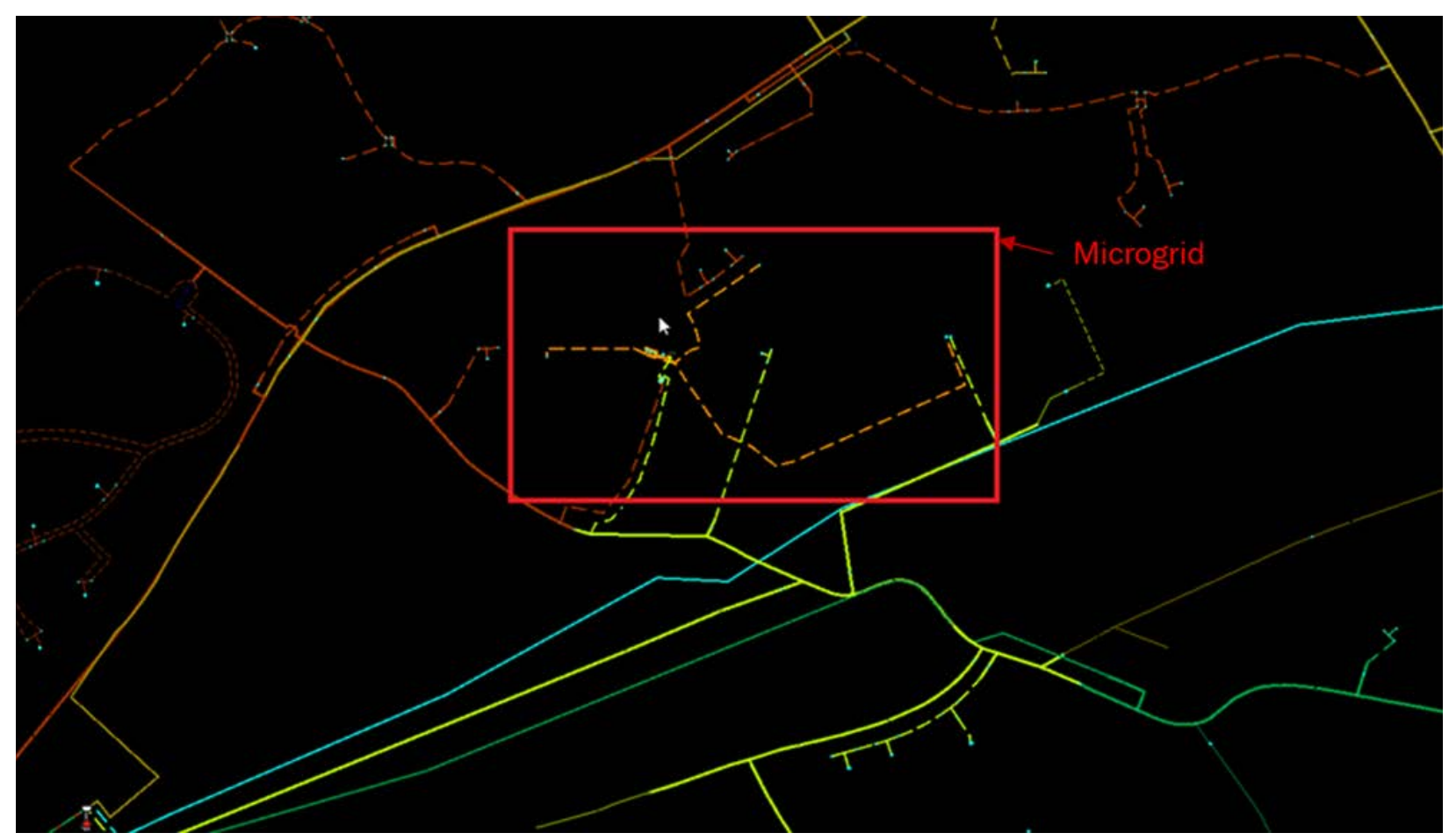

FIGURE 10 Geographic view

To have all elements of the microgrid visible in this view, they have to be modeled first. The composite view of the modeled microgrid feeder along with all relevant elements is shown in Figure 11. 


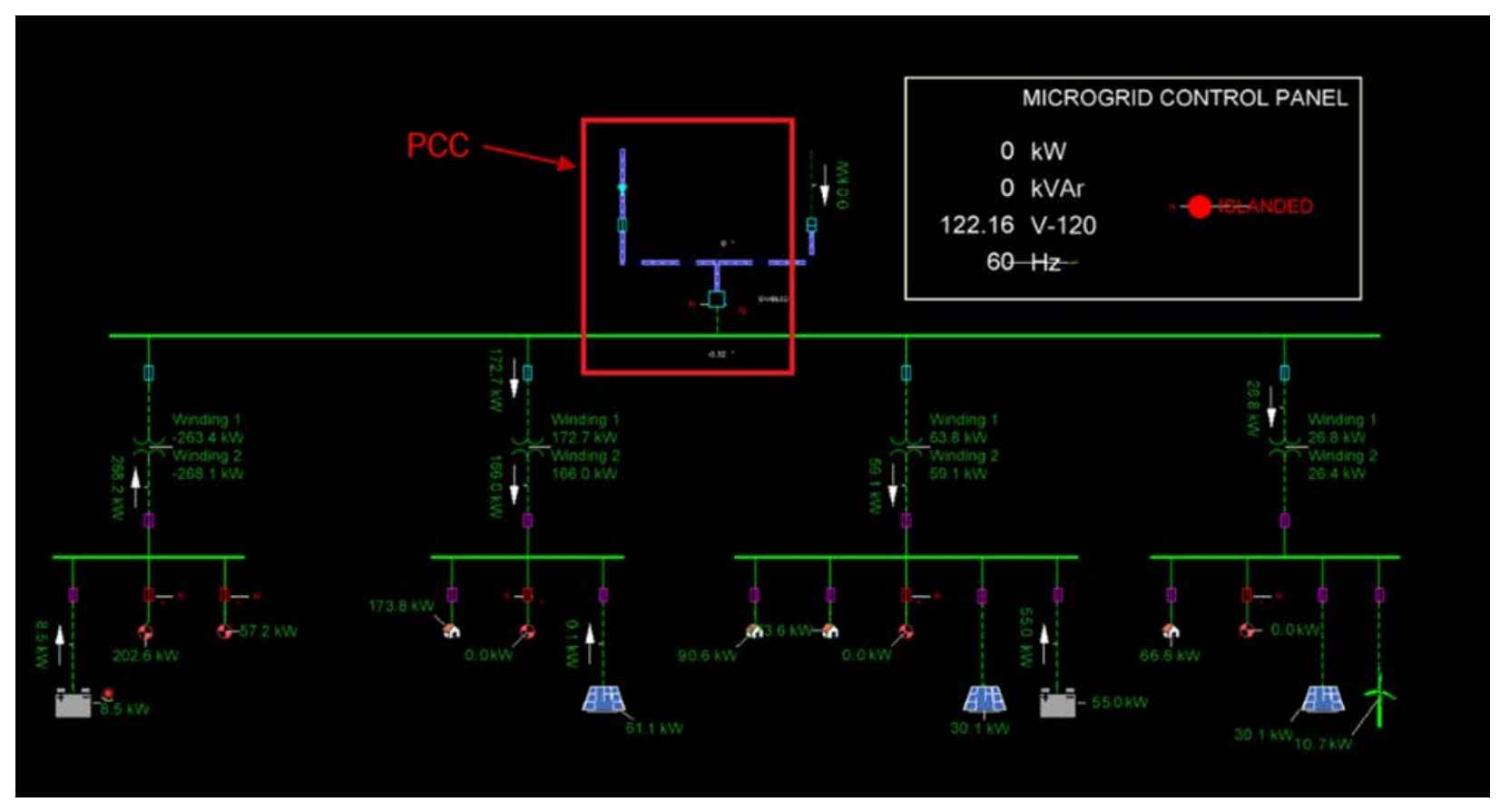

FIGURE 11 Microgrid composite view 


\section{COMMUNICATION BETWEEN SE ADMS WITH DERMS AND SEL CHIL}

For the IDMS project, the MGC was in Pullman, Washington, and the ADMS was in Houston, Texas. The connection between the two systems was via a VPN. A DMZ was established at each end of the VPN using Cisco network appliances, as shown in Figure 12.

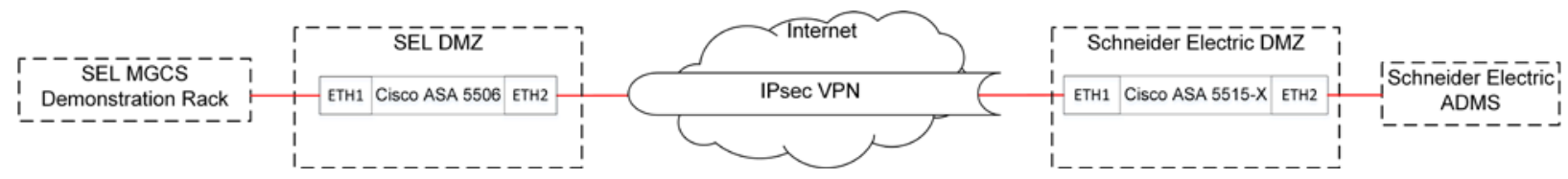

FIGURE 12 Network simulator components and data flows

The microgrid control system network topology is shown in Figure 13.

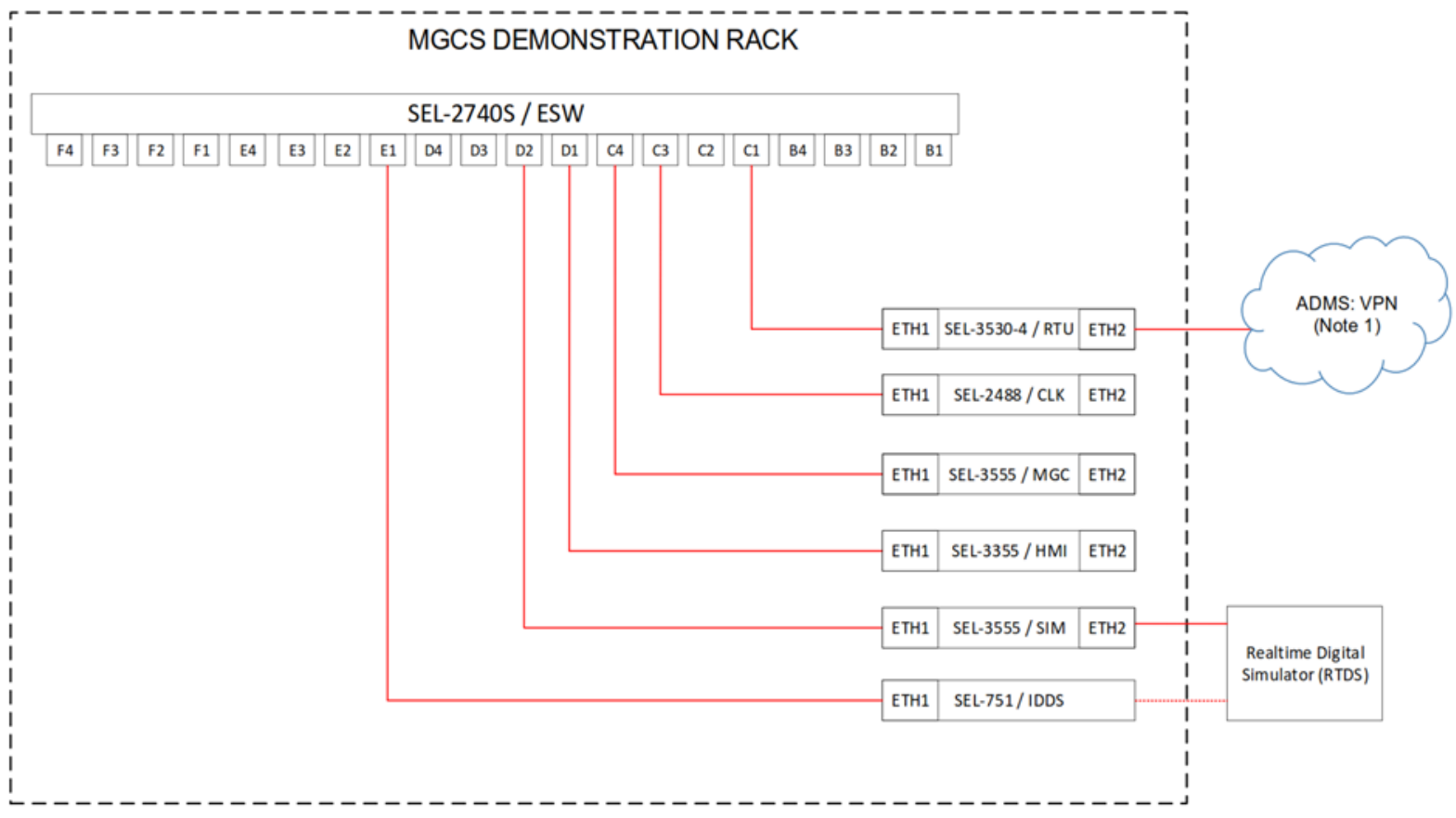

FIGURE 13 MGC network topology

Microgrid control is a very dynamic process in which excess latency can cause control issues. Because the ADMS and MGC systems were set up geographically distant from each other, the risk of potential latency was identified at the beginning of the project. By the end of the project, no control issues due to latency had materialized. This demonstrates a strength of the concept: The critical, rapid control decisions needed to operate the microgrid's DERs are 
handled locally by the microgrid controller over the local communications network rather than relying on a geographically distant ADMS that could introduce significant latency into feedback loops.

\subsection{I $\backslash$ O LIST}

Communication between the SE DERMS and the SEL MGC CHIL was established using DNP3 protocol. During a design workshop, a list of inputs and outputs between the ADMS/DERMS and SEL MGC was defined; this list, given in Appendix B, includes all analog and status inputs and outputs for all elements within the microgrid. The final I $\backslash$ O list was defined by SEL.

\subsection{ALARMS}

In addition to analog and status I/Os, a list of alarms was developed. The purpose of the alarms is to inform the operator of abnormal conditions in the microgrid. Figure 14 shows the ADMS alarm summary window. Details of alarms are given in Appendix C.

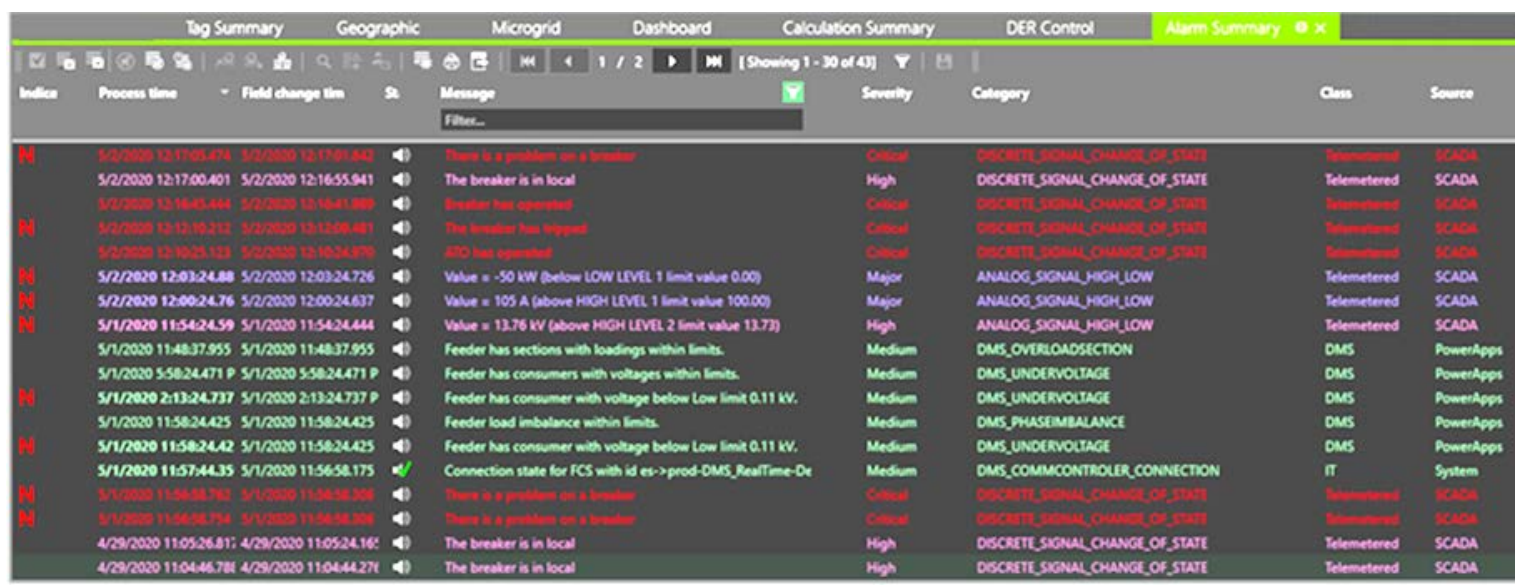

FIGURE 14 Alarm summary 


\section{DEMONSTRATION}

\subsection{MICROGRID CONTROLLER DASHBOARD}

This section shows how the microgrid controller dashboard can be operated from the DERMS. The microgrid controller dashboard serves as a useful tool with which the operator can monitor and operate the microgrid from the ADMS, highlighting alarms and various system health statuses. Figure 15 shows the microgrid controller dashboard in the ADMS. Figure 16 shows MGC dashboard in the SEL HMI.

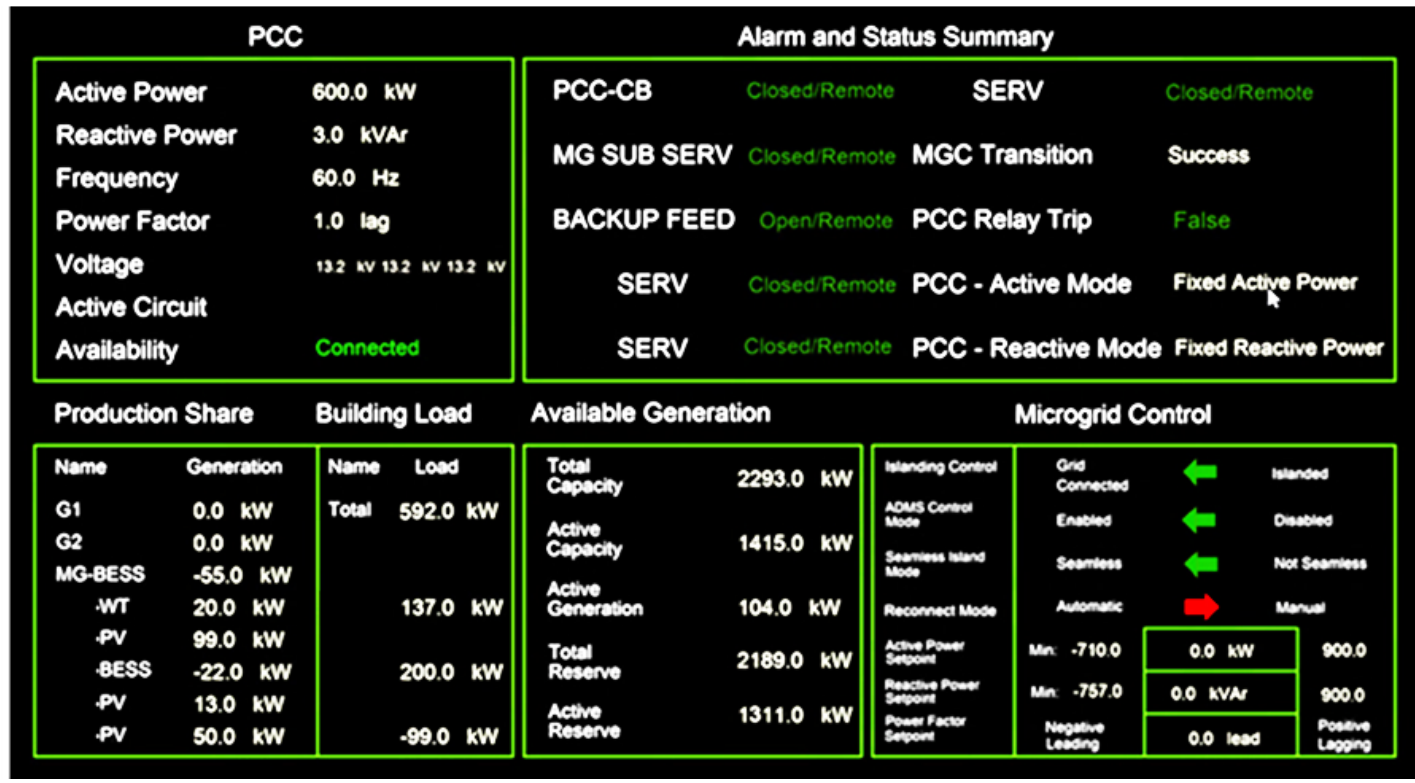

FIGURE 15 MGC dashboard DERMS user interface

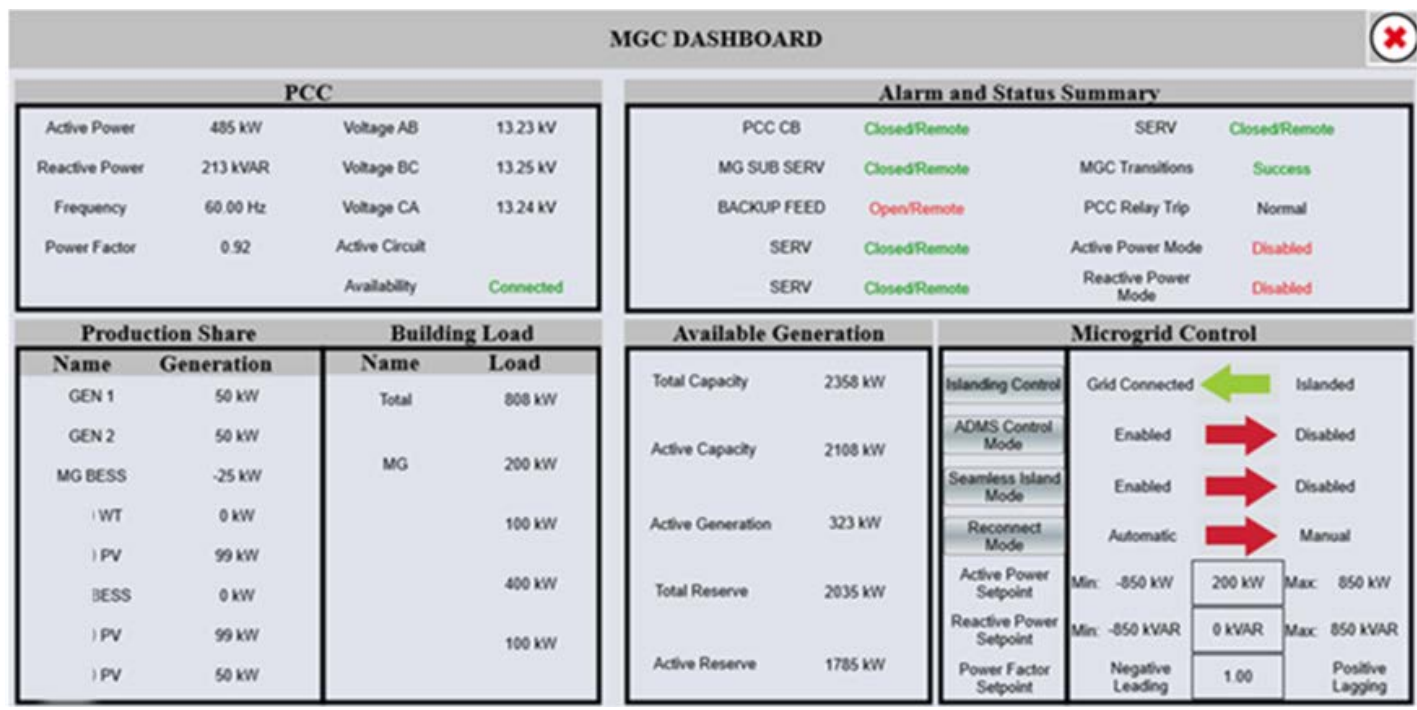

FIGURE 16 MGC dashboard user interface 
A detailed description of the dashboards is given in Appendix D.

\subsection{USE CASES FOR MICROGRID FUNCTIONS AND UTILITY INTERACTION TO PROVIDE GRID SERVICES}

This section presents the use cases that were defined during the design stage for Phase 2 . The following use cases were demonstrated:

- Use Case \#1 — Islanding and reconnection

- Use Case \#2 — DMS visibility and microgrid monitoring

- Use Case \#3 - Utility capacity management using microgrid resource

- Use Case \#4 - Utility voltage support using microgrid resource

The following preconditions for all use cases must be satisfied:

- Ensure all BESSs, PVs, and wind turbine (WT) systems are connected to the microgrid campus (modeled microgrid demonstration site)

- Ensure both generators are disconnected from the microgrid

- Set all DERs to automatic mode

- Set the PCC disconnect mode to seamless

- Set all PCC control modes to disabled

- Set MGC master control mode to enabled

\subsubsection{Use Case 1 - Microgrid Islanding and Reconnection from ADMS}

The purpose of Use Case 1 is to define the conditions and procedures for how the system operator will be able to connect or disconnect the microgrid from the utility grid using the ADMS. Planned and unplanned islanding scenarios are also described in this use case. In this use case, the following scenarios were demonstrated:

- Direct planned islanding

- Reconnection to grid

- Unplanned islanding

- Unsuccessful scenarios

The steps and actors of Use Case 1 are presented in Appendix E.

Significance: Use Case 1 proves out the requirement in IEEE 2030.7 for connecting/disconnecting (and transitions between them) at the point of interconnection. It establishes this compliance in relationship to the interconnection with the utility and its distribution management system, giving the utility the ability to manage the microgrid in response to the needs of the distribution network (which impacts all customers, not just those served by the microgrid). 


\subsubsection{Use Case 2 - DMS Visibility and Monitoring of Microgrid}

Use Case 2 enables real-time monitoring of the microgrid's condition at key nodes using the ADMS. The use case defines various alarms to capture violations in the microgrid indicating events or conditions needing operator attention. Use Case 2 also enables monitoring of key power system parameters such as active powers, reactive powers, voltages, switch statuses of breakers on the PCC, DERs, etc.

The steps and actors in Use Case 2 are presented in Appendix E.

Significance: Visibility of the microgrid and the DER within the microgrid provides distribution operators with the information to manage the impacts of the DER on their systems, as well as providing for the future communication of this visibility to transmission system operators in the future to meet their (and the North American Electric Reliability Corporation's [NERC's]) growing concerns about the tripping of interconnected distributed generation causing cascading outages.

\subsubsection{Use Case 3 - Capacity Management by DMS Using Microgrid}

The purpose of Use Case 3 is to define scenarios in which the system operator will have the ability to manage system capacity constraints and control active power flows at the PCC using the microgrid. The load relief function in this use case is particularly important in utilizing the microgrid as a resource to provide flexible grid services (real power and frequency support) to the bulk grid. This function can be further extended to utilize other resources, such as utility owned and operated DERs, to provide capacity service. When the ADMS detects an overload on the feeder, an alarm is generated, and load relief will be automatically triggered in order to resolve the existing problem in the network. The application will send a command to the microgrid controller requesting a different active power flow across the PCC that will lead to overload resolution.

In addition to automatic execution of load relief, which in ADMS terminology is called closed loop, it is also possible to run load relief in open loop. This means that load relief will only calculate the optimal value of active power across the PCC and suggest it to the operator. After that, an operator can confirm this action and execute it in the field.

In order to improve voltage conditions in the grid and manage reactive power flows, volt/VAR watt optimization (VVWO) can be used. In this project, VVWO will use both the active and reactive power of the microgrid as a resource to optimize the state of the system. Like load relief, VVWO can be run in both closed loop and open loop. In addition, VVWO in closed loop can be triggered at predefined time intervals (typically 15 minutes) and also when a voltage violation is detected. 
In this use case, the following scenarios were demonstrated:

- Active power management across the PCC

- Reactive power management across the PCC

- Autonomous load relief scenario - no operator intervention

- Autonomous power factor mitigation

The steps and actors of Use Case 3 are presented in Appendix E.

Significance: Load relief is one of the applications in capacity management. The LR application provides the optimal switching plan to neutralize unwanted conditions such as overloading in the network. If the overloading problem is not resolved, it may result in feeder outage and loss of service to customers, increased customer interruption time, and in the worst case, loss of equipment and devices.

\subsubsection{Use Case 4 - Utility Voltage Support by ADMS Using Microgrid}

Use Case 4 defines scenarios in which the system operator will be able to use the active and/or reactive power of the microgrid to manage and resolve voltage and reactive power violations. The VVWO function in this use case is particularly important in utilizing a microgrid as a resource to provide flexible grid services (voltage support) to the bulk grid. This function can be further extended to utilize other resources, such as utility owned and operated DERs, to provide voltage service. The steps and actors of Use Case 4 are presented in Appendix E.

Significance: Maintaining the voltage profile within acceptable limits under all loading conditions is a primary objective of distribution system management and the main indicator of the quality of the electric power that is delivered to end users. The intended benefits of using VVWO in this use case are a leveled voltage profile for all the customers on a feeder, improved power factor and reduced line losses, energy savings (conservation voltage reduction or CVR), peak shaving, avoidance of load shedding, safe network operations, and avoidance of network overloads.

\subsection{COMPARISON OF PHASES 1 AND 2}

In Phase 1 of the project, an ADMS MGC simulator was used, and the functionalities provided by SE DERMS were tested. In Phase 2 of the project, instead of the ADMS simulator, the SEL MGC and RTDS (the CHIL system) were used. The task of the SEL MGC is to determine and execute the optimal control decisions of the microgrid, while the task of the RTDS is to simulate the electrical response of the microgrid and its DERs to the commands sent by the MGC. In the following table, the differences between these two microgrid controller simulators are shown. 
TABLE 3 Phase 1 and Phase 2 Microgrid Controller Simulators

\begin{tabular}{|c|c|c|}
\hline Functionality & Phase 1 -ADMS Simulator & Phase 2 - SEL MGC \\
\hline Planned disconnection from utility & $\begin{array}{l}\text { The ADMS controller provides } \\
\text { planned disconnection from utility. } \\
\text { When the request for planned } \\
\text { disconnection is received, the ADMS } \\
\text { reduces the active power at the PCC } \\
\text { to zero. A drawback of the ADMS } \\
\text { controller is that only active power } \\
\text { setpoints can be controlled, whereas } \\
\text { reactive power cannot be specified } \\
\text { for the PCC. Also, the ADMS } \\
\text { controller does not start or stop the } \\
\text { generators, and it will use only the } \\
\text { generators already running to reduce } \\
\text { active power to zero. }\end{array}$ & $\begin{array}{l}\text { The MGC provides planned } \\
\text { disconnection from utility. When the } \\
\text { request for planned disconnection is } \\
\text { received, MGC will first start } \\
\text { necessary generators, then will } \\
\text { reduce active power and reactive } \\
\text { power at the PCC to zero. }\end{array}$ \\
\hline Reconnection to utility & $\begin{array}{l}\text { The ADMS controller provides the } \\
\text { reconnection to the utility. When } \\
\text { the request for reconnection is } \\
\text { received, the ADMS closes the } \\
\text { PCC breaker and returns the active } \\
\text { power setpoint at the PCC to the } \\
\text { setpoint provided by the } \\
\text { ADMS/DERMS. The ADMS } \\
\text { controller does not control reactive } \\
\text { power. }\end{array}$ & $\begin{array}{l}\text { The MGC provides the } \\
\text { reconnection to the utility. When } \\
\text { the request for reconnection is } \\
\text { received, the MGC closes the PCC } \\
\text { breaker and returns the active and } \\
\text { reactive power setpoints at the PCC } \\
\text { to the setpoint provided by the } \\
\text { ADMS/DERMS. }\end{array}$ \\
\hline $\begin{array}{l}\text { Unplanned disconnection from } \\
\text { utility }\end{array}$ & $\begin{array}{l}\text { The ADMS controller provides a } \\
\text { seamless unplanned disconnection } \\
\text { from the utility. When the utility } \\
\text { source is lost, the ADMS will } \\
\text { recognize this and open the PCC } \\
\text { breaker. It will try to maintain the } \\
\text { stability of the microgrid using the } \\
\text { resources already connected to the } \\
\text { system. The ADMS controller will } \\
\text { not start the generators; it only uses } \\
\text { already connected generators. The } \\
\text { operator can manually start a } \\
\text { generator, and the ADMS controller } \\
\text { will start to use it. }\end{array}$ & $\begin{array}{l}\text { The MGC provides a seamless } \\
\text { unplanned disconnection from the } \\
\text { utility. When the utility source is } \\
\text { lost, the MGC will recognize this } \\
\text { and open the PCC breaker. It will } \\
\text { try to maintain the stability of the } \\
\text { microgrid using the resources } \\
\text { already connected to the system. } \\
\text { Also, the MGC will start all } \\
\text { necessary generators in order to use } \\
\text { them to maintain the stability of the } \\
\text { system. }\end{array}$ \\
\hline Unsuccessful scenarios & $\begin{array}{l}\text { In unsuccessful scenarios, the } \\
\text { ADMS controller triggers, } \\
\text { appropriate alarms. }\end{array}$ & $\begin{array}{l}\text { In unsuccessful scenarios, the MGC } \\
\text { triggers appropriate alarms. }\end{array}$ \\
\hline Active power control & $\begin{array}{l}\text { The ADMS controller provides the } \\
\text { active power control at the PCC. } \\
\text { When the setpoint from the } \\
\text { DERMS is received, the ADMS } \\
\text { simulator dispatches DERs in order } \\
\text { to achieve the active power setpoint } \\
\text { at the PCC. }\end{array}$ & $\begin{array}{l}\text { The MGC provides the active } \\
\text { power control in PCC. When the } \\
\text { setpoint from the DERMS is } \\
\text { received, the MGC will dispatch } \\
\text { DERs in order to obtain the } \\
\text { expected active power } \\
\text { measurement at the PCC. }\end{array}$ \\
\hline
\end{tabular}




\begin{tabular}{|c|c|c|}
\hline Functionality & Phase 1 - ADMS Simulator & Phase 2 - SEL MGC \\
\hline Reactive power control & $\begin{array}{l}\text { The ADMS controller does not } \\
\text { provide the reactive power control } \\
\text { at the PCC. }\end{array}$ & $\begin{array}{l}\text { The MGC provides the reactive } \\
\text { power control at the PCC. When } \\
\text { the setpoint from DERMS is } \\
\text { received, the MGC will dispatch } \\
\text { DERs in order to obtain the } \\
\text { expected reactive power } \\
\text { measurement at the PCC. }\end{array}$ \\
\hline Island operation & $\begin{array}{l}\text { In island operation, the ADMS } \\
\text { controller tries to maintain the } \\
\text { stability of the system. It will } \\
\text { control only the active power } \\
\text { setpoints of DERs. It dispatches } \\
\text { only DERs that are already } \\
\text { connected to the system, and it } \\
\text { cannot automatically start a } \\
\text { generator. }\end{array}$ & $\begin{array}{l}\text { In island operation, the MGC tries } \\
\text { to maintain the stability of the } \\
\text { system. It will control both active } \\
\text { and reactive power setpoints of } \\
\text { DERs. The MGC is capable of } \\
\text { automatically starting a generator. }\end{array}$ \\
\hline
\end{tabular}

\subsection{INTEGRATION ISSUES}

Each project involving the integration of two vendors requires a detailed integration $I \backslash O$ list. SE ADMS/DERMS in its baseline solution has a precisely defined list of signals according to which advanced functions exchange messages with the controller and interpret them. In order to ensure full integration, it is necessary that the description of these signals coincide with the description of signals provided by the controller, which essentially means that the description of the messages exchanged must be the same. As this is generally not the case (for example, the ADMS sends an absolute value for a setpoint while the controller expects to receive a percentage value of maximum power), it is usually necessary to develop a custom adapter that will match these messages. In this project, the description of the messages expected by the DERMS and MGC were the same, and therefore it was not necessary to develop custom integration. During the implementation of any project in which multiple systems are integrated, it is necessary to perform point-to-point verification to ensure that the messages in each system match. The integration of the MGC and DERMS employed hundreds of SCADA points, and the verification of all of them can be challenging. The methodology used in this project proved to be successful, and therefore both vendors are now confident in using the methodology in future projects.

\subsection{CHALLENGES AND LESSONS LEARNED}

Following are some of the findings and lessons learned.

- Interoperability is a challenge and significant effort.

o Key system-to-system integrations required: 7

o People-hours spent on integration work during Phase 1 and Phase 2 workshops: 608

o Total possible I/O signals between MGC and ADMS: 1,044 
- There will be significant user complexity due to advanced apps (Figure 17).

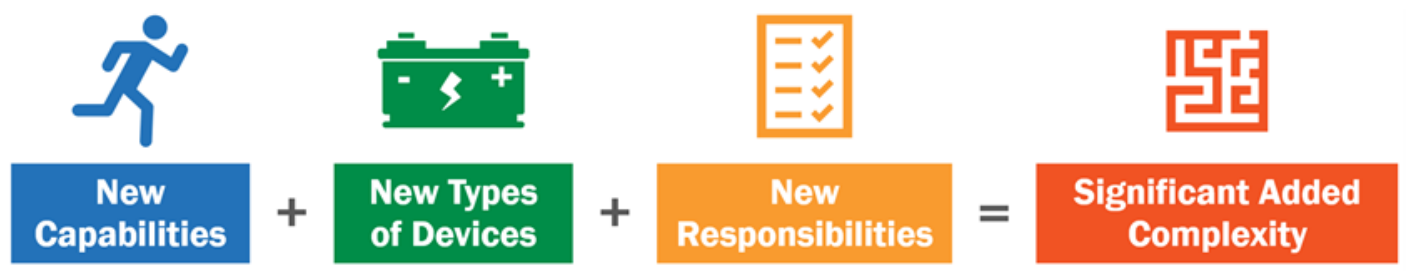

FIGURE 17 Added complexity

- The utility needs significant preparatory work for advanced application data quality, mainly because a geographic information system (GIS) is the foundation for ADMS advanced applications (Figure 18). PECO's one GIS circuit had 421 potential errors. In addition, accurate state estimation and power flow require adequate telemetry on the circuit.
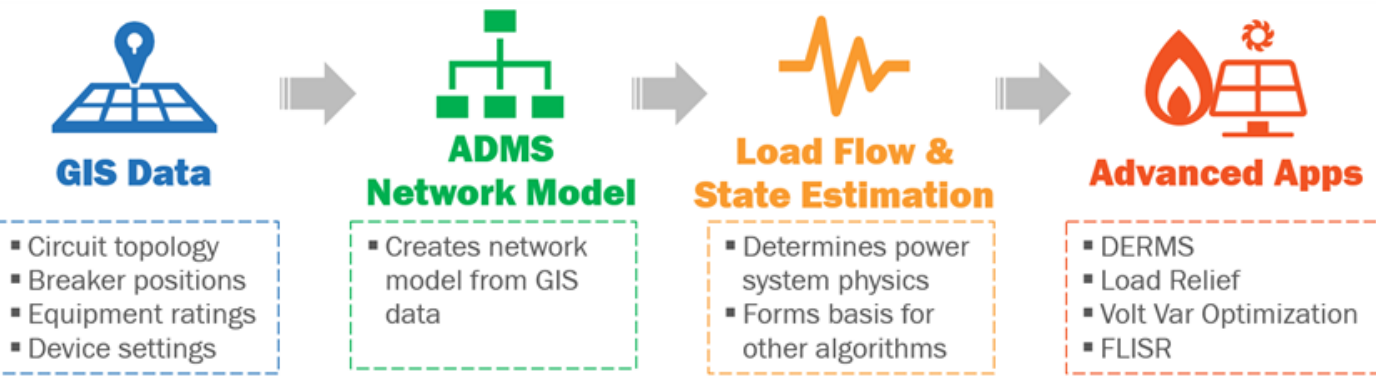

FIGURE 18 Information for advanced applications

- An IDMS provides flexibility for management of the microgrid and DERs within a microgrid.

- An ADMS/DERMS can manage multiple microgrids and DERs on the network.

- An ADMS can provide monitoring for all microgrids and interconnected DERs, single and aggregated.

- When grid services are offered and taken, they are metered. This metering can be matched with tariffs (not part of IDMS now at PECO).

- IDMS measurements quantify the provision of service. This capability is helpful for showing regulators that the DERs in the utility microgrid are actually being used for grid support (not providing generation for sale).

- The location of the microgrid is important for voltage support. This can be a factor in siting microgrids and their interconnection, and the utility can use the ADMS simulation to help with this as part of its planning process.

- Specific metering strategies are needed to show the overall effect of the ADMS/MGC over time. 
- Pockets of functionality can be aggregated. Any mix of DERs (PV, BESS, generators, WT) are managed locally and presented to the utility as a suite of grid services. The MGC handles local hardware and operating constraints. The ADMS can treat the microgrid as a single asset with specific capabilities.

- Situational awareness of the distribution system is improved. Integrating an aggregated microgrid controlled by a MGC with an ADMS provides a means for the ADMS to receive data that might otherwise be too diffuse to be useful. This allows the ADMS to have superior situational awareness of the loads on its system.

- The MGC can act as a demarcation point. The owner of the microgrid can provide grid services in any number of different ways to meet its operational objectives: PV, wind, load management, and/or battery charge/discharge strategies. The manner is not important to the utility as long as the aggregate grid services are available. The microgrid owner is free to innovate solutions that make sense for its specific operation.

- The utility distribution network is routinely reconfigured due to storm activity, maintenance, and other operating considerations. Well-placed microgrids with grid services capabilities are ideal for supporting configurations that would otherwise result in voltage sags or overloads on part of the distribution network. This is an advantage to both the utility and the owner of the microgrid. 


\section{CONCLUSION}

The conclusions of this report cover the second phase of a two-phase research project that explores the integration of PECO's ADMS system with a model of a utility owned microgrid. In the second phase of this project, a virtual simulation machine and network model were developed to evaluate four utility grid support use cases. In this phase, actual utility network topology and equipment data were used in conjunction with a MGC CHIL system that was remotely connected to the Schneider virtual machine. The intent of Phase 2 was to gain additional insights into communications and interoperability challenges associated with two different vendor systems.

In summary, the following activities were successfully concluded in Phase 2:

- All necessary SCADA points for the operation and demonstration of use cases were included in the model.

- A microgrid controller dashboard was developed.

- The alarms necessary for the operation of the microgrid from DERMS were developed.

- Use cases were defined with all necessary steps.

- ADMS modeling functionalities were tested and demonstrated.

- The system was configured to execute the four utility use cases.

- The four utility use cases were tested and demonstrated using DERMS and a CHIL system.

It was demonstrated that the HIL system developed in this project was able to perform the simulations for the specified use cases. Situational awareness for the microgrid was provided through composite and geographic views along with ADMS summaries (alarm summary and DERMS summaries). Commands to the microgrid were demonstrated manually by the utility operator and automatically using the advanced applications in the DMS.

\subsection{SUMMARY OF USE CASE DEMONSTRATIONS}

\subsubsection{Use Case 1 - Microgrid Islanding and Reconnection by ADMS}

This use case defined the conditions and procedures for distribution system operators to seamlessly connect/disconnect the microgrid to/from the utility grid using the ADMS. The demonstration showed how the microgrid and utility power systems would behave in the event of planned and unplanned islanding events.

This use case proves out the requirement in IEEE 2030.7 for connecting/disconnecting (and transitions between them) at the point of interconnection and establishes compliance in the interconnection with the utility and its distribution management system. 


\subsubsection{Use Case 2 - Visibility and Monitoring of Microgrid by ADMS}

Real-time monitoring of the microgrid's condition at key nodes within the microgrid using the ADMS was demonstrated in this use case. It defined various alarms for events or conditions needing operator attention in the microgrids Also, it showed that key power system parameters such as active power, reactive power, voltage, and switch status on breakers at the PCC and DERs could be monitored.

This use case demonstrated that distribution system operators could have visibility of the microgrid and the DERs in the microgrid and access to information to manage the impacts of DERs on their systems, as well as the ability to provide this visibility to transmission system operators.

\subsubsection{Use Case 3- Capacity Management Using Microgrid by ADMS}

This use case defined scenarios in which operators manage system capacity constraints and control active power flows in the microgrid at the PCC using ADMS/DERMS. The load relief function in this use case can be used as a resource to provide flexible grid services (real power and frequency support) to the utility grid. The LR function was shown to be able to adjust the contribution of the available energy resources to the network and/or transfer a minimal amount of the circuit loading to/from the adjacent circuits to neutralize overloads or reverse flow conditions.

This use case demonstrated that load relief as an application in capacity management could provide for optimal switching planning to neutralize unwanted conditions, such as overloading in the network, feeder outage and loss of service to customers, increased customer interruption time, and in the worst case, loss of equipment and devices. This function can be further extended to utilize other resources, such as utility owned and operated DERs, in providing capacity service.

\subsubsection{Use Case 4 - Utility Voltage Support Using Microgrid by ADMS}

This use case defined scenarios for how DERMS could be used by the system operator to manage the reactive power of the microgrid and resolve voltage and reactive power violations at the PCC. The DERMS enabled the VVWO function to use the microgrid as a resource in providing flexible grid services (voltage support) to the utility grid.

This use case demonstrated that voltage profiles could be maintained within acceptable limits under all loading conditions using the microgrid/ADMS. The benefits shown in this use case for VVWO include leveled voltage profiles for all customers on a feeder, improved power factor and reduced line losses, energy savings (conservation voltage reduction or CVR), peak shaving, avoidance of load shedding, safe network operations, and avoidance of network overloads. 
In Use Cases 3 and 4, the way an operator could manage active and reactive power flows at the PCC, using advanced applications like LR and VVWO to resolve utility overloads and voltage violations, was demonstrated.

During the demonstration, it was shown that the power system modeled could effectively resolve system loading constraints using LR. The effectiveness of resolving voltage violations using VVWO depends on the system topology and the location of the connection of the modeled microgrid to the feeder head. The closer the microgrid connection is to the feeder head, the less effective this method is. In this use case, the effectiveness was minimal due to the close proximity of the microgrid to the feeder head. Specifically, it was demonstrated that the microgrid could only increase the voltage value by 0.5 volts when attempting to resolve the voltage violation. While this does not detract from the value of the power system as modeled, it does illustrate the grid impact resulting from the location of planned microgrids and DERs. In this case, the modeled microgrid contributes significantly to improving network reliability by supplying the consumers within the microgrid when the utility grid is unavailable.

With grids worldwide transforming rapidly, and a multitude of concepts remaining to be proven, demonstration projects like this provide powerful examples for the industry to look toward, offer important lessons learned, and advance understanding of the practical challenges involved in grid modernization.

Through the successful demonstration of these use cases with commercial hardware and software, this project has illustrated the feasibility and potential applications of a system that integrates utility distribution management systems with microgrid controller systems. This type of integration with the utility is essential to realizing the full range of benefits that microgrids and distributed energy can provide to the electric grid.

\subsection{FUTURE WORK}

\subsubsection{Field Demonstration}

A demonstration of the ADMS/DERMS and microgrid controller when the generation and storage are installed on-site at the PECO microgrid campus can be done at the time these resources are commissioned as a microgrid, using the same use cases and with real-time operational data.

\subsubsection{IDMS with Multiple Microgrids and Virtual Power Plants}

In a project to extend the IDMS to multiple microgrids and aggregated DERs connected to the distribution network, the utility ADMS/DERMS would be used to manage multiple microgrids and virtual power plants as aggregations. This project would establish how microgrids and virtual power plants could be networked in distribution systems, as shown in Figure 19. 


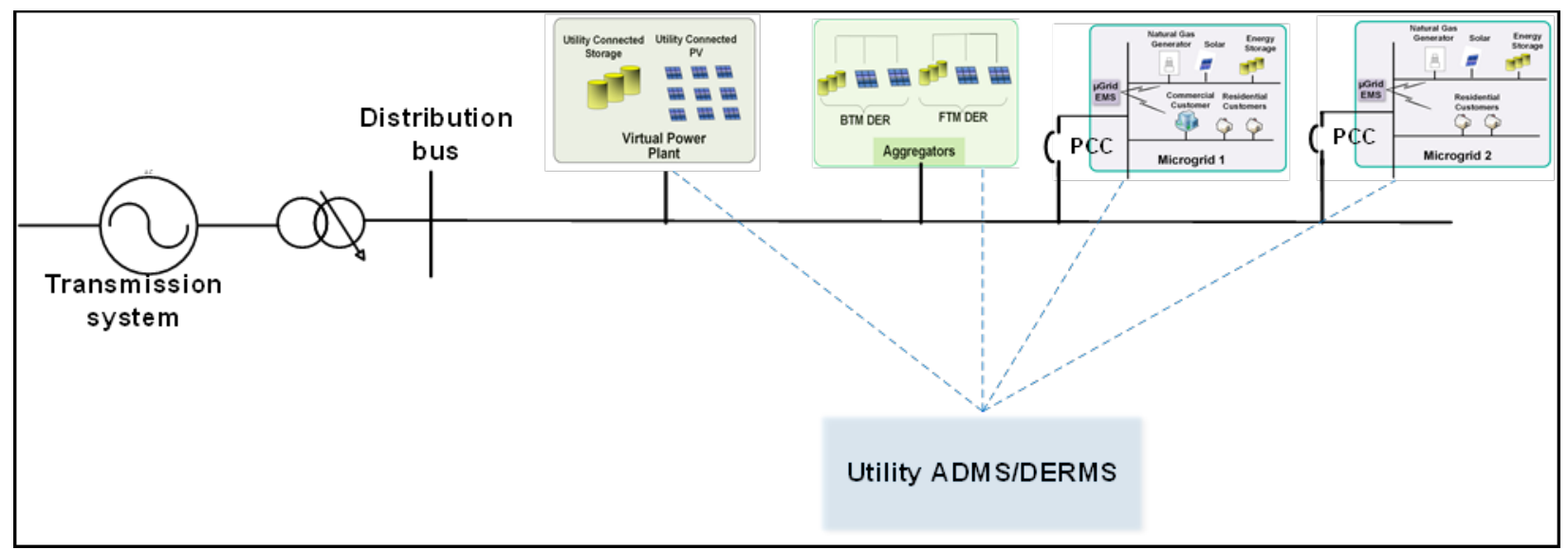

FIGURE 19 Distribution bus with multiple microgrids, VPPs and aggregators

This project could be expanded to demonstrate how an IDMS manages microgrids and VPPs to provide services for the grid — transmission and distribution. 


\section{APPENDIX A: SEL POWERMAX MICROGRID CONTROL SYSTEM}

\section{A.1 GRID-CONNECTED STATE}

When the microgrid is in the grid-connected state, the MGC provides the following control modes:

Grid parallel mode - The MGC manages the available DERs when the microgrid is connected to the main grid while maintaining the operating constraints of the local distribution system. If no other dispatch mode is enabled, the MGC dispatches the available DERs to their default setpoints. The real and reactive power flow through the microgrid PCC is allowed to freely change within limits to supply building loads within the microgrid. This mode is the default PCC control mode. It is enabled when the MGC is enabled. Other modes may be enabled to further specify the power flow at the PCC and DERs. However, the limits specified for grid parallel mode will remain in effect. Grid parallel mode includes active power limits, reactive power limits, and voltage limits at the PCC.

Smoothing mode - The MGC will operate the BESS assets so as to smooth the power output from the intermittent resources (solar, wind) present at the microgrid by controlling the BESS assets to limit the maximum rate of change of power flow at the PCC.

Fixed power dispatch mode - The MGC will manage the available DERs when the microgrid is connected to the main grid while maintaining the operating constraints of the local distribution system. If no other dispatch mode is enabled, the MGC dispatches the available DERs to their default setpoints with regulation based on the dispatch priority of the DERs. The real and reactive power flow through the microgrid PCC will be maintained at user-specified setpoints. These setpoints may be provided by an external system such as an ADMS.

Economic dispatch mode - The MGC will manage the available DERs when the microgrid is connected to the main grid while maintaining the operating constraints of the local distribution system. The power flow through the microgrid PCC and the power output of the available DERs will be managed to minimize the net cost of supplying energy to the microgrid. The MGC determines a schedule of base setpoints for all DERs based on economic and forecast information. The MGC dispatches the available DERs to these base setpoints with regulation based on their dispatch priority.

Low-emission dispatch mode - The MGC manages the available DERs when the microgrid is connected to the main grid while maintaining the operating constraints of the local distribution system. The power flow through the microgrid PCC and the power output of the available DERs will be managed to result in the lowest emissions. Low-emission dispatch mode uses the same parameters as the economic dispatch mode with the addition of emission-based costs. 
Peak shaving mode - The MGC operates the DERs so as to reduce the real power demand during the peak demand period. The peak demand time interval is specified by the user. The demand limit, as measured at the microgrid PCC, is specified by the user.

Load shifting mode - The MGC operates the DERs in a manner that results in a desired load profile over a user-specified period as measured at the microgrid PCC.

Grid support mode - The MGC can dispatch the DERs in support of grid voltage, capacity, or contingency support efforts by autonomously setting the amounts of active and reactive power to be generated or consumed (e.g., volt/VAR control). If the requested amount of real or reactive power support is not delivered, then the MGC will generate an alarm to alert the system operator about the problem. The grid support use case will remain in effect until canceled by the user or through other programmed settings.

Market participation mode - The MGC can support participation in demand response markets that may be available for PECO's commercial customers. For example, when a call for such services is received on a day-ahead basis, the MGC should be able to determine the level of DER resources that are available to participate in such markets, with due consideration of the current operating status of all equipment (such as battery states of charge and reciprocating engines' on or off status), the currently active use case, the rated capacity of each asset, and the forecast capacity and status for the proposed time of the event.

Underfrequency load shed participation mode - The MGC can support participation in underfrequency-based load shedding (UFLS) schemes as directed by the PECO ADMS. The MGC will operate in the previously described grid support or grid parallel-to-island mode use case to achieve maximum load reduction without interruption to the microgrid. This function will be initiated on an automated basis via existing utility communications protocols, as well as be capable of manual execution via the local HMI or utility ADMS system.

\section{A.2 ISLANDED STATE}

When the microgrid is in an islanded state, the MGC provides frequency control and voltage control modes:

Frequency control/real power sharing - The MGC will command one of the DERs to operate in isochronous mode. This DER will operate to maintain the island frequency at the nominal value $(60 \mathrm{~Hz})$. The MGC will command the remaining DERs to operate in droop mode or constant power mode. The MGC will adjust the power output setpoints of these DERs to share the microgrid load and to ensure the isochronous DER has enough operating margin to respond to frequency deviations.

Voltage control/reactive power sharing - The MGC will command two generators and the BESS assets to operate in voltage droop mode. These DERs will operate to regulate their terminal voltages according to their droop line. The MGC will adjust the voltage setpoints of these DERs to ensure that their terminal voltages do not exceed preset limits. The MGC will 
command the remaining DERs to operate in constant reactive power mode. The MGC will adjust the reactive power output setpoints of these DERs to ensure that their terminal voltages do not exceed preset limits. The MGC will adjust the voltage setpoints and reactive power setpoints of the DERs to share the microgrid reactive power requirement to maintain the medium voltage bus at the configured voltage setpoint.

\section{A.3 BLACKOUT}

When the microgrid is in a blackout state, the MGC commands the DERs to disconnect from the microgrid electrical system. The DERs remain disconnected until a black-start sequence is initiated, or the microgrid is reconnected to the utility grid (see the following Transitions subsection).

\section{A.4 PLANNED SEAMLESS DISCONNECT}

The MGC will respond to a command to disconnect the microgrid from the utility by dispatching the DERs and opening the microgrid PCC. Prior to opening the PCC, the MGC will execute control actions to prepare the microgrid for a successful transition to island operation and to mitigate the need to shed load. The MGC performs the following during a planned seamless disconnect:

- Verifies permissive conditions to proceed with the disconnect

- Starts standby generators to provide additional spinning reserve and inertia on the microgrid

- Changes modes of specific DERs to provide enhanced voltage and frequency support

- Adjusts renewable DER power outputs for island operation

- Dispatches DERs to reduce real power flow across the microgrid PCC

- Dispatches DERs to reduce reactive power flow across the microgrid PCC

- Opens the PCC breaker when the real and reactive power flows are within disconnects limits

- Changes one DER to isochronous mode

\section{A.5 UNPLANNED SEAMLESS DISCONNECT}

An unplanned islanding case occurs because of a sudden loss of utility voltage, a fault at the utility substation, or the opening of switches in the utility system upstream from the microgrid. If seamless unplanned islanding is enabled, the MGC will detect voltage, current, and frequency events with the SEL-751 relay on the microgrid PCC. This will trigger the MGC to perform a seamless transition to islanded mode by dispatching the DERs and opening the microgrid PCC. If seamless unplanned islanding is enabled, the MGC will execute control actions to prepare the microgrid for a successful transition to island operation and mitigate the need to shed load should a decoupling event occur. If a decoupling event is detected, the MGC 
and the PCC relay will execute control actions to perform a seamless transition of the microgrid from grid-connected state to islanded state:

- PCC relay opens the PCC breaker.

- MG-SUB-BESS responds to the frequency change based on its droop characteristic.

- MGC sheds load if needed to balance power supply with load on the island (load shed is done only as a last resort).

- MGC dispatches the MG-SUB-BESS to compensate for the frequency droop. The MG-SUB-BESS will respond on its own based on its droop characteristic. This may result in a frequency offset on the islanded microgrid. The MGC will compensate by requesting the MG-SUB-BESS to shift its droop line.

- MGC starts standby generators to provide additional spinning reserve and inertia on the microgrid.

- Once the standby generators are running and synchronized to the island, the MGC transfers load from the MG-SUB-BESS to the generators.

- MGC adjusts renewable DER power outputs for island operation.

- $\quad$ MGC dispatches the DERs within the microgrid according to Figure 7.

\section{A.6 NON-SEAMLESS DISCONNECT AND BLACKOUT EVENTS}

There are scenarios that may result in disconnection from the utility in non-seamless manner. These scenarios will likely result in a microgrid blackout. If the microgrid blacks out, then the MGC will disconnect all DERs from the dead electrical system and set all setpoints to prepare for a manual or automatic black-start operation. Once the microgrid is blacked out, it may be re-energized by one of the following methods:

- The operator may re-energize the microgrid by operating load breakers and starting DERs to manually re-energize the microgrid from local DERs.

- If the loss of utility is temporary, the operator may re-energize the microgrid by operating the microgrid PCC breaker to manually re-energize the microgrid from the utility.

- The operator may re-energize the microgrid by initiating a MGC black-start sequence.

- If the automatic reconnect function is enabled, then the MGC will automatically attempt to re-energize the microgrid after a blackout has occurred using the microgrid PCC breaker.

- If the automatic black-start function is enabled, then the MGC will automatically attempt to re-energize the microgrid after a blackout has occurred using a local DER.

\section{A.7 RECONNECT LIVE MICROGRID}

A request to reconnect the live microgrid to the utility may be initiated from the local HMI, the remote ADMS, or the automatic reconnect function of the MGC. The MGC will respond to a request to reconnect the live microgrid to the utility by executing the following actions:

- Confirm that the utility voltage is within healthy limits 
- Confirm that the utility frequency is within healthy limits

- Dispatch the DERs to synchronize the live microgrid with the utility

- Close the microgrid PCC breaker

\section{A.8 RECONNECT DEAD MICROGRID}

Reconnecting the microgrid to the utility after a blackout is the fastest way to restore power and operation. A request to reconnect the dead microgrid to the utility may be generated from the local HMI, the remote ADMS, or the automation reconnect function of the MGC. The MGC will respond to a request to reconnect the dead microgrid to the utility by executing the following actions:

- Confirm that the utility voltage is within healthy limits

- Confirm that the utility frequency is within healthy limits

- Close the microgrid PCC breaker

\section{A.9 BLACK START MICROGRID}

Black starting the microgrid differs from the procedure in Figure 7 in that this sequence will start the microgrid under its own power using available DERs. This method will allow the microgrid to be restored and operated during a utility outage. A request to black start the dead microgrid may be generated from the local HMI or the automation black-start function of the MGC. The MGC will respond to a request to black start the dead microgrid by confirming the following conditions:

- Confirm that the microgrid voltage is below the microgrid dead threshold

- Confirm that all DERs are disconnected from the microgrid island.

- Start up assets in MG substation

- Energize the medium voltage bus

- Energize first building

- Energize second building

- Energize third building

- Reconnect renewables 


\section{APPENDIX B: I/O LIST}

\section{B.1 DISTRIBUTED ENERGY RESOURCES}

This section provides the analog and digital input and output signals that refer to all DERs in the microgrid.

\section{B.1.1. Analog Outputs}

Since commanding of DERs from the ADMS is not available (in this project, commanding of an individual DER is done only from the MGC), there are no analog outputs.

\section{B.1.2. Analog Inputs}

Information about analog indications is provided in the table below.

TABLE 4 Analog Inputs

\begin{tabular}{|c|c|c|c|}
\hline \multirow[b]{2}{*}{ No. } & Asset & Point Description & Units \\
\hline & \multicolumn{3}{|c|}{ Description } \\
\hline \multirow{2}{*}{1.} & All & Terminal voltage & $\mathrm{kV}$ \\
\hline & \multicolumn{3}{|c|}{ Line voltage at DER terminal given between $\mathrm{AB}, \mathrm{BC}$ and $\mathrm{CA}$ phases } \\
\hline \multirow{2}{*}{2.} & All & Active power & $\mathrm{kW}$ \\
\hline & \multicolumn{3}{|c|}{ Three-phase active power } \\
\hline \multirow{2}{*}{3.} & All & Reactive power & kVAR \\
\hline & \multicolumn{3}{|c|}{ Three-phase reactive power } \\
\hline \multirow{2}{*}{4.} & All & Power factor & \\
\hline & \multicolumn{3}{|c|}{ Power factor } \\
\hline \multirow{2}{*}{5.} & All & Frequency & $\mathrm{Hz}$ \\
\hline & \multicolumn{3}{|c|}{ Measured frequency within the microgrid microgrid } \\
\hline \multirow[t]{2}{*}{6.} & $\begin{array}{l}\text { Energy } \\
\text { storage }\end{array}$ & State of charge (SOC) & $\%$ \\
\hline & \multicolumn{3}{|c|}{ State of charge } \\
\hline
\end{tabular}

\section{B.1.3. Discrete Outputs}

Since the control of DERs is not possible directly from the ADMS, there are no discrete outputs. 


\section{B.1.4. Discrete Indication}

Information on discrete indications is provided in the table below.

TABLE 5 Discrete Indications

\begin{tabular}{|c|c|c|}
\hline \multirow[b]{2}{*}{ No. } & Asset & Point Description \\
\hline & \multicolumn{2}{|r|}{ Description } \\
\hline \multirow[b]{2}{*}{1.} & All & Available for control \\
\hline & \multicolumn{2}{|c|}{$\begin{array}{l}\text { Indicates whether or not DER is available. On the screen, green dots indicate available and red dots } \\
\text { unavailable. }\end{array}$} \\
\hline \multirow{2}{*}{2.} & All & Running status \\
\hline & \multicolumn{2}{|c|}{ Indicates whether or not DER is running. } \\
\hline \multirow[b]{2}{*}{3.} & All & Critical alarm \\
\hline & \multicolumn{2}{|c|}{$\begin{array}{l}\text { Indicates detection of some abnormal situation. Green dot indicates normal situation and red dot } \\
\text { abnormal. }\end{array}$} \\
\hline \multirow[t]{2}{*}{4.} & All & Local/remote \\
\hline & \multicolumn{2}{|c|}{ Indicates whether DER is in local or remote mode. } \\
\hline \multirow{2}{*}{5.} & All & Auto/manual \\
\hline & \multicolumn{2}{|c|}{ Auto means DER will be controlled by MGC; otherwise, it needs to be controlled manually. } \\
\hline \multirow{2}{*}{6.} & All & Breaker status \\
\hline & \multicolumn{2}{|c|}{ Indicates switch status of breaker at DER, which can be open or closed. } \\
\hline \multirow{2}{*}{7.} & GEN 1, 2 energy storage & Active power mode \\
\hline & \multicolumn{2}{|c|}{ Mode of DER: Unknown = 0, Isoc $=1$, Droop $=2$, Constant $\mathrm{P}=3$. } \\
\hline \multirow{2}{*}{8.} & GEN 1, 2 energy storage & Reactive power mode \\
\hline & \multicolumn{2}{|c|}{ Mode of DER: Unknown = 0, Voltage = 1, Constant Q = 2, Constant PF = 3.} \\
\hline
\end{tabular}

\section{B.2 SWITCHES}

This section provides analog and digital input and output signals that refer to all breakers in the microgrid.

\section{B.2.1. Analog Outputs}

Since commanding of switches is not available to the ADMS (in this project, the control of the switches within the microgrid is done only from the MGC), there are no analog outputs. 


\section{B.2.2. Analog Inputs}

In the table below, information about analog indications is provided.

TABLE 6 Analog Inputs

\begin{tabular}{|c|c|c|c|}
\hline \multirow[b]{2}{*}{ No. } & Asset & Point Description & Units \\
\hline & \multicolumn{3}{|c|}{ Description } \\
\hline \multirow{2}{*}{1.} & All & Current & A \\
\hline & \multicolumn{3}{|c|}{ Current measurement across the breaker per phase A, B and C } \\
\hline \multirow{2}{*}{2.} & All & Voltage terminal & $\mathrm{kV}$ \\
\hline & \multicolumn{3}{|c|}{ Line voltage at DER's terminal given between $\mathrm{AB}, \mathrm{BC}$ and CA phases } \\
\hline \multirow{2}{*}{3.} & All & Sync voltage & $\mathrm{kV}$ \\
\hline & \multicolumn{3}{|c|}{ Single-phase voltage on the source side of the breaker when it is opened } \\
\hline \multirow{2}{*}{4.} & All & Active power & $\mathrm{kW}$ \\
\hline & \multicolumn{3}{|c|}{ Three-phase active power } \\
\hline \multirow{2}{*}{5.} & All & Reactive power & kVAR \\
\hline & \multicolumn{3}{|c|}{ Three-phase reactive power } \\
\hline \multirow{2}{*}{6.} & All & Power factor & \\
\hline & \multicolumn{3}{|c|}{ Three-phase power factors } \\
\hline \multirow{2}{*}{7.} & All & Frequency & $\mathrm{Hz}$ \\
\hline & \multicolumn{3}{|c|}{ Frequency measurement } \\
\hline
\end{tabular}

\section{B.2.3. Discrete Outputs}

Since the control of switches is not possible from the ADMS, there are no discrete outputs. 


\section{B.2.4. Discrete Indication}

Information on discrete indications is provided in the table below.

TABLE 7 Discrete Indications

\begin{tabular}{l|l|l}
\multirow{2}{*}{ No. } & \multicolumn{1}{|c}{ Asset } & \multicolumn{1}{c}{ Point Description } \\
\cline { 2 - 3 } & \multicolumn{2}{|c}{ Description } \\
\hline \multirow{2}{*}{1.} & All & $\begin{array}{l}\text { Indicates that some abnormal situation has been detected. Green dot indicates normal situation and red dot } \\
\text { abnormal. }\end{array}$ \\
\cline { 2 - 3 } 2. & All & Critical alarm. \\
\cline { 2 - 3 } & Indication whether switch is in local or remote mode. \\
\hline \multirow{2}{*}{3.} & All & Auto/manual \\
\cline { 2 - 3 } & Auto means switch will be controlled by MGC; otherwise, it needs to be controlled manually. \\
\hline \multirow{2}{*}{4.} & All & Switch status \\
\cline { 2 - 3 } & \multicolumn{2}{|l}{ Status of tie breaker switch, which can be open or closed. } \\
\hline \multirow{2}{*}{5.} & All & Protection trip \\
\cline { 2 - 3 } & Indicates that there is some fault and the breaker is tripped. \\
\hline
\end{tabular}

\section{B.3 MICROGRID CONTROLLER (MGC)}

This section provides the analog and digital input and output signals that refer to the MGC.

\section{B.3.1. Analog Outputs}

Information about analog outputs is provided in the table below. 
TABLE 8 Analog Outputs

\begin{tabular}{|c|c|c|c|}
\hline & Asset & Point Description & Units \\
\hline No. & \multicolumn{3}{|c|}{ Description } \\
\hline \multirow{2}{*}{1.} & MGC & MGC-PCC_ACTIVE_POWER_SETPOINT & $\mathrm{kW}$ \\
\hline & \multicolumn{3}{|c|}{ Active power setpoint: Positive value if microgrid imports energy from main grid } \\
\hline \multirow{2}{*}{2.} & MGC & MGC-PCC_REACTIVE_POWER_SETPOINT & $\mathrm{kVAR}$ \\
\hline & \multicolumn{3}{|c|}{ Reactive power setpoint: Positive value if microgrid imports energy from main grid } \\
\hline \multirow{2}{*}{3.} & MGC & MGC-PCC_POWER_FACTOR_SETPOINT & \\
\hline & \multicolumn{3}{|c|}{ Power factor setpoint } \\
\hline
\end{tabular}

\section{B.3.2. Analog Inputs}

Information about analog indications is provided in the table below.

TABLE 9 Analog Inputs

\begin{tabular}{|c|c|c|c|}
\hline & Asset & Point Description & Units \\
\hline No. & \multicolumn{3}{|c|}{ Description } \\
\hline \multirow{2}{*}{1.} & MGC & MGC-PCC_ACTIVE_POWER & $\mathrm{kW}$ \\
\hline & \multicolumn{3}{|c|}{ Measurement of active power across the PCC: positive value if microgrid imports energy from main grid. } \\
\hline \multirow[b]{2}{*}{2.} & MGC & MGC-PCC_REACTIVE_POWER & kVAR \\
\hline & \multicolumn{3}{|c|}{$\begin{array}{l}\text { Measurement of reactive power across the PCC: positive value if microgrid imports energy from main } \\
\text { grid. }\end{array}$} \\
\hline \multirow{2}{*}{3.} & MGC & MGC-PCC_POWER_FACTOR & \\
\hline & \multicolumn{3}{|c|}{ Measurement of power factor across the PCC. } \\
\hline \multirow{2}{*}{4.} & MGC & MGC-PCC_ACTIVE_POWER_HI & $\mathrm{kW}$ \\
\hline & \multicolumn{3}{|c|}{ Active power high limit for microgrid flexibility seen from PCC. } \\
\hline \multirow{2}{*}{5.} & MGC & MGC-PCC_ACTIVE_POWER_LO & $\mathrm{kW}$ \\
\hline & \multicolumn{3}{|c|}{ Active power low limit for microgrid flexibility seen from PCC. } \\
\hline \multirow{2}{*}{6.} & MGC & MGC-PCC_REACTIVE_POWER_HI & kVAR \\
\hline & \multicolumn{3}{|c|}{ Reactive power high limit for microgrid flexibility seen from PCC. } \\
\hline 7. & MGC & MGC-PCC_REACTIVE_POWER_LO & kVAR \\
\hline
\end{tabular}




\begin{tabular}{|c|c|c|c|}
\hline \multirow{3}{*}{ No. } & Asset & Point Description & Units \\
\hline & \multicolumn{3}{|c|}{ Description } \\
\hline & \multicolumn{3}{|c|}{ Reactive power low limit for microgrid flexibility seen from PCC. } \\
\hline \multirow{2}{*}{8.} & MGC & MGC-PCC_FREQUENCY_SUPPORT_SLOPE & $\mathrm{kW} / \mathrm{Hz}$ \\
\hline & \multicolumn{3}{|c|}{ Support for frequency when generators are in grid support mode. } \\
\hline \multirow{2}{*}{9.} & MGC & MGC-PCC_VOLTAGE_SUPPORT_SLOPE & $\mathrm{kVAR} / \mathrm{V}$ \\
\hline & \multicolumn{3}{|c|}{ Support for frequency when generators are in grid support mode: $\mathrm{Q}-\mathrm{V}$ curve. } \\
\hline \multirow[b]{2}{*}{10.} & MGC & MGC-ACTIVE_CAPACITY & $\mathrm{kW}$ \\
\hline & \multicolumn{3}{|c|}{$\begin{array}{l}\text { Active capacity: Capacity of DERs that are running and synchronized to the system. Includes present } \\
\text { output of PV and WT. }\end{array}$} \\
\hline \multirow[b]{2}{*}{11.} & MGC & MGC-TOTAL_CAPACITY & $\mathrm{kW}$ \\
\hline & \multicolumn{3}{|c|}{$\begin{array}{l}\text { Total capacity: Capacity of DERs that are available (running or not running). Includes present output of } \\
\text { PV and WT. }\end{array}$} \\
\hline \multirow{2}{*}{12.} & MGC & MGC-ACTIVE_GENERATION & $\mathrm{kW}$ \\
\hline & \multicolumn{3}{|c|}{ Active generation: Present output of all DERs. } \\
\hline \multirow{2}{*}{13.} & MGC & MGC-GROSS_LOAD & $\mathrm{kW}$ \\
\hline & \multicolumn{3}{|c|}{ Total gross load within the microgrid. } \\
\hline \multirow[b]{2}{*}{14.} & MGC & MGC_STATUS_01 & \\
\hline & \multicolumn{3}{|c|}{$\begin{array}{l}\text { Planned disconnect status register: Analog point determining the abnormal status during planned } \\
\text { disconnection process of microgrid. Used only for history. }\end{array}$} \\
\hline \multirow[b]{2}{*}{15.} & MGC & MGC_ALARM_01 & \\
\hline & \multicolumn{3}{|c|}{$\begin{array}{l}\text { Planned disconnect alarm: Analog point determining alarms issued by MGC during planned } \\
\text { disconnection process of microgrid. Used only for history. }\end{array}$} \\
\hline \multirow[b]{2}{*}{16.} & MGC & MGC_STATUS_02 & \\
\hline & \multicolumn{3}{|c|}{$\begin{array}{l}\text { Unplanned disconnect status register: Analog point determining the abnormal status during unplanned } \\
\text { disconnection process of microgrid. Used only for history. }\end{array}$} \\
\hline \multirow[b]{2}{*}{17.} & MGC & MGC_ALARM_02 & \\
\hline & \multicolumn{3}{|c|}{$\begin{array}{l}\text { Unplanned disconnect alarm register: Analog point determining alarms issued by MGC during unplanned } \\
\text { disconnection process of microgrid. Used only for history. }\end{array}$} \\
\hline \multirow[b]{2}{*}{18.} & MGC & MGC_STATUS_03 & \\
\hline & \multicolumn{3}{|c|}{$\begin{array}{l}\text { Reconnect live status register: Analog point determining the abnormal status during reconnection process } \\
\text { of microgrid. Used only for history. }\end{array}$} \\
\hline \multirow[b]{2}{*}{19.} & MGC & MGC_ALARM_03 & \\
\hline & \multicolumn{3}{|c|}{$\begin{array}{l}\text { Reconnect live alarm register: Analog point determining alarms issued by MGC during reconnection } \\
\text { process of microgrid. Used only for history. }\end{array}$} \\
\hline
\end{tabular}




\begin{tabular}{|c|c|c|c|}
\hline & Asset & Point Description & Units \\
\hline No. & \multicolumn{3}{|c|}{ Description } \\
\hline \multirow[b]{2}{*}{20.} & MGC & MGC_STATUS_04 & \\
\hline & \multicolumn{3}{|c|}{$\begin{array}{l}\text { Reconnect dead status register: Analog point determining the abnormal status during reconnection process } \\
\text { of microgrid. Used only for history. }\end{array}$} \\
\hline \multirow[b]{2}{*}{21.} & MGC & MGC_ALARM_04 & \\
\hline & \multicolumn{3}{|c|}{$\begin{array}{l}\text { Reconnect dead alarm register: Analog point determining alarms issued by MGC during reconnection } \\
\text { process of microgrid. Used only for history. }\end{array}$} \\
\hline \multirow[b]{2}{*}{22.} & MGC & MGC_STATUS_05 & \\
\hline & \multicolumn{3}{|c|}{$\begin{array}{l}\text { Black start status register: Analog point determining the abnormal status during black start. Used only for } \\
\text { history. }\end{array}$} \\
\hline \multirow{2}{*}{23.} & MGC & MGC_ALARM_05 & \\
\hline & \multicolumn{3}{|c|}{$\begin{array}{l}\text { Black start alarm register: Analog point determining alarms issued by MGC during black start process. } \\
\text { Used only for history. }\end{array}$} \\
\hline
\end{tabular}

\section{B.3.3. Discrete Outputs}

Information about discrete outputs is provided in the table below.

\section{TABLE 10 Discrete Outputs}

\begin{tabular}{|c|c|c|}
\hline \multirow[b]{2}{*}{ No. } & Asset & Point Description \\
\hline & \multicolumn{2}{|r|}{ Description } \\
\hline \multirow{2}{*}{1.} & MGC & MGC_CONTROLLER_MODE_CMD \\
\hline & \multicolumn{2}{|c|}{ Enables/disables all MGC automatic operations. } \\
\hline \multirow{2}{*}{2.} & MGC & MGC-PCC_ACTIVE_POWER_MODE_CMD \\
\hline & \multicolumn{2}{|c|}{ If enabled, constant P mode will be specified to the MGC. } \\
\hline \multirow{2}{*}{3.} & MGC & MGC-PCC_REACTIVE_POWER_MODE_CMD \\
\hline & \multicolumn{2}{|c|}{ If enabled, constant Q mode will be specified to the MGC. } \\
\hline \multirow{2}{*}{4.} & MGC & MGC-PCC_POWER_FACTOR_MODE_CMD \\
\hline & \multicolumn{2}{|c|}{ If enabled, constant power factor mode will be specified to the MGC. } \\
\hline \multirow{2}{*}{5.} & MGC & MGC-PCC_FREQUENCY_SUPPORT_MODE_CMD \\
\hline & \multicolumn{2}{|c|}{ If enabled, frequency support mode will be specified to the MGC while grid-connected. } \\
\hline 6. & MGC & MGC-PCC_VOLTAGE_SUPPORT_MODE_CMD \\
\hline
\end{tabular}




\begin{tabular}{|c|c|c|}
\hline \multirow{3}{*}{ No. } & Asset & Point Description \\
\hline & \multicolumn{2}{|r|}{ Description } \\
\hline & \multicolumn{2}{|c|}{ If enabled, voltage support mode will be specified to the MGC while grid-connected. } \\
\hline \multirow{2}{*}{7.} & MGC & MGC-PCC_PEAK_SHAVE_MODE_CMD \\
\hline & \multicolumn{2}{|c|}{ If enabled, peak shaving mode will be specified to the MGC while grid-connected. } \\
\hline \multirow{2}{*}{8.} & MGC & MGC_PCC_DISCONNECT_MODE_CMD \\
\hline & \multicolumn{2}{|c|}{ Used to prepare the system to have seamless or not-seamless change. } \\
\hline \multirow{2}{*}{9.} & MGC & MGC_PCC_RECONNECT_MODE_CMD \\
\hline & \multicolumn{2}{|c|}{ Used to determine whether the reconnect is automatic or not. } \\
\hline \multirow{2}{*}{10.} & MGC & MGC_PCC_DISCONNECT_CMD \\
\hline & \multicolumn{2}{|c|}{ Starts disconnection. } \\
\hline \multirow{2}{*}{11.} & MGC & MGC-PCC_RECONNECT_CMD \\
\hline & \multicolumn{2}{|c|}{ Starts reconnection. } \\
\hline \multirow{2}{*}{12.} & MGC & MGC-PCC_OPEN_CMD \\
\hline & \multicolumn{2}{|c|}{ If enabled, status of PCC is OPEN. } \\
\hline \multirow{2}{*}{13.} & MGC & MGC-PCC_CLOSE_CMD \\
\hline & \multicolumn{2}{|c|}{ If enabled, status of PCC is CLOSED. } \\
\hline
\end{tabular}

\section{B.3.4. Discrete Indications}

Information on discrete indications is provided in the table below.

\section{TABLE 11 Discrete Indications}

\begin{tabular}{l|l|l}
\multirow{2}{*}{ No. } & \multicolumn{1}{|c}{ Asset } & \multicolumn{1}{c}{ Point Description } \\
\cline { 2 - 3 } 1. & \multicolumn{2}{|c}{ Description } \\
\cline { 2 - 3 } 1. & MGC & MGC-PCC_STATUS \\
\cline { 2 - 3 } & Indicates PCC breaker status. \\
\hline \multirow{2}{*}{2.} & MGC & MGC-PCC_TRIPPED \\
\cline { 2 - 3 } & Indicates that breaker tripped due to unplanned islanding. \\
\hline \multirow{2}{*}{3.} & MGC & MGC-PCC_ACTIVE_POWER_MODE \\
\cline { 2 - 3 } & Indicates that fixed active power mode is active. \\
\hline \multirow{2}{*}{4.} & MGC & MGC-PCC_REACTIVE_POWER_MODE \\
\hline
\end{tabular}




\begin{tabular}{|c|c|c|}
\hline \multirow{3}{*}{ No. } & Asset & Point Description \\
\hline & \multicolumn{2}{|r|}{ Description } \\
\hline & \multicolumn{2}{|c|}{ Indicates that fixed reactive power mode is active. } \\
\hline \multirow{2}{*}{5.} & MGC & MGC-PCC_POWER_FACTOR_MODE \\
\hline & \multicolumn{2}{|c|}{ Indicates that fixed power factor mode is active. } \\
\hline \multirow{2}{*}{6.} & MGC & MGC-PCC_FREQUENCY_SUPPORT_MODE \\
\hline & \multicolumn{2}{|c|}{ Indicates that frequency support mode is active. } \\
\hline \multirow{2}{*}{7.} & MGC & MGC-PCC_VOLTAGE_SUPPORT_MODE \\
\hline & \multicolumn{2}{|c|}{ Indicates that voltage support mode is active. } \\
\hline \multirow{2}{*}{8.} & MGC & MGC-PCC_PEAK_SHAVE_MODE \\
\hline & \multicolumn{2}{|c|}{ Indicates that peak shaving mode is active. } \\
\hline \multirow{2}{*}{9.} & MGC & MGC-PCC_DISCONNECT_MODE \\
\hline & \multicolumn{2}{|c|}{ Indicates that disconnect mode is active. } \\
\hline \multirow{2}{*}{10.} & MGC & MGC-PCC_RECONNECT_MODE \\
\hline & \multicolumn{2}{|c|}{ Indicates that reconnect mode is active. } \\
\hline \multirow{2}{*}{11.} & MGC & MGC-PCC_DISCONNECT_PERMISSIVE \\
\hline & \multicolumn{2}{|c|}{ Indicates that disconnection of microgrid is permitted. } \\
\hline \multirow{2}{*}{12.} & MGC & MGC-PCC_DISCONNECT_INPROGRESS \\
\hline & \multicolumn{2}{|c|}{ Indicates that disconnection of microgrid in progress. } \\
\hline \multirow{2}{*}{13.} & MGC & MGC-PCC_DISCONNECT_FAIL \\
\hline & \multicolumn{2}{|c|}{ Indicates that disconnection of microgrid has failed. } \\
\hline \multirow{2}{*}{14.} & MGC & MGC-PCC_RECONNECT_PERMISSIVE \\
\hline & \multicolumn{2}{|c|}{ Indicates that reconnection of microgrid is permitted. } \\
\hline \multirow{2}{*}{15} & MGC & MGC-PCC_RECONNECT_INPROGRESS \\
\hline & \multicolumn{2}{|c|}{ Indicates that reconnection of microgrid in in progress. } \\
\hline \multirow{2}{*}{16.} & MGC & MGC-PCC_RECONNECT_FAIL \\
\hline & \multicolumn{2}{|c|}{ Indicates that reconnection of microgrid has failed. } \\
\hline \multirow{2}{*}{17.} & MGC & MGC-BLACKSTART_PERMISSIVE \\
\hline & \multicolumn{2}{|c|}{ Indicates that black start of microgrid is permitted. } \\
\hline \multirow{2}{*}{18.} & MGC & MGC-BLACKSTART_INPROGRESS \\
\hline & \multicolumn{2}{|c|}{ Indicates that black start of microgrid is in progress. } \\
\hline
\end{tabular}




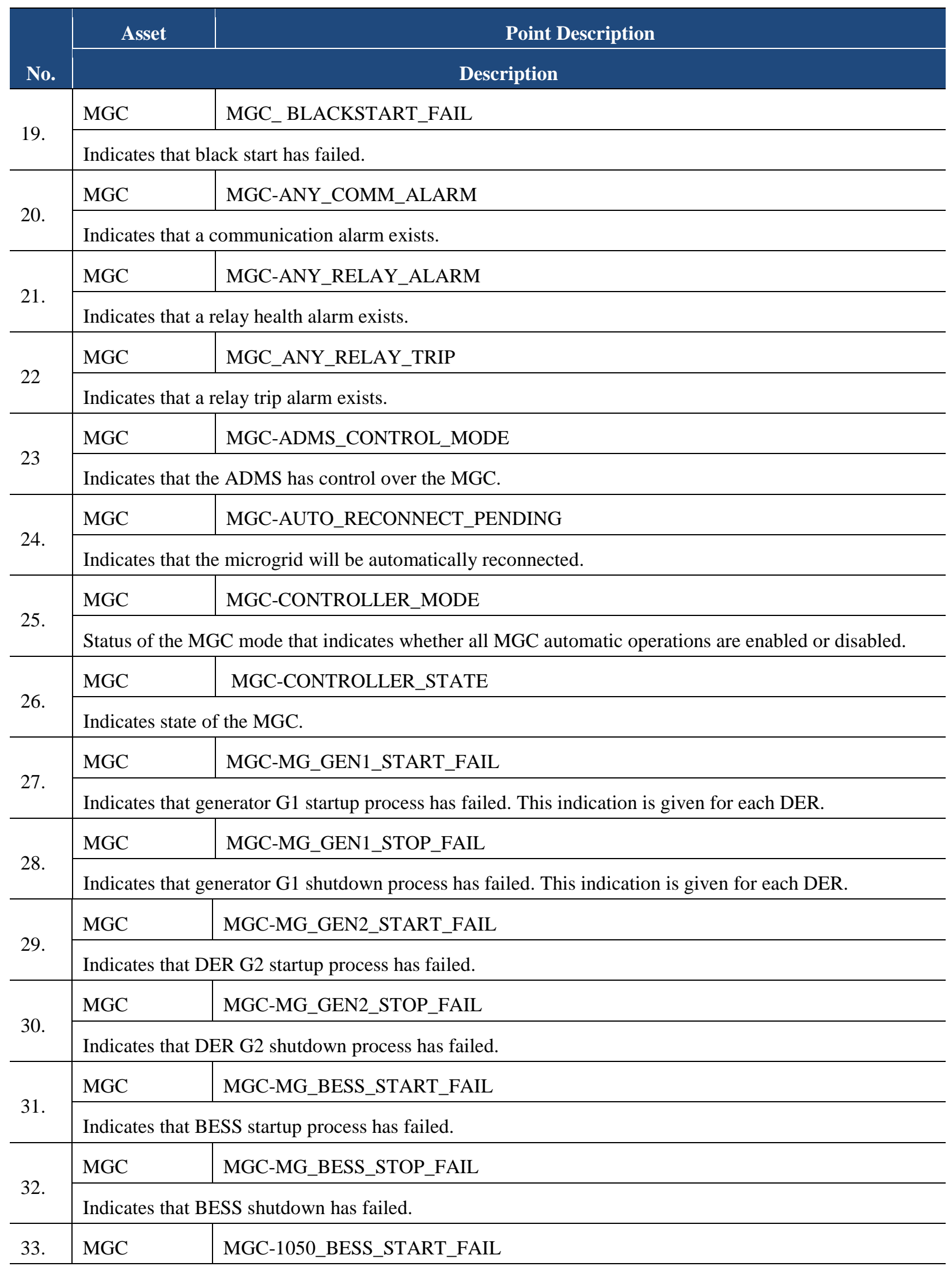




\begin{tabular}{|c|c|c|}
\hline \multirow{3}{*}{ No. } & Asset & Point Description \\
\hline & \multicolumn{2}{|r|}{ Description } \\
\hline & \multicolumn{2}{|c|}{ Indicates that BESS 1050 startup has failed. } \\
\hline \multirow{2}{*}{34.} & MGC & MGC-1050_BESS_STOP_FAIL \\
\hline & \multicolumn{2}{|c|}{ Indicates that BESS 1050 shutdown process has failed. } \\
\hline \multirow{2}{*}{35.} & MGC & MGC-1050_PV1_START_FAIL \\
\hline & \multicolumn{2}{|c|}{ Indicates that DER PV 1050 startup process has failed. } \\
\hline \multirow{2}{*}{36.} & MGC & MGC-1050_PV1_STOP_FAIL \\
\hline & \multicolumn{2}{|c|}{ Indicates that DER PV 1050 shutdown process has failed. } \\
\hline \multirow{2}{*}{37.} & MGC & MGC-1060_PV1_START_FAIL \\
\hline & \multicolumn{2}{|c|}{ A Indicates that DER PV 1050 startup process has failed. } \\
\hline \multirow{2}{*}{38.} & MGC & MGC-1060_PV1_STOP_FAIL \\
\hline & \multicolumn{2}{|c|}{ Indicates that DER PV 1060 shutdown process has failed. } \\
\hline \multirow{2}{*}{39.} & MGC & MGC-1040_PV1_START_FAIL \\
\hline & \multicolumn{2}{|c|}{ Indicates that DER PV 1040 startup process has failed. } \\
\hline \multirow{2}{*}{40.} & MGC & MGC-1040_PV1_STOP_FAIL \\
\hline & \multicolumn{2}{|c|}{ Indicates that DER PV 1040 shutdown process has failed. } \\
\hline \multirow{2}{*}{41.} & MGC & MGC-1040_WT_START_FAIL \\
\hline & \multicolumn{2}{|c|}{ Indicates that DER WT 1040 startup process has failed. } \\
\hline \multirow{2}{*}{42.} & MGC & MGC-1040_WT_STOP_FAIL \\
\hline & \multicolumn{2}{|c|}{ Indicates that DER WT 1040 shutdown process has failed. } \\
\hline \multirow[b]{2}{*}{43.} & MGC & MGC-CAMPUS_STATE \\
\hline & \multicolumn{2}{|c|}{$\begin{array}{l}\text { Indicates that microgrid campus is in one of these states: } 0=\text { Unknown, } 1=\text { Connected, } 2=\text { Islanded, } \\
3=\text { Blackout. }\end{array}$} \\
\hline
\end{tabular}




\section{APPENDIX C: ALARMS}

\section{C.1 DMS OVERLOAD ALARM: MEDIUM SEVERITY}

The purpose of the DMS overload alarm is to inform the operator that an overload of some sections of the system has been detected. As the measurement redundancy in the distribution network is low, and there is no measurement of power flows through each section, this alarm is triggered based on the results of the state estimation and load flow calculation. With this alarm, the operator is notified that the overload on some section is detected. This alarm, with the appropriate message, is shown in Figure 20. The figure also shows the message that will be seen when the overload is no longer present in the system.

\section{5/1/2020 11:38:36.369 (D) Feeder has section with loading above High limit 100 A. Medium}

5/1/2020 11:48:37.955 (i) Feeder has sections with loadings within limits. Medium

\section{FIGURE 20 DMS overload alarm}

\section{C.2 PCC VOLTAGE ALARM: HIGH SEVERITY}

The purpose of the PCC voltage alarm is to inform the operator that the voltage measurement at the PCC is higher or lower than the predefined limits. This is a SCADA alarm, which means it is triggered based on the value from the field. Figure 21 shows the defined alarm limits. Figure 22 shows the messages seen when the PCC voltage alarm is triggered.

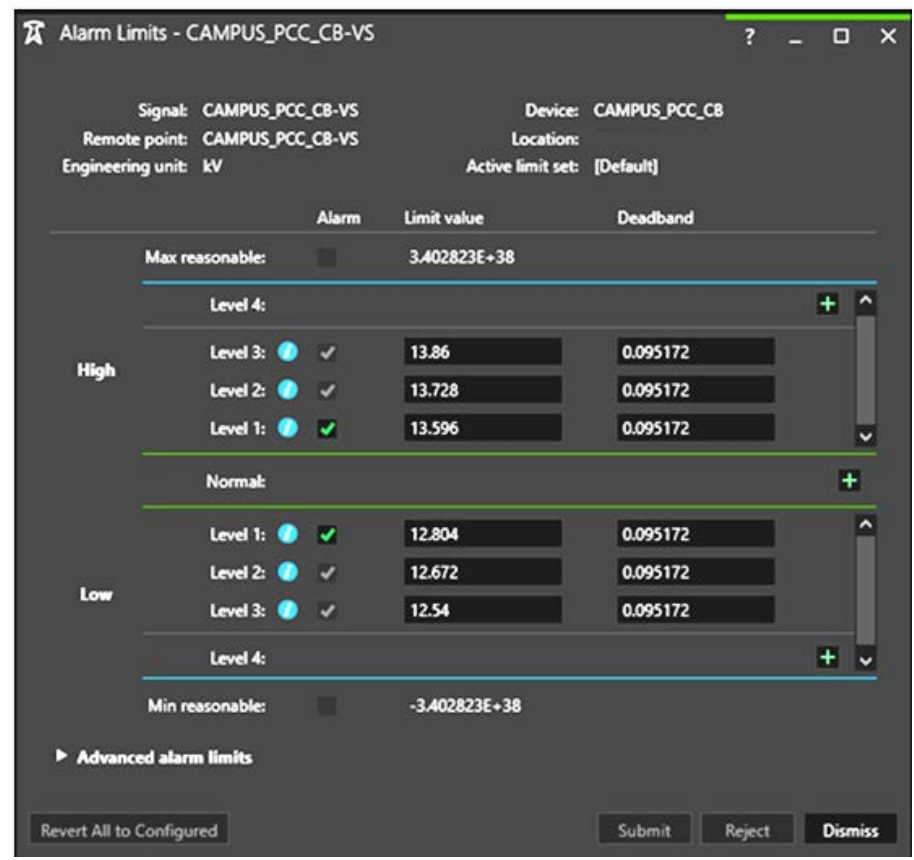

FIGURE 21 PCC voltage alarm limits 
FIGURE 22 PCC voltage alarm message

\section{C.3 PCC CURRENT ALARM: MAJOR SEVERITY}

The purpose of the PCC current alarm is to inform the operator that the current measurement at the PCC is higher than the predefined limits. It is a SCADA alarm, which means it is triggered based on the value from the field. Figure 23 shows the defined alarm limits. Figure 24 shows the message seen when the PCC current alarm is triggered.

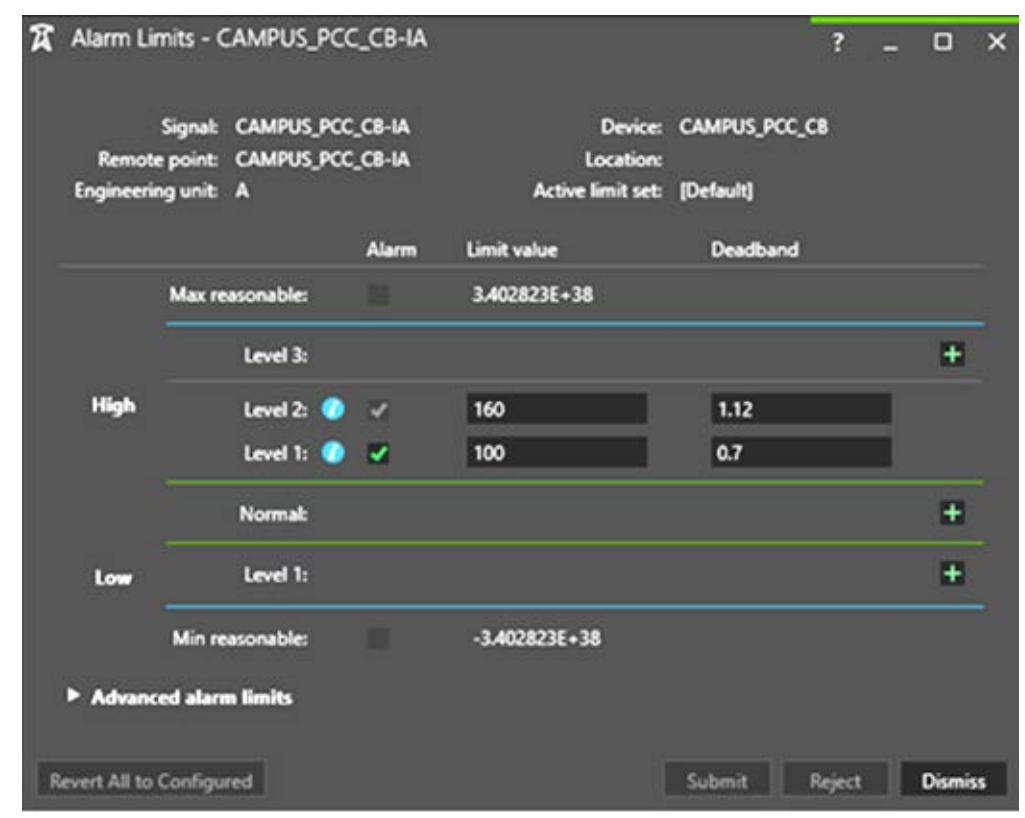

FIGURE 23 PCC current alarm limits

5/2/2020 12:00:24.637 Value = 105 A (above HIGH LEVEL 1 limit value 100.00)

FIGURE 24 PCC current alarm message

\section{C.4 PCC REVERSE POWER FLOW ALARM: MAJOR SEVERITY}

The purpose of the PCC reverse power flow alarm is to inform the operator about reverse power flow at the PCC. It is a SCADA alarm, which means it is triggered based on the active power measurement obtained from the field. Figure 25 shows the message seen when the PCC reverse power flow alarm is triggered. 
FIGURE 25 PCC reverse power flow message

The location where the alarm is triggered can be found using the context menu of the alarm. Figure 26 shows the alarm representation in the MGC view.

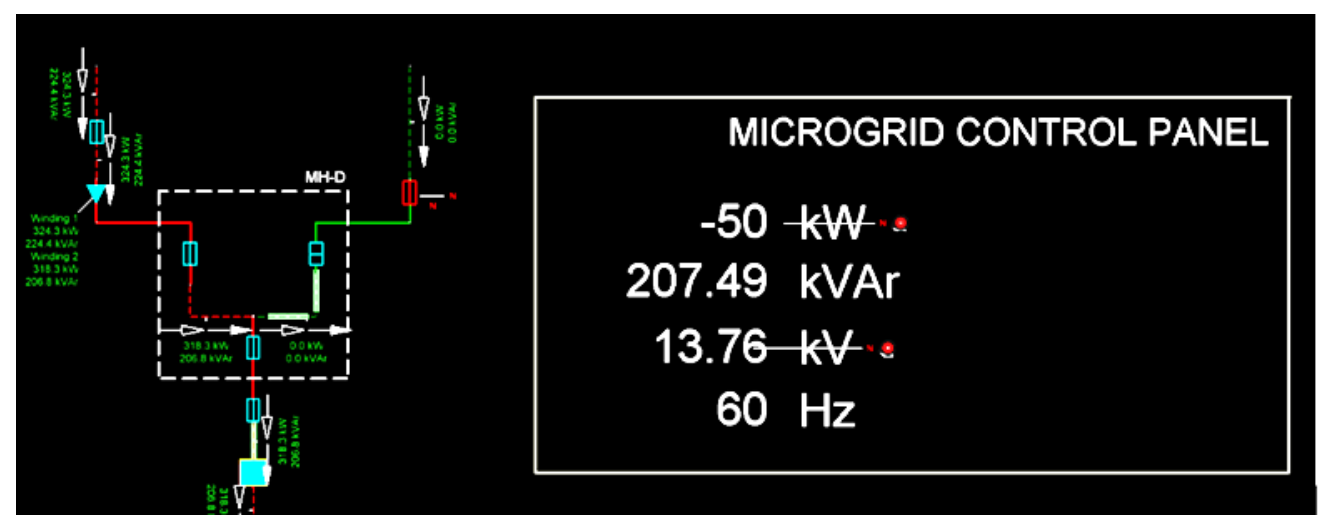

FIGURE 26 Alarm representation in MGC view

\section{C.5 AUTOMATIC THROW OVER (ATO) OPERATION ALARM: CRITICAL}

Each time the ATO operates, ADMS will trigger the alarm to notify the operator.

The message of this alarm is shown in Figure 27.

\section{5/2/2020 12:10:24.970 4) ATO has operated}

FIGURE 27 ATO operation alarm message

\section{C.6 BREAKER PROTECTION TRIP ALARM: CRITICAL}

The breaker protection trip alarm is triggered each time the value "trip" is obtained through SCADA, indicating that a protection has tripped a breaker. The message of this alarm is shown in Figure 28. 


\section{C.7 BREAKER CHANGE OF STATE ALARM: CRITICAL}

The breaker change of state alarm is triggered each time the switch status of a breaker is changed. This information is received through SCADA. The message of this alarm is shown in Figure 29.

FIGURE 29 Breaker change of state alarm message

\section{C.8 BREAKER LOCAL ALARM: HIGH SEVERITY}

The breaker local alarm is triggered each time a breaker is changed from remote mode to local mode. This information is received through SCADA. The message of this alarm is shown in Figure 30.

FIGURE 30 Breaker local alarm message

\section{C.9 BREAKER GENERAL ALARM: CRITICAL}

The breaker general alarm is triggered each time the general alarm is received for a breaker. This information is received through SCADA and indicates to the operator that there is some problem with a breaker, and the operator needs to check this. The message of this alarm is shown in Figure 31.

\section{(1)}

FIGURE 31 Breaker general alarm message

\section{C.10 DER GENERAL ALARM: HIGH SEVERITY}

A DER general alarm is triggered each time a general alarm is received for a DER. This information is received through SCADA and indicates to the operator that there is some problem with a DER, and the operator needs to check this. The message of this alarm is shown in Figure 32.

FIGURE 32 DER general alarm message 


\section{C.11 DER AVAILABILITY ALARMS: HIGH SEVERITY}

A DER availability alarm is triggered when DER is not available for control from the MGC. This information is received through SCADA. The message of this alarm is shown in Figure 33.

FIGURE 33 DER availability alarm message

\section{C.12 MGC GROUP STATUS ALARMS: CRITICAL}

MGC group status alarms are triggered when the microgrid status is changed to island or when a blackout occurs. The message of this alarm is shown in Figure 34.

FIGURE 34 MGC group status alarms

\section{C.13 ADMS CONTROL MODE ALARM: HIGH SEVERITY}

An ADMS control mode alarm is triggered when the ADMS control of the MGC is disabled. This information is received through SCADA. The message of this alarm is shown in Figure 35.

FIGURE 35 ADMS control mode alarm

\section{C.14 MASTER MGC CONTROLLER DISABLED ALARM: HIGH SEVERITY}

The master MGC controller disabled alarm is triggered when the information that master MGC controller is disabled is received through SCADA. The message of this alarm is shown in Figure 36.

FIGURE 36 Master MGC controller disabled alarm 


\section{C.15 DISCONNECTION FAILED ALARM: CRITICAL}

The disconnection failed alarm is triggered when a disconnection of the microgrid fails. The message of this alarm is shown in Figure 37. This information is received through SCADA.

\section{5/2/2020 10:34:03.359 Disconnection process has failed Critical}

FIGURE 37 Disconnection failed alarm

\section{C.16 RECONNECTION FAILED ALARM: CRITICAL}

A reconnection failed alarm is triggered when reconnection of the microgrid fails. The message of this alarm is shown in Figure 38. This information is received through SCADA.

\section{5/2/2020 10:34:13.739 (1) Reconnection process has failed Critical}

FIGURE 38 Reconnection failed alarm

\section{C.17 BLACK START FAILED ALARM: CRITICAL}

A black start failed alarm is triggered when a black start of the microgrid fails. The message of this alarm is shown in Figure 39. This information is received through SCADA.

\section{4)}

Blackstart has failed

Gritical

FIGURE 39 Black start failed alarm

\section{C.18 MGC ANY COMMUNICATION ALARM: CRITICAL}

The any communication alarm is received when there is some problem with the communication between MGC and devices within the microgrid. The message of this alarm is shown in Figure 40. This information is received through SCADA.

\section{5/2/2020 10:46:12.244 There is some problem with connection with microgric}

FIGURE 40 MGC any communication alarm message 


\section{APPENDIX D: MGC DASHBOARD DESCRIPTION}

\section{D.1 POINT OF COMMON COUPLING (PCC)}

This section presents basic information characterizing the microgrid at the PCC, as shown on the MGC dashboard.

Active power defines the active power of the microgrid at the PCC. A positive number indicates that the microgrid imports active power from the external grid, while a negative number indicates that the microgrid exports power to the external grid.

Reactive power defines the reactive power of the microgrid at the PCC. A positive number indicates that the microgrid imports active power from the external grid, while a negative number indicates that the microgrid exports power to the external grid.

Frequency refers to the frequency of the microgrid. In grid-connected operation, this value is dictated by the external grid, and it is expected that there will be no significant variations around $60 \mathrm{~Hz}$. In island operation, this value is affected by the power imbalance between consumption and production, and it is expected that frequency variability will be much higher than in grid-connected operation.

Power factor indicates power factor at the PCC. In this project, a positive number indicates lagging, and a negative number indicates leading.

Voltage indicates line-to-line voltages at the PCC, represented in absolute values.

Active circuit shows the utility feeder to which the microgrid is connected. There are two possible options in this project, to reflect dual feed service from the utility.

Availability shows whether the microgrid is in grid-connected mode, island mode or in blackout.

Figure 41 shows microgrid active power, reactive power, frequency, voltage and power factor values shown on the MGC dashboard and in the MGC view. 

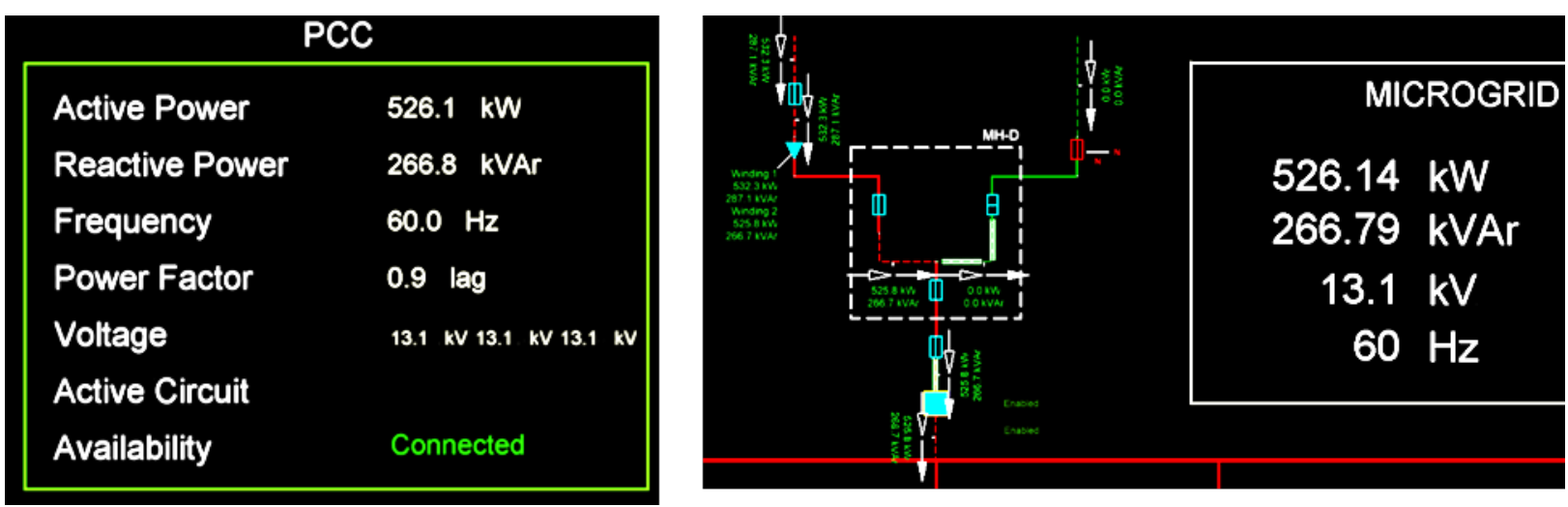

FIGURE 41 a.) PCC information on the MGC dashboard, b.) PCC information in the MGC view

If the connection point of the microgrid is changed from the first feeder to the second feeder, this will be indicated on the dashboard. Figure 42 shows PCC information on the MGC dashboard and in the MGC view when the microgrid is connected to the second feeder. During normal operation, the microgrid is connected to the first feeder, shown in red in the diagram. The alarm is also shown on the MGC dashboard.

When microgrid operation is changed to island mode, this will be indicated as shown in Figure 43. In case of a blackout event, the appropriate indication will be shown on the MGC dashboard. This is shown in Figure 44.

\begin{tabular}{|ll|}
\hline \multicolumn{2}{|c|}{ PCC } \\
\hline Active Power & $526.1 \mathrm{~kW}$ \\
Reactive Power & $266.8 \mathrm{kVAr}$ \\
Frequency & $60.0 \mathrm{~Hz}$ \\
Power Factor & $0.9 \mathrm{lag}$ \\
Voltage & $13.1 \mathrm{kv} 13.1 \mathrm{kV} 13.1 \mathrm{kv}$ \\
Active Circuit & \\
Availability & Connected \\
\hline
\end{tabular}

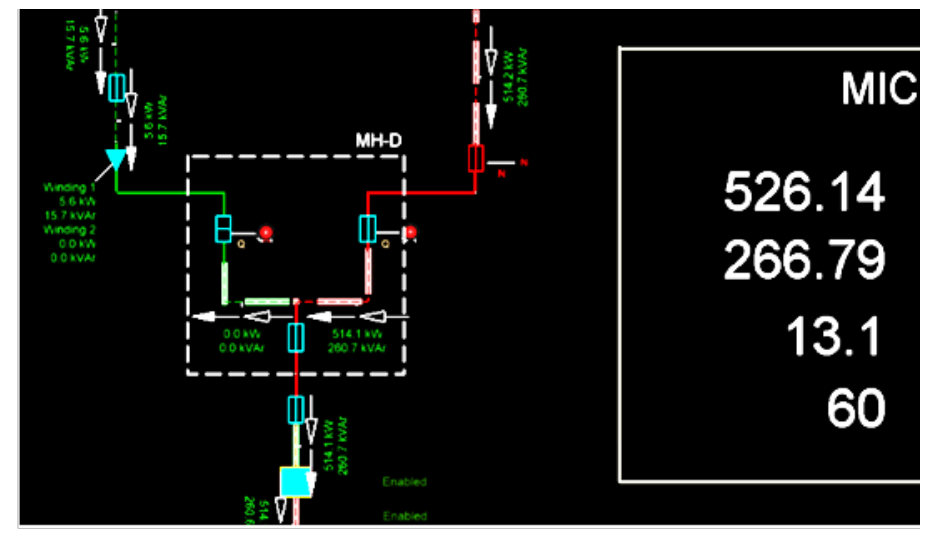

FIGURE 42 a.) MGC dashboard when microgrid is connected to the second feeder, b.) MGC view when microgrid is connected to the second feeder 

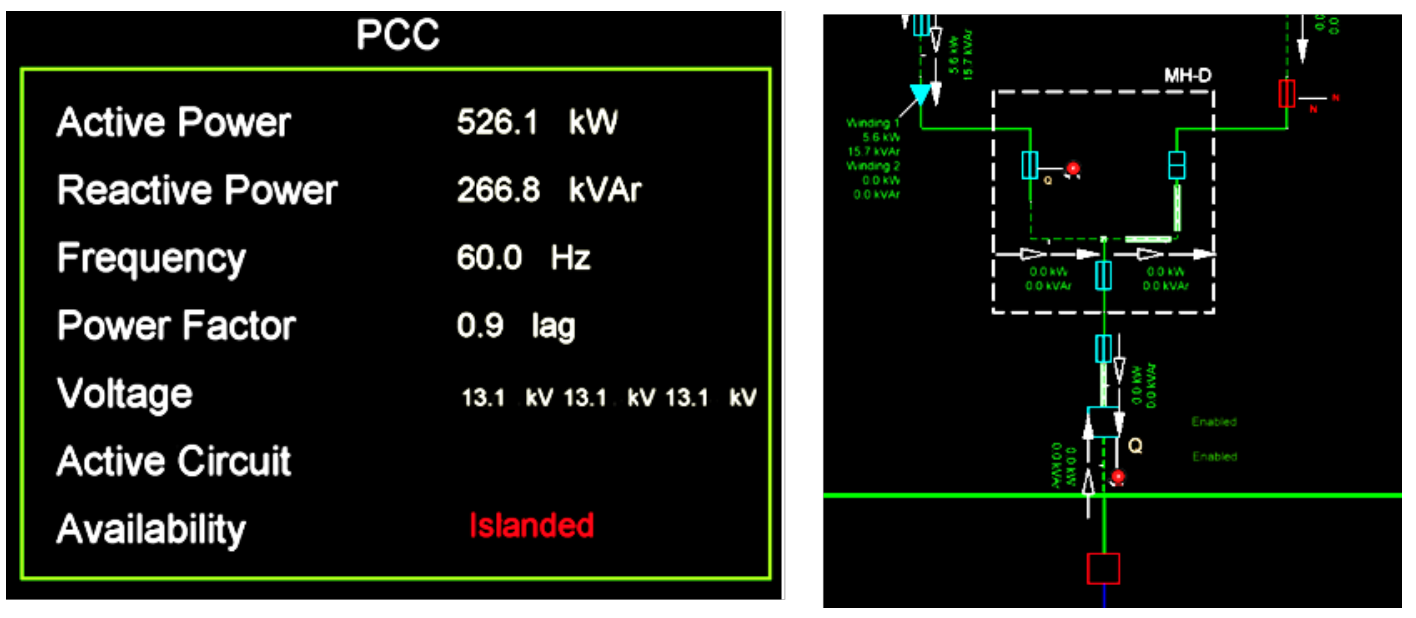

FIGURE 43 a.) MGC dashboard when microgrid is in island operation, b.) MGC view when microgrid is in island operation

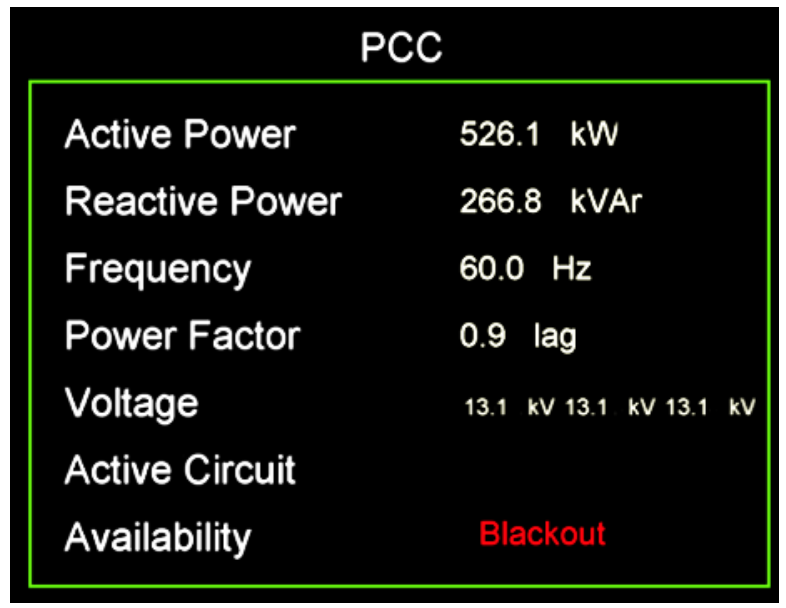

FIGURE 44 MGC dashboard in blackout event

\section{D.2 ALARM AND STATUS SUMMARY}

This section presents basic information characterizing the microgrid at the PCC.

- In the alarm and status summary window (Figure 45), the following indications are presented:

o Switch status of load break devices

o Indication whether a device is in local control or remote control

0 Indication whether there is an alarm triggered on a device

- Indication of the outcome of MGC transition (success/fail)

- Indication whether the PCC breaker relay has tripped (true/false)

- Indication of the PCC active power mode:

o Fixed active power 
o Peak shave

o Frequency support

- Indication of the PCC reactive power mode:

o Fixed reactive power

o Fixed power factor

o Voltage support

Figure 45 shows different combinations of the breaker statuses. Red indicates the presence of an alarm, green indicates that there is no alarm on a device. Switch statuses and indication of local or remote control are indicated with an appropriate message (closed/open, local/remote).

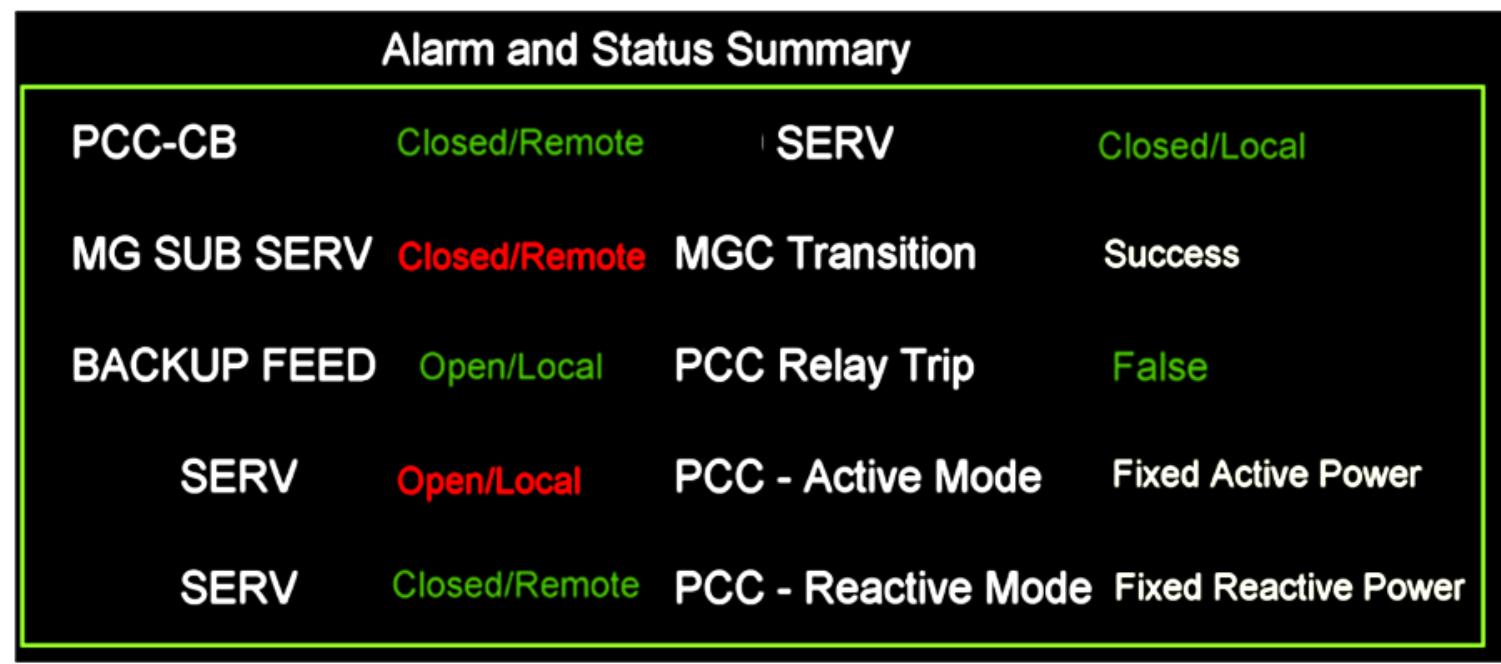

FIGURE 45 Alarm and status summary for different combinations of breaker status

Figure 46 shows alarms and statuses when an MGC transition is not successful. It actually represents the status of the last MGC transition and shows the indication that the PCC relay has tripped. As those two states are considered abnormal, the appropriate alarms can be seen on the MGC dashboard. 


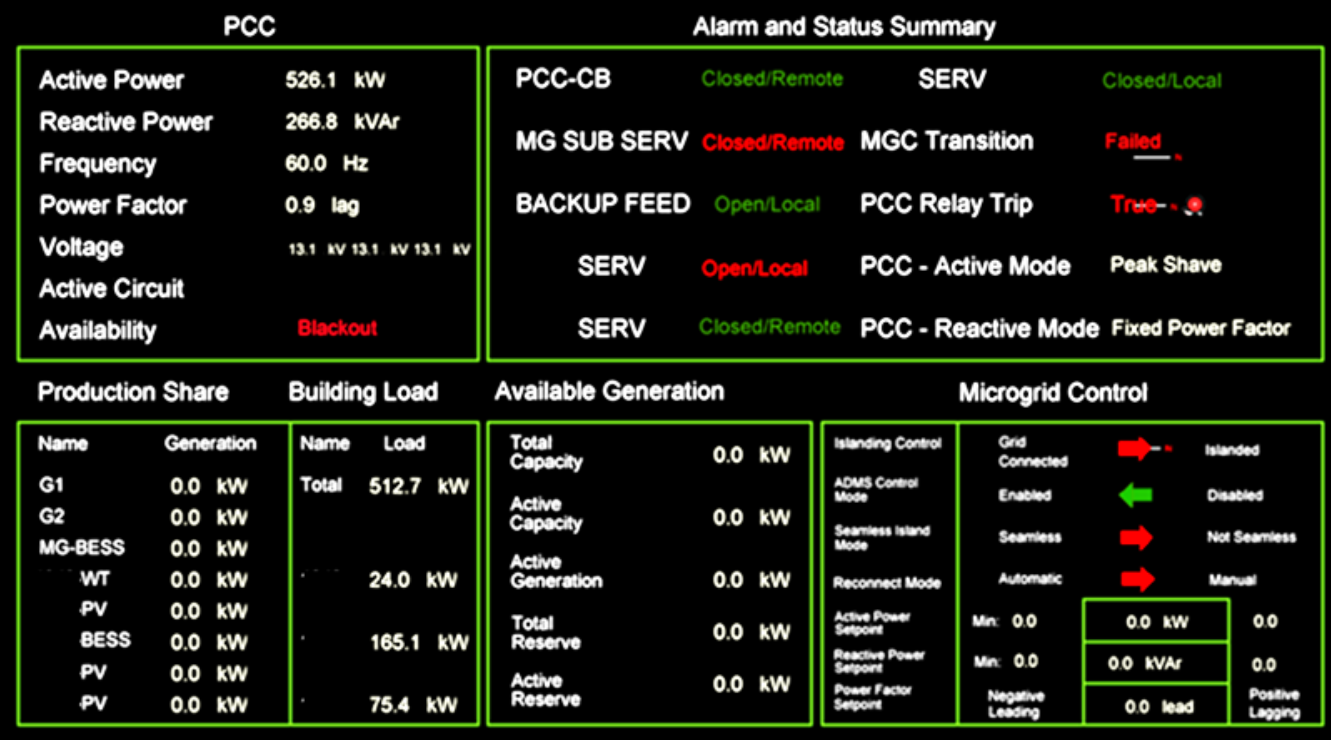

FIGURE 46 Indication of the MGC transition and PCC relay trip

\section{D.3 PRODUCTION SHARE AND BUILDING LOAD}

This section presents basic information about the generation values of PV systems, wind turbine systems, diesel generators, and battery storage devices. This section also presents load values, calculated based on the measurements of the active power through different switches, as well as the total load value of the whole microgrid. Figure 47 and Figure 48 show appropriate production and consumption seen from the MGC view.

\begin{tabular}{|c|c|c|c|}
\hline \multicolumn{2}{|c|}{ Production Share } & \multicolumn{2}{|c|}{ Building Load } \\
\hline Name & Generation & Name & Load \\
\hline G1 & $0.0 \mathrm{~kW}$ & Total & $512.7 \mathrm{~kW}$ \\
\hline G2 & $0.0 \mathrm{~kW}$ & & \\
\hline MG-BESS & $0.0 \mathrm{~kW}$ & & \\
\hline WT & $1.3 \mathrm{~kW}$ & & $23.6 \mathrm{~kW}$ \\
\hline PV & $63.2 \mathrm{~kW}$ & & \\
\hline BESS & $0.0 \mathrm{~kW}$ & & $117.0 \mathrm{~kW}$ \\
\hline PV & $63.2 \mathrm{~kW}$ & & \\
\hline PV & $31.6 \mathrm{~kW}$ & & $75.9 \mathrm{~kW}$ \\
\hline
\end{tabular}

FIGURE 47 Production share and building share section of MGC dashboard 


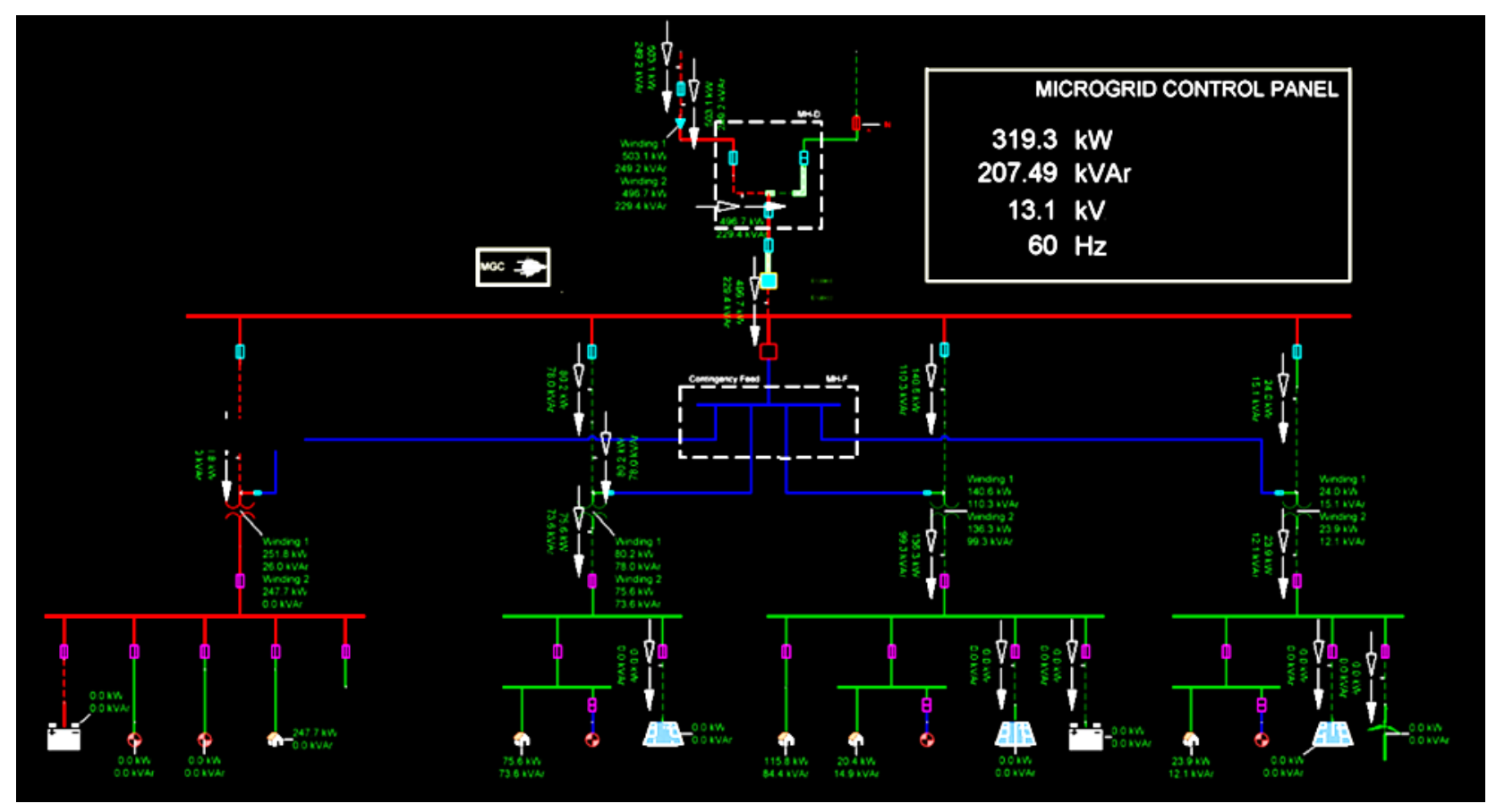

FIGURE 48 Production and consumption as seen on the MGC view

\section{D.4 AVAILABLE GENERATION}

This section presents basic information about the available generation parameters. Figure 49 shows a microgrid dashboard that displays the following parameters:

- Total capacity

- Active capacity

- Active generation

- Total reserve, equal to total capacity minus active generation

- Active reserve, equal to active capacity minus active generation 


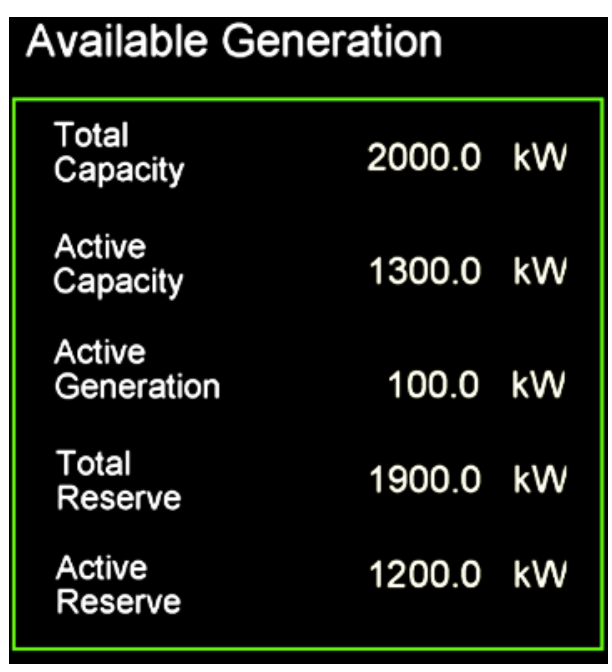

FIGURE 49 MGC Dashboard with available generation parameters

\section{D.5 MICROGRID CONTROL}

This section provides an overview of the basic parameters for monitoring and controlling the microgrid (shown in Figure 50).

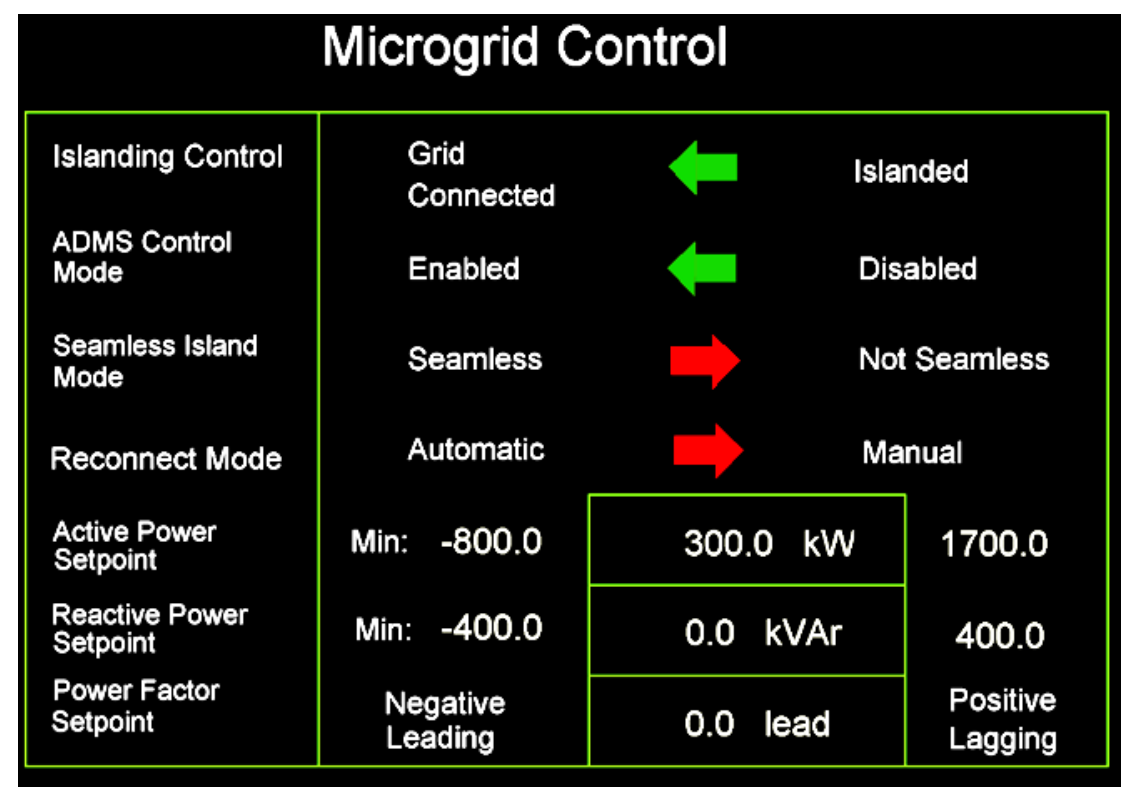

FIGURE 50 Microgrid control field

Grid-connected/islanded - a green arrow indicates that the microgrid is in gridconnected mode, and a red arrow indicates that the microgrid is in island mode. By clicking on 
the arrow, the operator obtains the ability to submit a request for disconnection or reconnection of the microgrid (Figure 51).

Enabled/disabled - a green arrow indicates that ADMS control is enabled, while a red arrow indicates that ADMS control is disabled.

Seamless/not seamless - a green arrow indicates that the microgrid will have seamless transition to island mode and a red arrow indicates that the microgrid will have non-seamless transition to island mode. By clicking on the arrow, the operator obtains the ability to choose whether disconnection from the grid will be seamless or non-seamless, as with the gridconnected/islanded field.

Automatic/manual - a green arrow indicates that the microgrid will be automatically connected to the grid when appropriate conditions are met, and a red arrow indicates that the microgrid will not be automatically connected to the grid when appropriate conditions are met. By clicking on the arrow, the operator obtains the ability to choose whether the transition to grid will be automatic or not, as with the grid-connected/islanded field.

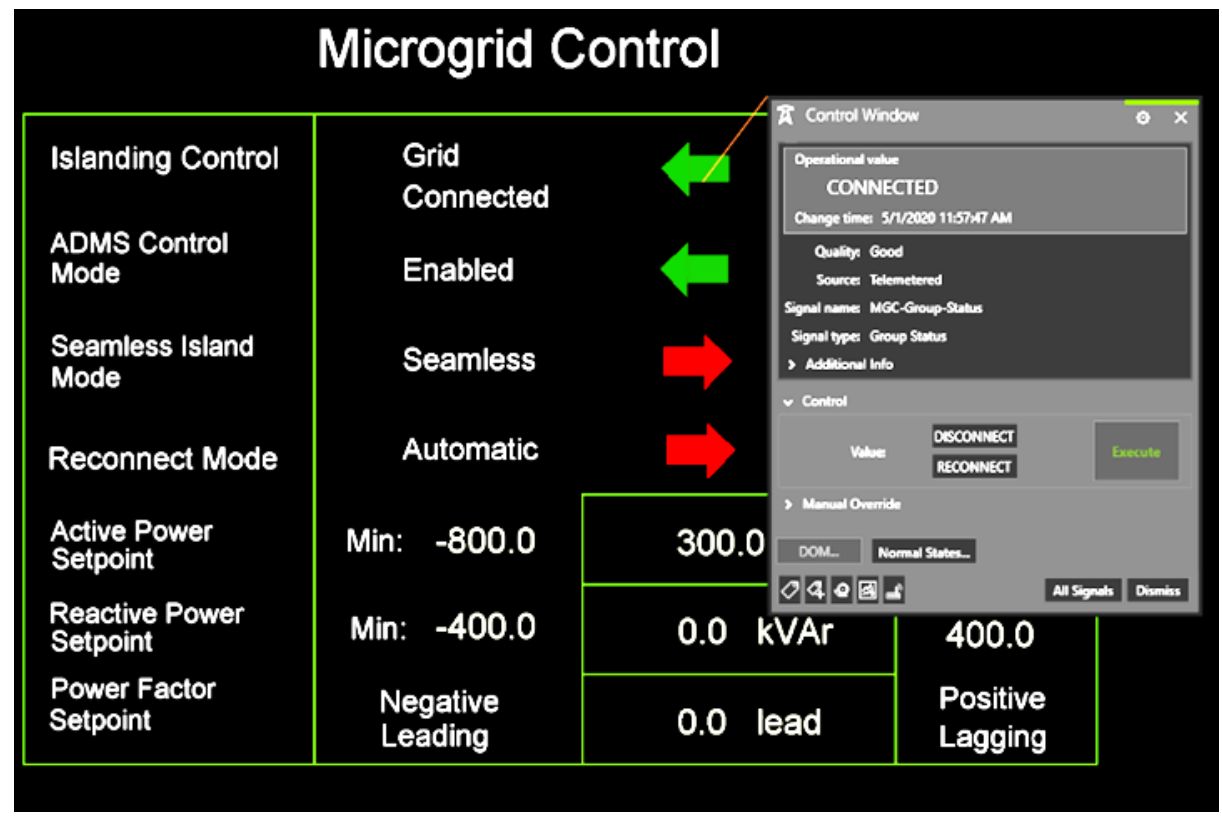

FIGURE 51 Sending a request for island mode operation

The last three fields provide information on microgrid active power, reactive power and power factor. Information about minimum and maximum values for active and reactive power are provided from the microgrid. These indicators are used by advanced DERMS applications like VVWO and LR as information about flexibility services provided by the microgrid. Note that the value of the last setpoint sent from the microgrid is provided. By clicking on the button, the operator can send a setpoint directly to the microgrid. In addition, the operator can schedule 
the active and reactive power of the microgrid, and the DERMS will automatically send appropriate setpoints. This is shown in Figure 52.

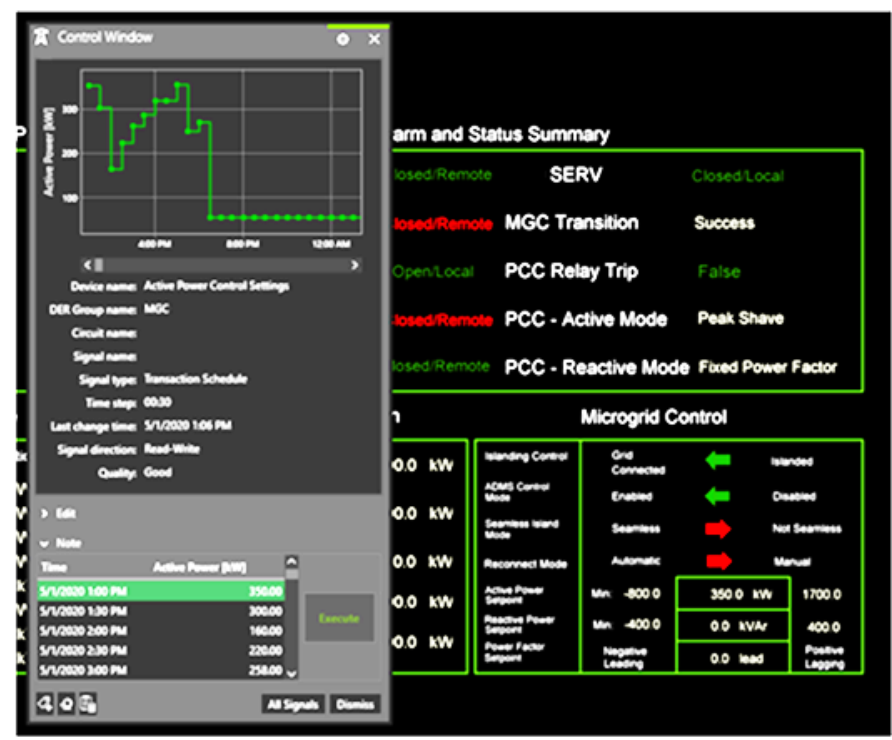

FIGURE 52 Scheduling of the microgrid 


\section{APPENDIX E: USE CASES}

\section{E.1 USE CASE 1: MICROGRID ISLANDING AND RECONNECTION FROM ADMS}

TABLE 12 Use Case 1

\begin{tabular}{|c|c|c|}
\hline Step & Actor & Description \\
\hline \multicolumn{3}{|c|}{ Transition Between Grid-Connected and Islanded Mode } \\
\hline \multicolumn{3}{|c|}{ Scenario 1 - Direct Planned Islanding } \\
\hline 1. & MGC & $\begin{array}{l}\text { ADMS control of microgrid is enabled from MGC HMI. ADMS receives indication that } \\
\text { ADMS_CONTROL_MODE signal is } 1 \text { (enabled). } \\
\text { Note: This step can be considered a precondition. If it is already satisfied, it does not need } \\
\text { to be executed. }\end{array}$ \\
\hline 2. & ADMS & $\begin{array}{l}\text { Operator sets constant active and reactive power mode control from ADMS by sending } \\
\text { value } 1 \text { (enabled) to signals PCC_P_MODE_CMD and PCC_Q_MODE_CMD. } \\
\text { Note: This step can be considered a precondition. If it is already satisfied, it does not need } \\
\text { to be executed. After this action, } P \text { and } Q \text { setpoints will be used by ADMS to control MGC } \\
\text { active and reactive power. }\end{array}$ \\
\hline 3. & MGC & $\begin{array}{l}\text { When all conditions are satisfied, MGC sends indication to ADMS that it is permitted to } \\
\text { start planned islanding procedure. The value of signal } \\
\text { PCC_DISCONNECT_PERMISSIVE is } 1 \text { (permitted). }\end{array}$ \\
\hline 4. & ADMS & $\begin{array}{l}\text { System operator sends request for planned islanding to microgrid controller using } \\
\text { PCC_DISCONNECT_CMD signal, which should be equal to } 1 \text {. }\end{array}$ \\
\hline 5. & MGC & $\begin{array}{l}\text { Microgrid controller receives request from ADMS for planned islanding. The value of } \\
\text { signal PCC_DISCONNECT_INPROGRESS is changed to } 1 \text { (in progress). }\end{array}$ \\
\hline 6. & MGC & Microgrid controller starts standby generators. \\
\hline 7. & MGC & Microgrid controller reduces PV and WT output to below the island participation limit. \\
\hline 8. & MGC & $\begin{array}{l}\text { Microgrid controller reduces active and reactive power in PCC to } 0 \text { (values of signals } \\
\text { PCC_P and PCC_Q are equal to } 0 \text { ). }\end{array}$ \\
\hline 9. & MGC & $\begin{array}{l}\text { Microgrid controller opens the switch and continues the operation in island mode. It sends } \\
\text { an indication to ADMS that it is in island mode. }\end{array}$ \\
\hline 10. & MGC & Microgrid controller sets generator 1 to isochronous mode. \\
\hline 11. & ADMS & $\begin{array}{l}\text { ADMS receives an indication that microgrid is in island operation and } \\
\text { CAMPUS_ISLANDED signal is equal to } 1 \text { (islanded). ADMS receives information that } \\
\text { the PCC switch is opened, PCC_STATUS signal is equal to } 0 \text { (open). }\end{array}$ \\
\hline
\end{tabular}




\begin{tabular}{|c|c|c|}
\hline Step & Actor & Description \\
\hline \multicolumn{3}{|c|}{ Scenario 2 - Reconnection to Grid } \\
\hline 1. & MGC & $\begin{array}{l}\text { ADMS is enabled to control MGC from MGC HMI. ADMS receives an indication that } \\
\text { ADMS_CONTROL_MODE signal is } 1 \text { (enabled). } \\
\text { Note: This step can be considered a precondition. If it is already satisfied, it does not need } \\
\text { to be executed. }\end{array}$ \\
\hline 2. & ADMS & $\begin{array}{l}\text { Operator sets constant active and reactive power mode control from ADMS by sending } \\
\text { value } 1 \text { (enabled) to signals PCC_P_MODE_CMD and PCC_Q_MODE_CMD. } \\
\text { Note: This step can be considered a precondition. If it is already satisfied, it does not need } \\
\text { to be executed. }\end{array}$ \\
\hline 3. & MGC & $\begin{array}{l}\text { When conditions are satisfied, MGC sends indication to ADMS that it is permitted to start } \\
\text { the reconnection procedure. The value of signal PCC_RECONNECT_PERMISSIVE is } 1 \\
\text { (permitted). } \\
\text { Note: Conditions for permissive signal are: } \\
\text { Utility voltage is within healthy limits. } \\
\text { Utility frequency is within healthy limits. }\end{array}$ \\
\hline 4. & ADMS & $\begin{array}{l}\text { System operator sends request for reconnection to microgrid controller using PCC_ } \\
\text { RECONNECT_CMD signal, which should be equal to } 1 \text {. }\end{array}$ \\
\hline 5. & MGC & $\begin{array}{l}\text { Microgrid controller receives request from ADMS. The value of signal } \\
\text { PCC_RECONNECT_INPROGRESS is changed to } 1 \text { (in progress). }\end{array}$ \\
\hline 6. & MGC & $\begin{array}{l}\text { Microgrid controller adjusts the generator and/or BESS to bring the microgrid frequency } \\
\text { and voltage and the angle across the PCC breaker to within the sync check limits. }\end{array}$ \\
\hline 7. & MGC & $\begin{array}{l}\text { Microgrid controller closes the PCC breaker via the sync check element in the PCC relay } \\
\text { and continues work in grid-connected mode. }\end{array}$ \\
\hline 8. & MGC & Microgrid controller commands the isochronous generator to droop mode. \\
\hline 9. & MGC & Microgrid controller releases the island participation limit on PV and WT assets. \\
\hline 10. & MGC & Microgrid controller adjusts the DER output to meet the PCC setpoint from the ADMS. \\
\hline 11. & ADMS & $\begin{array}{l}\text { ADMS receives an indication that microgrid is in grid-connected mode. } \\
\text { CAMPUS_CONNECTED signal is equal to } 1 \text { (connected). ADMS receives information } \\
\text { that the PCC switch is closed and PCC_STATUS signal is equal to } 1 \text { (closed). }\end{array}$ \\
\hline
\end{tabular}

\begin{tabular}{l|l|l}
\multicolumn{2}{l}{ Scenario 3-Unplanned Islanding } \\
\hline 1. & MGC & $\begin{array}{l}\text { ADMS is enabled to control MGC from MGC HMI. ADMS receives an indication that } \\
\text { ADMS_CONTROL_MODE signal is 1 (enabled). } \\
\text { Note: This step can be considered a precondition If it is already satisfied, it does not need } \\
\text { to be executed. }\end{array}$ \\
\hline 2. & ADMS & $\begin{array}{l}\text { Operator sets constant active and reactive power mode control from ADMS by sending } \\
\text { value 1 (ENABLED) to signals PCC_P_MODE_CMD and PCC_Q_MODE_CMD. } \\
\text { Note: This step can be considered a precondition. If it is already satisfied, it does not need } \\
\text { to be executed. After this action, P and Q setpoints will be used by ADMS to control MGC } \\
\text { active and reactive power. }\end{array}$ \\
\hline
\end{tabular}




\begin{tabular}{l|l|l}
\multicolumn{1}{c|}{ Step } & \multicolumn{1}{|c}{ Actor } & \multicolumn{1}{c}{ Description } \\
3. & ADMS & $\begin{array}{l}\text { System operator wants to open feeder head breaker. When they click on the switch, they } \\
\text { obtain a warning validation message that microgrid should be in island operation before } \\
\text { feeder breaker is opened. }\end{array}$ \\
\hline 4. & ADMS & $\begin{array}{l}\text { System operator can obtain location of microgrid to which they can send signal to change } \\
\text { the operation of microgrid to island mode (Use Case 1 - Scenario 1). }\end{array}$ \\
\hline 5. & MGC & In MGC HMI, unplanned islanding is simulated by opening the switch above PCC. \\
\hline 6. & MGC & Microgrid losses supply from the external grid. It starts to work in unplanned island mode. \\
\hline 7. & MGC & PCC relay detects the condition and trips the PCC breaker \\
\hline 9. & MGC & MG SUB BESS responds to microgrid frequency based on its droop characteristic. \\
\hline 10. & MGC & $\begin{array}{l}\text { Microgrid sheds load if needed to balance power supply with load on the island (load } \\
\text { shed is done only as a last resort). }\end{array}$ \\
\hline 11. & MGC & Microgrid controller reduces PV and WT output to below island participation limit. \\
\hline 12. & ADMS & Operator can see that PCC breaker is open: PCC_STATUS signal is equal to 0 (open). \\
\hline 13. & ADMS & $\begin{array}{l}\text { ADMS receives an indication from MGC that disconnect process is in progress. The value } \\
\text { of signal PCC_DISCONNECT_INPROGRESS is changed to 1 (in progress). }\end{array}$ \\
\hline 14. & ADMS & $\begin{array}{l}\text { ADMS receives an indication that microgrid is in island operation, } \\
\text { CAMPUS_ISLANDED signal is equal to 1 (islanded). }\end{array}$ \\
\hline ADMS & $\begin{array}{l}\text { ADMS receives information and alarm that the PCC has tripped: PCC_TRIPPED signal is } \\
\text { equal to 1 (tripped). }\end{array}$ \\
\hline
\end{tabular}

\section{Unsuccessful Scenarios}

\begin{tabular}{l|l|l}
\multicolumn{2}{l}{ Scenario 4-Unsuccessful Planned Islanding } \\
\hline 1. & MGC & $\begin{array}{l}\text { ADMS is enabled to control MGC from MGC HMI. ADMS receives an indication that } \\
\text { ADMS_CONTROL_MODE signal is 1 (enabled). } \\
\text { Note: This step can be considered a precondition. If it is already satisfied, it does not need } \\
\text { to be executed. }\end{array}$ \\
\hline 2. & ADMS & $\begin{array}{l}\text { Operator sets constant active and reactive power mode control from ADMS by sending } \\
\text { value 1 (enabled) to signals PCC_P_MODE_CMD and PCC_Q_MODE_CMD. } \\
\text { Note: This step can be considered a precondition. If it is already satisfied, it does not need } \\
\text { to be executed. After this action,P and Q setpoints will be used by ADMS to control MGC } \\
\text { active and reactive power. }\end{array}$ \\
\hline 3. & MGC & $\begin{array}{l}\text { When the conditions are satisfied, MGC sends an indication to ADMS that it is permitted } \\
\text { to start planned islanding procedure. The value of signal } \\
\text { PCC_DISCONNECT_PERMISSIVE is 1 (permitted). }\end{array}$ \\
\hline 5. & ADMS & $\begin{array}{l}\text { System operator sends request for planned islanding to microgrid controller through signal } \\
\text { PCC_DISCONNECT_CMD, value 1. }\end{array}$ \\
\hline
\end{tabular}




\begin{tabular}{|c|c|c|}
\hline Step & Actor & Description \\
\hline 6. & MGC & Microgrid controller starts standby generators. \\
\hline 7. & MGC & Microgrid controller reduces PV and WT output to below the island participation limit. \\
\hline 8. & MGC & $\begin{array}{l}\text { Microgrid controller reduces active and reactive power in PCC to } 0 \text { (values of signals } \\
\text { PCC_P and PCC_Q are equal to } 0 \text { ). }\end{array}$ \\
\hline 9. & MGC & $\begin{array}{l}\text { Microgrid controller opens the switch and continues the operation in island mode. It sends } \\
\text { indication to ADMS that it is in island mode. }\end{array}$ \\
\hline 10. & MGC & $\begin{array}{l}\text { For some reason, the disconnection process fails. MGC sends indication to ADMS that } \\
\text { disconnection procedure has failed. } \\
\text { Note: Three possible reasons for failure are: } \\
\text { - } \quad \text { Generators fail to start } \\
\text { - PCC flow not reduced sufficiently } \\
\text { - PCC breaker fails to open }\end{array}$ \\
\hline 11. & ADMS & $\begin{array}{l}\text { ADMS receives an indication that disconnection procedure has failed. } \\
\text { PCC_DISCONNECT_FAIL signal is equal to } 1 \text { (fail). Appropriate alarm is generated. }\end{array}$ \\
\hline \multicolumn{3}{|c|}{ Scenario 5 - Unsuccessful Reconnection to Grid (this scenario will not be presented during demo) } \\
\hline 1. & MGC & $\begin{array}{l}\text { ADMS is enabled to control MGC from MGC HMI. ADMS receives an indication that } \\
\text { ADMS_CONTROL_MODE signal is } 1 \text { (enabled). } \\
\text { Note: This step can be considered a precondition. If it is already satisfied, it does not need } \\
\text { to be executed. }\end{array}$ \\
\hline 2. & ADMS & $\begin{array}{l}\text { Operator sets constant active and reactive power mode control from ADMS by sending } \\
\text { value } 1 \text { (enabled) to signals PCC_P_MODE_CMD and PCC_Q_MODE_CMD. } \\
\text { Note: This step can be considered a precondition. If it is already satisfied, it does not need } \\
\text { to be executed. After this action, P and Q setpoints will be used by ADMS to control MGC } \\
\text { active and reactive power. }\end{array}$ \\
\hline 3. & MGC & $\begin{array}{l}\text { When the conditions are satisfied, MGC sends an indication to ADMS that it is permitted } \\
\text { to start the reconnection procedure. The value of signal } \\
\text { PCC_RECONNECT_PERMISSIVE is } 1 \text { (permitted). }\end{array}$ \\
\hline 4. & ADMS & $\begin{array}{l}\text { System operator sends a request to reconnect the microgrid through signal } \\
\text { PCC_RECONNECT_CMD, value } 1 \text {. }\end{array}$ \\
\hline 5. & MGC & $\begin{array}{l}\text { Microgrid controller receives a request from ADMS. The value of signal } \\
\text { PCC_RECONNECT_INPROGRESS is changed to } 1 \text { (in progress). }\end{array}$ \\
\hline 6. & MGC & $\begin{array}{l}\text { Microgrid controller adjusts the generator and/or BESS to bring the microgrid frequency } \\
\text { and voltage, as well as the angle across the PCC breaker, to within the sync check limits. }\end{array}$ \\
\hline 7. & MGC & $\begin{array}{l}\text { Microgrid controller closes the PCC breaker via the sync check element in the PCC relay } \\
\text { and continues to work in grid-connected mode. }\end{array}$ \\
\hline 8. & MGC & Microgrid controller commands the isochronous generator to droop mode. \\
\hline 9. & MGC & Microgrid controller releases the island participation limit on PV and WT assets. \\
\hline 10. & MGC & Microgrid controller adjusts the DER output to meet the PCC setpoint from the ADMS. \\
\hline
\end{tabular}




\begin{tabular}{l|l|l}
\multicolumn{1}{c|}{ Step } & \multicolumn{1}{|c}{ Actor } & \\
11. & MGC & $\begin{array}{l}\text { For some reason, the reconnection process fails. MGC sends an indication to ADMS that } \\
\text { the reconnection procedure has failed. }\end{array}$ \\
\hline 12. & ADMS & $\begin{array}{l}\text { ADMS receives indication that reconnection procedure has failed. } \\
\text { PCC_RECONNECT_FAIL signal is equal to 1 (fail). Appropriate alarm is generated. }\end{array}$ \\
\hline Scenario 6 - Unsuccessful Unplanned Islanding (this scenario will not be presented during demo)
\end{tabular}

The screenshots created during the execution of these scenarios are shown in the following text.

\section{E.1.1. Scenario 1 - Direct Planned Islanding}

In this scenario, an operator sends a request for planned island operation of the microgrid. First, all conditions need to be satisfied. Figure 53 shows microgrid view in the initial state. Figure 54 shows a microgrid dashboard in the initial state. 


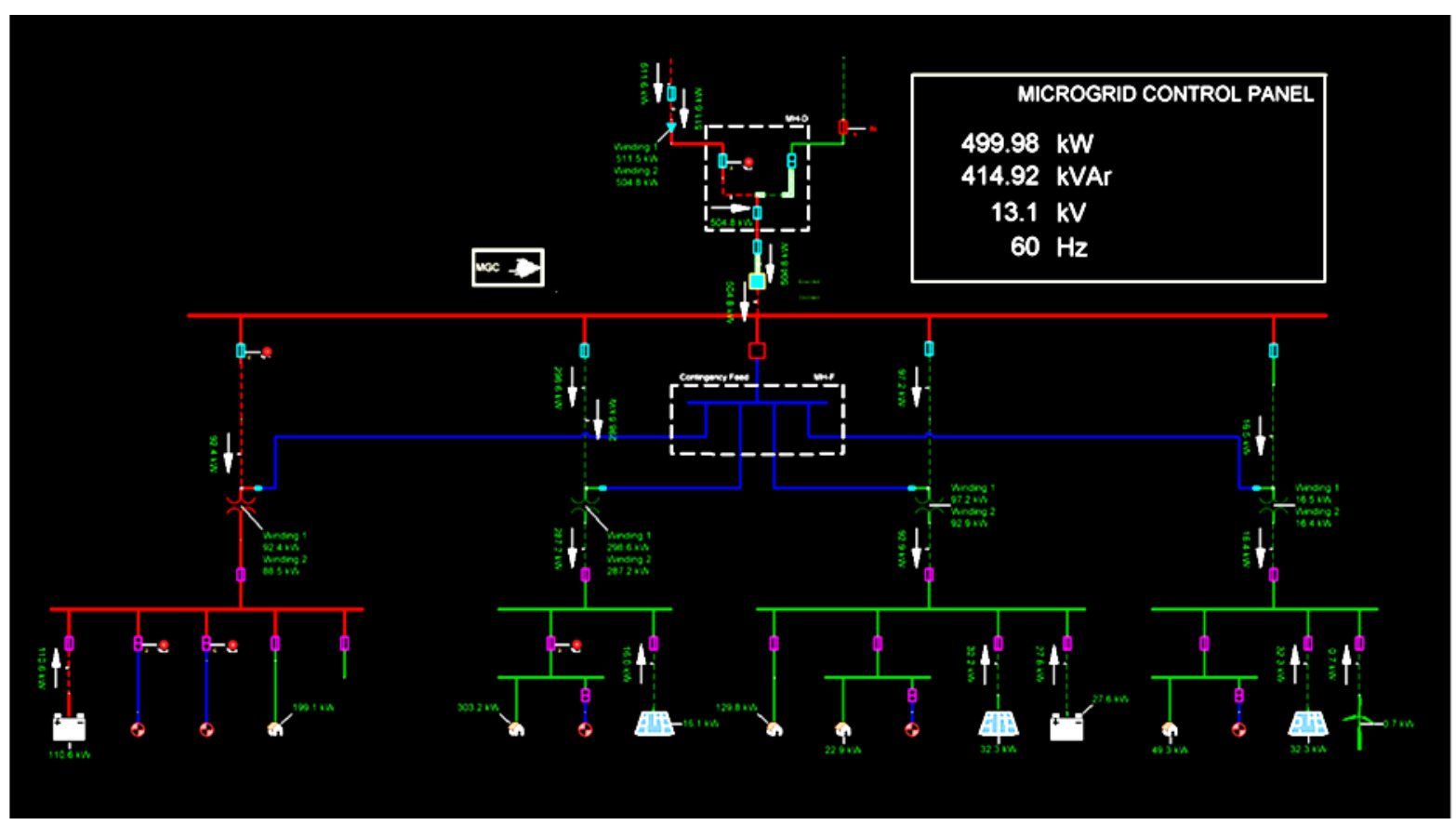

FIGURE 53 Microgrid view in initial state

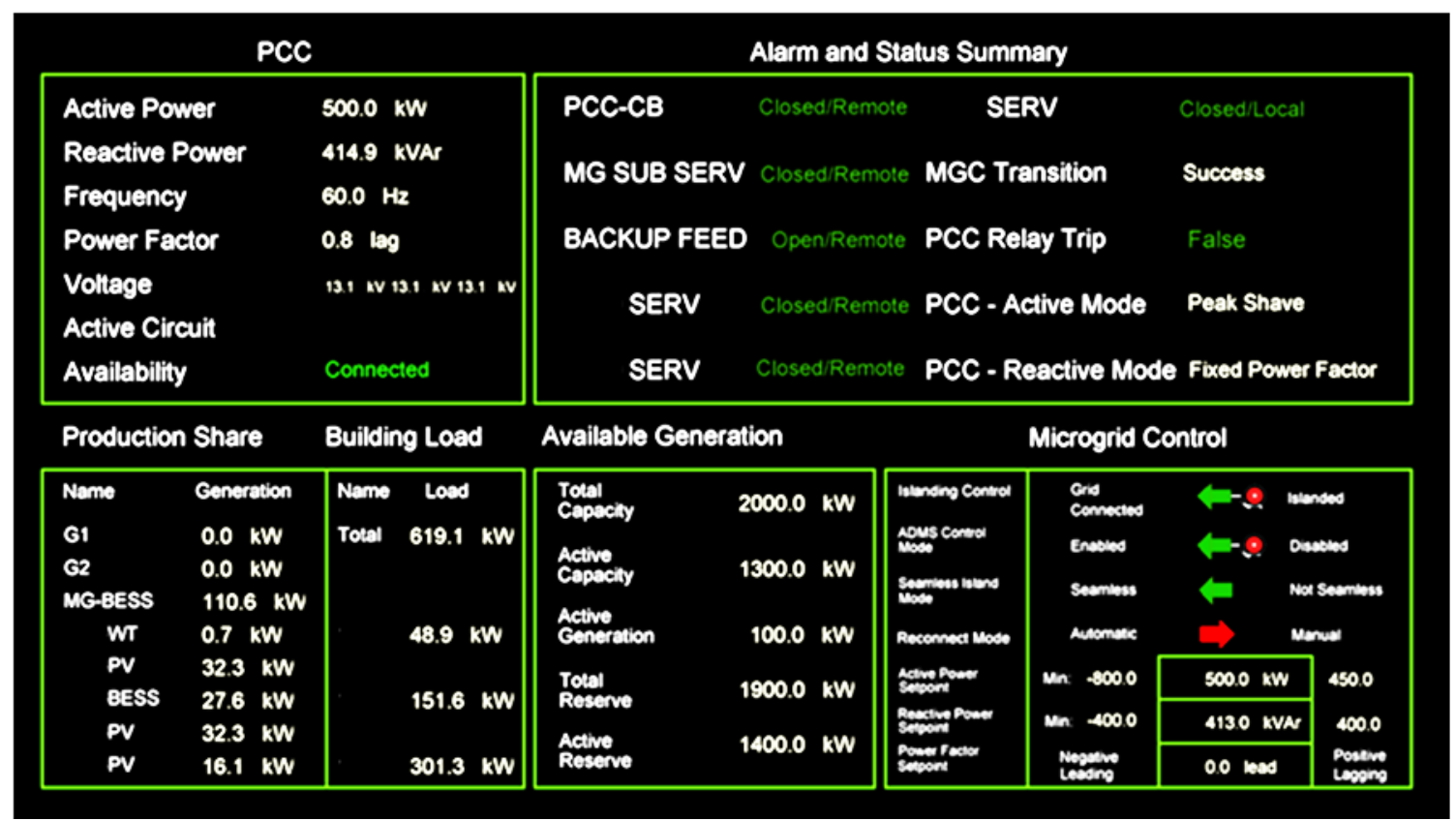

\section{FIGURE 54 Microgrid dashboard in initial state}

In the first step, the operator sends a request for a planned islanding of the microgrid. The request can be sent from the microgrid dashboard (Figure 55). The operator is notified with a warning validation message that the request for island operation of the microgrid will be sent. After the request is sent, the MGC will reduce active and reactive power in the PCC to zero and 
open the PCC breaker (Figure 56). Finally, the MGC sends an indication to the DERMS that it is working in island mode (Figure 57).

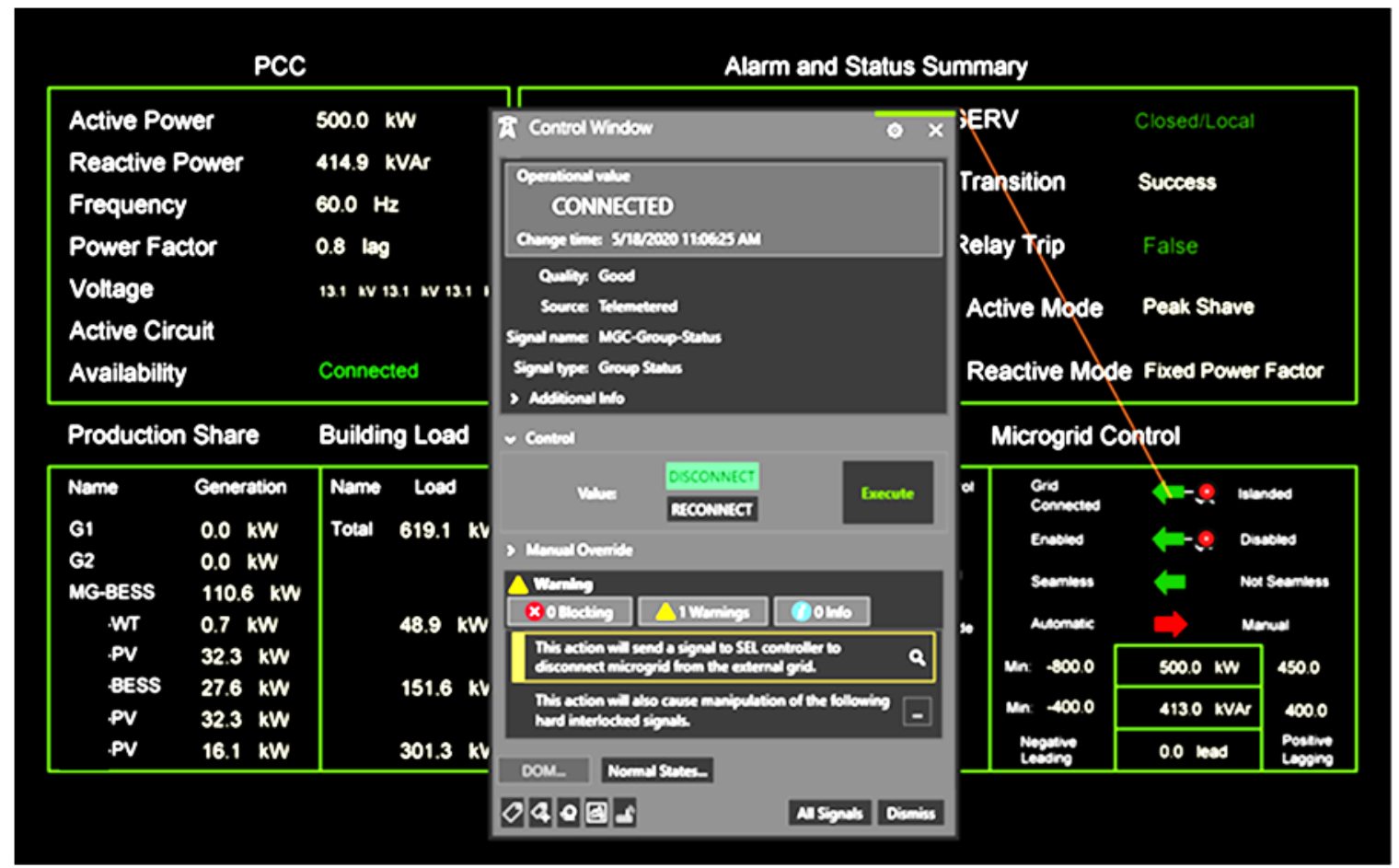

FIGURE 55 Request for planned disconnection

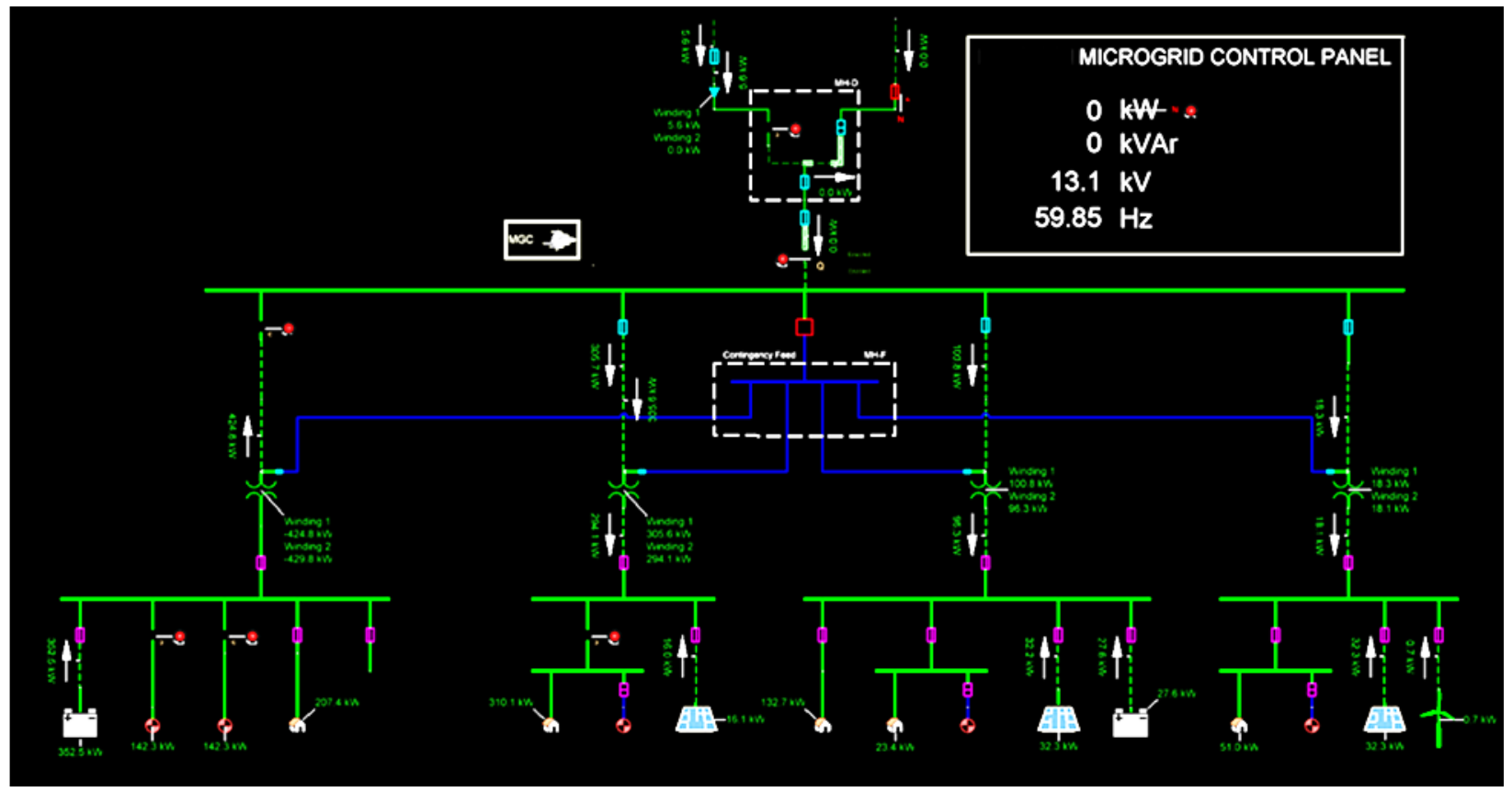

FIGURE 56 Operation of the microgrid in island 


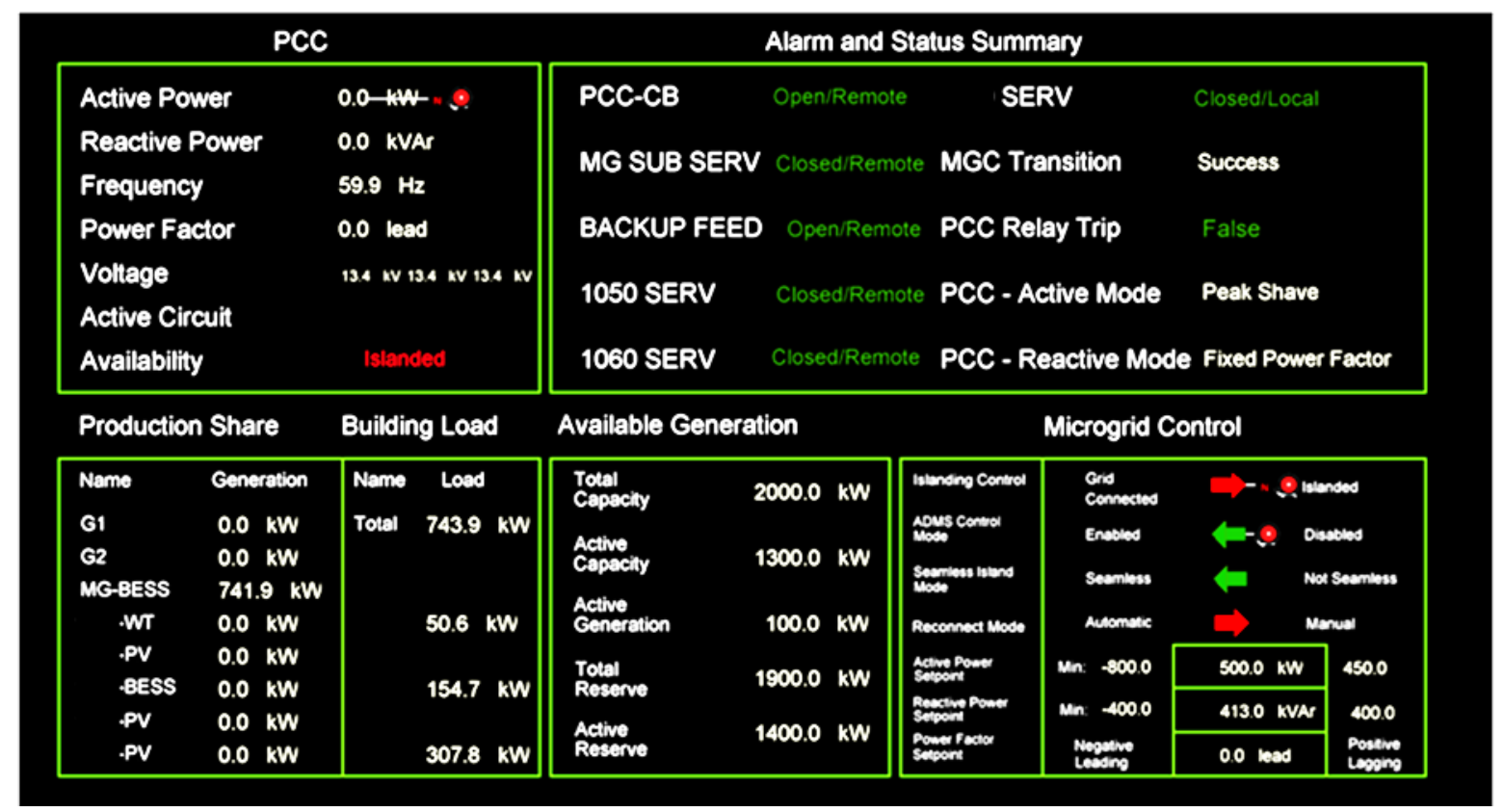

FIGURE 57 Microgrid dashboard in island operation

\section{E.1.2. Scenario 2 - Reconnection to Grid}

In this scenario, an operator sends a request for the microgrid to reconnect to the grid. Using the microgrid dashboard, the operator sends a request for the microgrid to go to gridconnected mode. This is shown in Figure 58. After that, the MGC closes the PCC breaker and returns active power to the setpoint obtained from the DERMS.

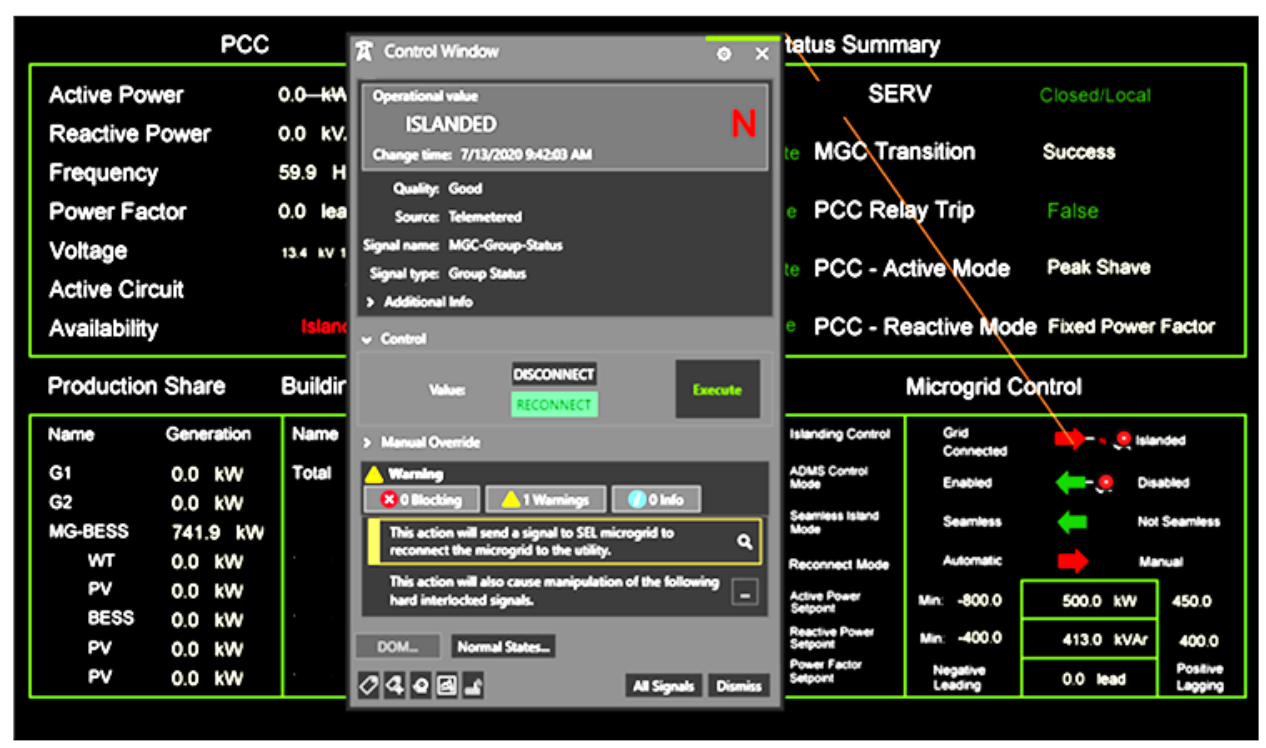

FIGURE 58 Request for grid-connected operation of the microgrid 


\section{E.1.3. Scenario 3 - Unplanned Islanding}

In this scenario, the MGC detects the loss of the voltage supply and provides seamless transition to island mode. The microgrid operation will look the same as what is shown in Figure 55 and Figure 56 above.

\section{E.1.4. Scenario 4 - Unsuccessful Scenarios}

In the unsuccessful scenarios, the MGC sends an indication that the disconnection or reconnection is unsuccessful, and the microgrid dashboard will show that the MGC transition has failed. This is shown in Figure 59.

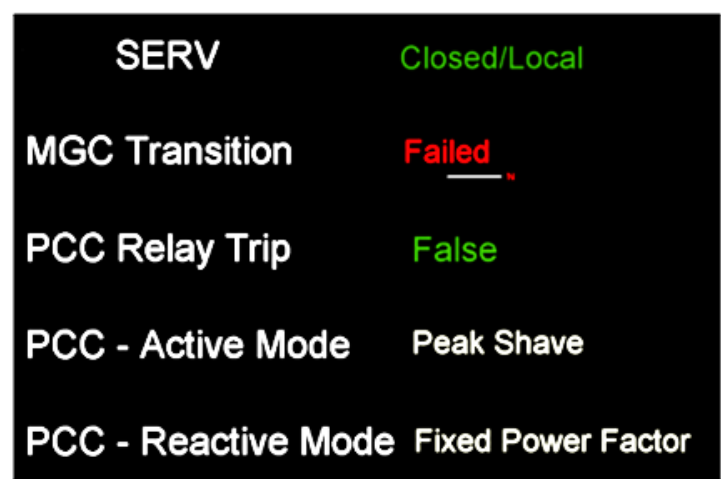

FIGURE 59 Microgrid operation in gridconnected mode after reconnection

\section{E.2 USE CASE 2: DMS VISIBILITY AND MONITORING OF MICROGRID}

TABLE 13 Use Case 2

\begin{tabular}{c|l|l} 
Step & Actor & \multicolumn{1}{c}{ Description } \\
Scenario 1 - DMS Alarm System for Events or Conditions Needing Operator Attention \\
\hline 1. & ADMS & ADMS provides different alarm limits and severity levels for each measurement. \\
\hline 2. & ADMS & ADMS provides DMS alarms for each estimated value. \\
\hline 3. & MGC & ADMS provides custom alarms, such as DER failure, controller does not work, etc. \\
\hline Scenario $2-$ Monitoring of Key Power System Parameters \\
\hline 1. & ADMS & $\begin{array}{l}\text { System operator has ability to monitor, on dynamic mimic diagram (DMD), real-time } \\
\text { measurements like active powers, reactive powers, voltages, etc. }\end{array}$ \\
\hline 2. & ADMS & $\begin{array}{l}\text { System operator has ability to monitor, on DMD, estimated values like active powers, } \\
\text { reactive powers, voltages, etc. }\end{array}$ \\
\hline
\end{tabular}




\begin{tabular}{c|c|l} 
Step & Actor & \multicolumn{1}{c}{ Description } \\
\hline 3. & ADMS & $\begin{array}{l}\text { System operator has ability to monitor, on DMD, switch statuses of breakers on PCC, DERs, } \\
\text { etc. }\end{array}$ \\
\hline 4. & ADMS & $\begin{array}{l}\text { System operator has ability to monitor operating conditions and measurements of microgrid } \\
\text { from dashboard. }\end{array}$ \\
\hline
\end{tabular}

\begin{tabular}{c|l|l}
\multicolumn{2}{c}{ Scenario 3-Other Monitoring Possibilities } \\
\hline 1. & ADMS & ADMS provides indication of SCADA and signal quality (good, bad, stale) \\
\hline 2. & ADMS & $\begin{array}{l}\text { ADMS provides several reports for monitoring system operating conditions, including state } \\
\text { estimation report, load flow report, performance indices report, and analog and status } \\
\text { summary. }\end{array}$ \\
\hline 3. & ADMS & $\begin{array}{l}\text { DMS provides ability to obtain historical data - tools like historical data configuration, } \\
\text { historical data browser and trending. MGC I/O with SCADA points that are stored in ADMS } \\
\text { historical data and can be transferred to PI will be attached. }\end{array}$ \\
\hline
\end{tabular}

\section{E.2.1. Scenario 1 - DMS Alarm System for Events or Conditions Needing Operator Attention}

In this scenario, DMS and SCADA alarms are defined and represented in ADMS. SCADA alarms are triggered when a measured SCADA value exceeds a predefined limit. SCADA alarms can have several levels, and for each of them an alarm with different severity would be triggered. SCADA alarms are part of the network model; however, they can be overridden in real time as shown in Figure 60.

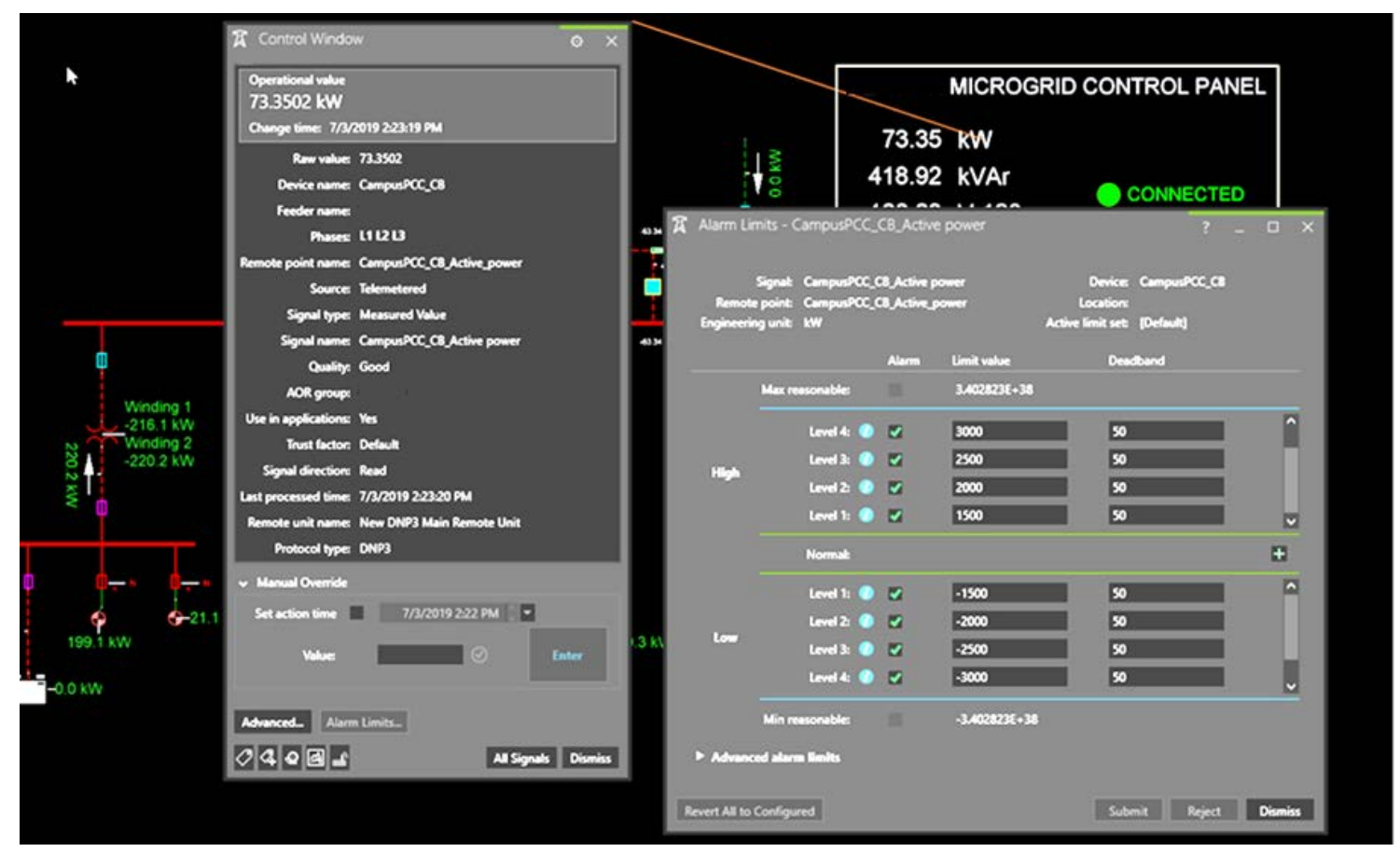

FIGURE 60 SCADA alarms (control window and alarm limits) 
In addition to SCADA alarms, it is possible to define DMS alarms in ADMS. DMS alarms are triggered when estimated values exceed predefined limits. The main purpose of DMS alarms is to notify the operator that in the non-observable part of the grid there might be a violation that was estimated by state estimation and load flow. Like SCADA alarms, DMS alarms can be defined with several severity levels. DMS alarms are also part of the network mode; however, they can be overridden from the DMD by an operator. This is shown in Figure 61.

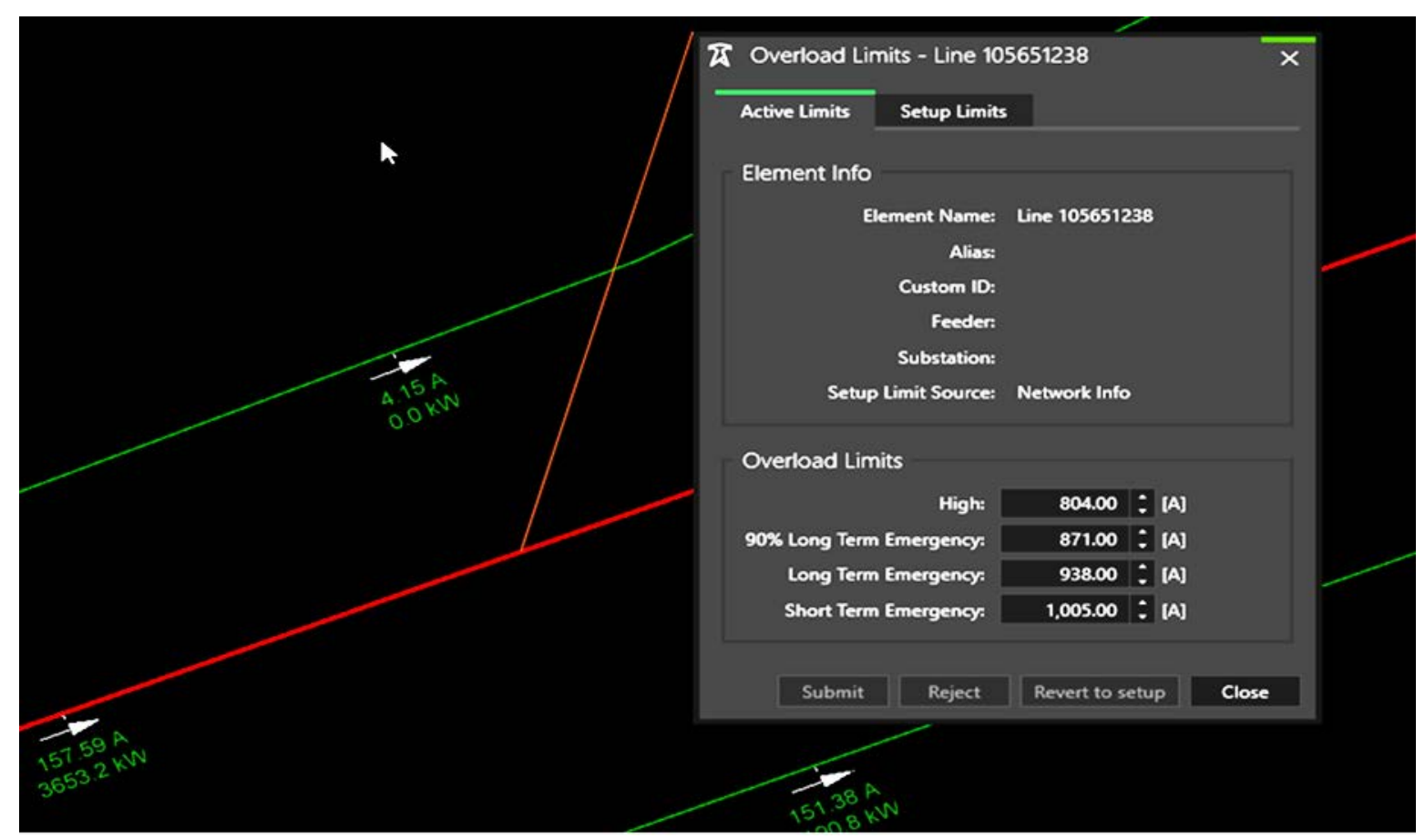

FIGURE 61 DMS alarms (right clicked to show overload limits)

\section{E.2.2. Scenario 2 - Monitoring Key Power System Parameters}

This scenario describes how an operator can monitor key power system parameters, as shown in Figure 62. There are four steps in this scenario. In the first step, an operator has the ability to monitor real-time measurements like active powers, reactive powers, voltages, etc. Real-time measurements are marked with a number 1 in Figure 62. In the second step, the system operator has the ability to monitor estimated values like active powers, reactive powers, voltages, etc., marked with a 2 . In the third step, the system operator has the ability to monitor switch statuses of breakers on the PCC, DERs, etc., marked with a 3. Finally, in the fourth step, the system operator has the ability to monitor operating conditions and measurements of the microgrid from the dashboard, marked with a 4. 


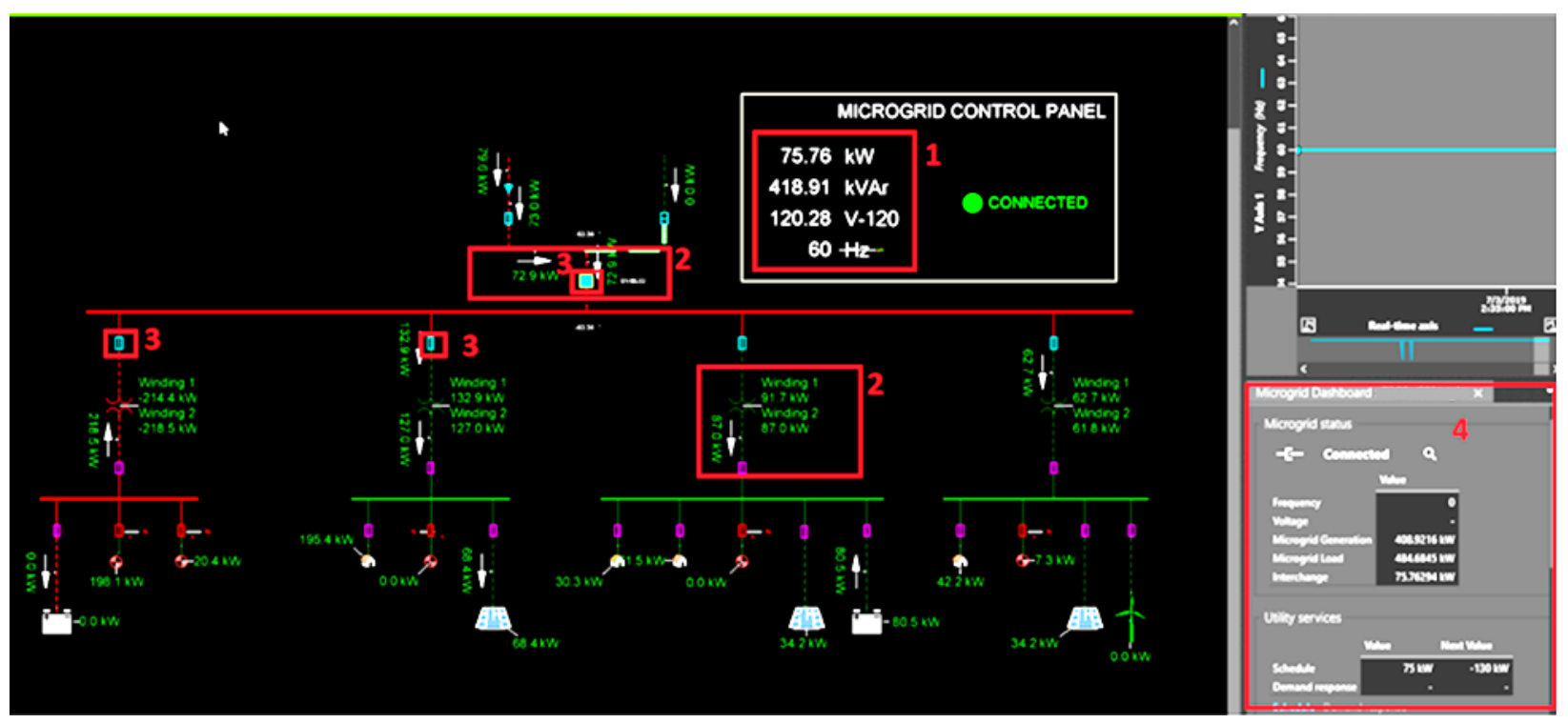

FIGURE 62 Monitoring of key power system parameters

\section{E.2.3. Scenario 3 - Other Monitoring Possibilities}

The ADMS can provide an indication of SCADA and signal quality. The ADMS can also provide several reports for monitoring operating conditions of the system, such as a state estimation report, load flow report, performance indices report, and analog and status summary. Reports can be found in the appropriate functional specification. In this document, only the state estimation report is shown (Figure 63). In the state estimation report, the most important tab is the measurements tab. In this tab, a list of all measurements can be found with their SCADA quality flags. For each measurement, the measured value and the estimated value can be seen, enabling the operator to confirm state estimation results.

The ADMS also provides a historical service through which historical data can be stored. It provides several tools for obtaining historical data, like a historical data browser, historical data export, and trending. The historical data browser provides the ability to show historical information, while historical data export provides the ability to export data. 


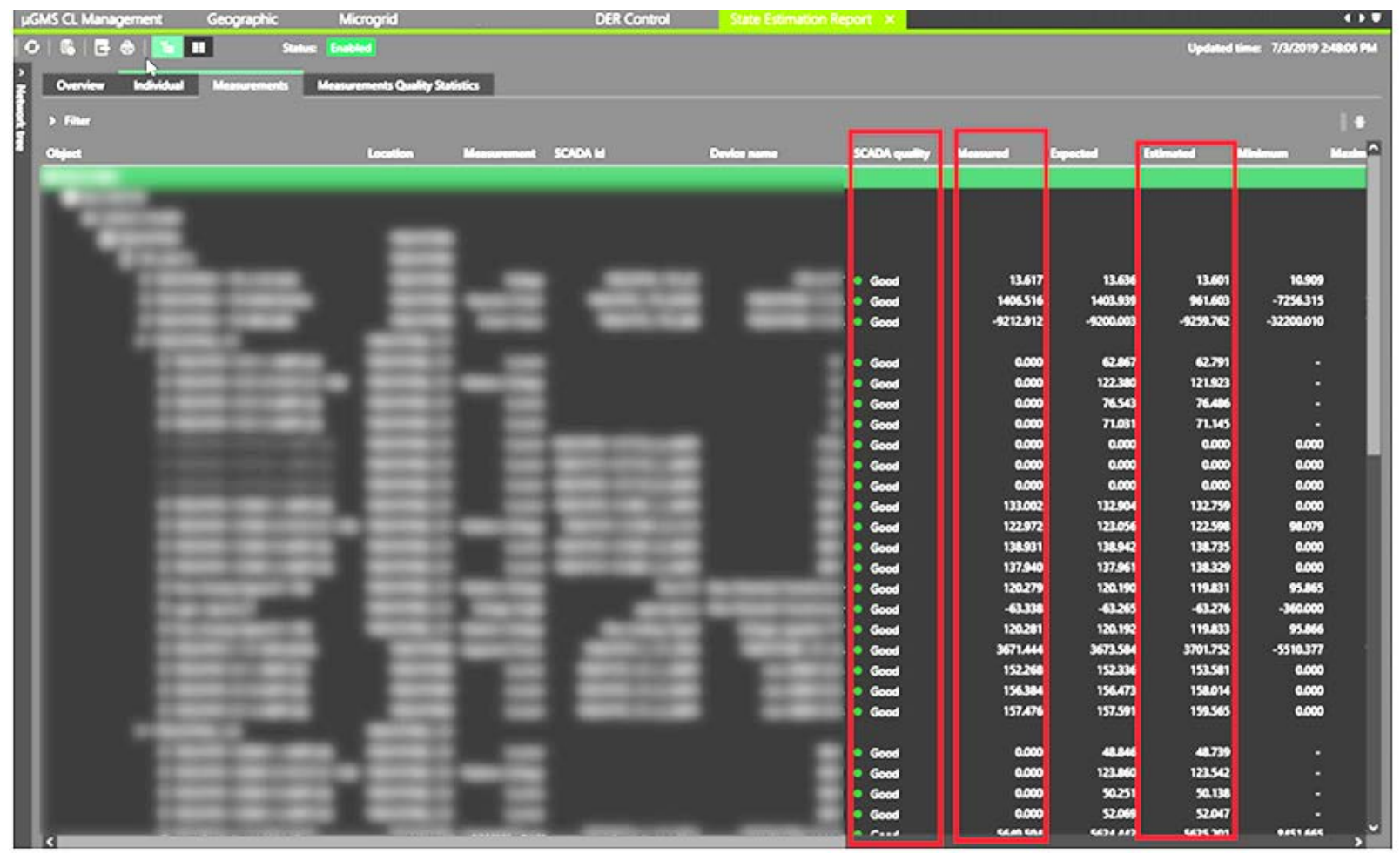

FIGURE 63 State estimation report (core apps and state estimation report)

\section{E.3 USE CASE 3 - CAPACITY MANAGEMENT USING MICROGRID BY DMS}

\section{TABLE 14 Use Case 3}

\begin{tabular}{l|l|l} 
Step & \multicolumn{1}{|c|}{ Actor } & \multicolumn{1}{c}{ Description } \\
Ability to Manage Power Flow Across PCC \\
\hline \multicolumn{2}{l}{ Scenario 1 - Active Power } \\
\hline 1. & MGC & $\begin{array}{l}\text { ADMS control of microgrid is enabled from MGC HMI. ADMS receives indication that } \\
\text { ADMS_CONTROL_MODE signal is 1 (enabled). } \\
\text { Note: This step can be considered aa precondition. If it is already satisfied, it does not } \\
\text { need to be executed. }\end{array}$ \\
\hline 2. & ADMS & $\begin{array}{l}\text { Operator sets constant active and reactive power mode control from ADMS by sending } \\
\text { value } 1 \text { (enabled) to signals PCC_P_MODE_CMD and PCC_Q_MODE_CMD. } \\
\text { Note: This step can be considered a precondition. If it is already satisfied, it does not need } \\
\text { to be executed. }\end{array}$ \\
\hline 3. & ADMS & $\begin{array}{l}\text { System operator sends desired active power setpoint to microgrid controller to control } \\
\text { active power across PCC, PCC_P_SET. The setpoint must be between high and low limits } \\
\text { shown on DMD (PCC_P_HI, PCC_P_LO). }\end{array}$ \\
\hline 4. & MGC & $\begin{array}{l}\text { Microgrid controller receives desired setpoint and uses this information to adjust output of } \\
\text { DERs. }\end{array}$ \\
\hline
\end{tabular}




\begin{tabular}{l|l|l}
\multicolumn{1}{c|}{ Step } & \multicolumn{1}{|c|}{ Actor } & \multicolumn{1}{c}{ Description } \\
\hline 5. & MGC & Measured value at PCC becomes equal to the setpoint. \\
\hline 6. & ADMS & ADMS receives measured value of active power in PCC (PCC_P). \\
\hline
\end{tabular}

\section{Scenario 2 - Reactive Power}

\begin{tabular}{|c|c|c|}
\hline 1. & MGC & $\begin{array}{l}\text { ADMS control of microgrid is enabled from MGC HMI. ADMS receives indication that } \\
\text { ADMS_CONTROL_MODE signal is } 1 \text { (enabled). } \\
\text { Note: This step can be considered a precondition. If it is already satisfied, it does not need } \\
\text { to be executed. }\end{array}$ \\
\hline 2. & ADMS & $\begin{array}{l}\text { Operator sets constant active and reactive power mode control from ADMS by sending } \\
\text { value } 1 \text { (enabled) to signals PCC_P_MODE_CMD and PCC_Q_MODE_CMD. } \\
\text { Note: This step can be considered a precondition. If it is already satisfied, it does not need } \\
\text { to be executed. }\end{array}$ \\
\hline 3. & ADMS & $\begin{array}{l}\text { System operator sends desired reactive power setpoint to microgrid controller to control } \\
\text { reactive power across PCC (PCC_Q_SET). The setpoint must be between high and low } \\
\text { limits shown on DMD (PCC_Q_HI, PCC_Q_LO). }\end{array}$ \\
\hline 4. & MGC & $\begin{array}{l}\text { Microgrid controller receives desired setpoint and uses this information to adjust output of } \\
\text { DERs. }\end{array}$ \\
\hline 5. & MGC & Measured value at PCC becomes equal to setpoint. \\
\hline 6. & ADMS & ADMS receives measured value of reactive power in PCC (PCC_Q). \\
\hline
\end{tabular}

Scenario 3 - Autonomous Load Relief Scenario, No Operator Intervention

\begin{tabular}{l|l|l}
\hline 1. & MGC & $\begin{array}{l}\text { ADMS control of microgrid is enabled from MGC HMI. ADMS receives indication that } \\
\text { ADMS_CONTROL_MODE signal is 1 (enabled). } \\
\text { Note: This step can be considered a precondition. If it is already satisfied, it does not need } \\
\text { to be executed. }\end{array}$ \\
\hline 2. & ADMS & $\begin{array}{l}\text { Operator sets constant active and reactive power mode control from ADMS by sending } \\
\text { value 1 (enabled) to signals PCC_P_MODE_CMD and PCC_Q_MODE_CMD. } \\
\text { Note: This step can be considered } \text { a precondition. If it is already satisfied, it does not need } \\
\text { to be executed. }\end{array}$ \\
\hline 3. & ADMS & ADMS detects overload on the feeder currently grid-connected with microgrid. \\
\hline 4. & ADMS & Load relief in closed loop is triggered. \\
\hline 5. & ADMS & MGC provides high and low limits for active power in PCC (PCC_P_HI, PCC_P_LO). \\
\hline 6. & ADMS & $\begin{array}{l}\text { Load relief uses high and low limits obtained from microgrid controller to calculate new } \\
\text { active power setpoint (PCC_P_SET). }\end{array}$ \\
\hline 7. & ADMS & ADMS sends new setpoint to MGC to control active power across PCC. \\
\hline 8. & MGC & $\begin{array}{l}\text { Microgrid controller receives desired setpoint and uses this information to adjust output of } \\
\text { DERs. }\end{array}$ \\
\hline 9. & MGC & Measured value in PCC becomes equal to the setpoint. \\
\hline
\end{tabular}




\begin{tabular}{|c|c|c|}
\hline Step & Actor & Description \\
\hline 10. & ADMS & ADMS receives measured value of active power in PCC (PCC_P). \\
\hline \multicolumn{3}{|c|}{ Scenario 4 - Autonomous Power Factor Mitigation } \\
\hline 1. & MGC & $\begin{array}{l}\text { ADMS control of microgrid is enabled from MGC HMI. ADMS receives indication that } \\
\text { ADMS_CONTROL_MODE signal is } 1 \text { (enabled). } \\
\text { Note: This step can be considered a precondition. If it is already satisfied, it does not need } \\
\text { to be executed. }\end{array}$ \\
\hline 2. & ADMS & $\begin{array}{l}\text { Operator sets constant active and reactive power mode control from ADMS by sending } \\
\text { value } 1 \text { (enabled) to signals PCC_P_MODE_CMD and PCC_Q_MODE_CMD. } \\
\text { Note: This step can be considered a precondition. If it is already satisfied, it does not need } \\
\text { to be executed. }\end{array}$ \\
\hline 3. & ADMS & $\begin{array}{l}\text { After sending new active power setpoint, ADMS detects that power factor constraint at } \\
\text { primary side of supply transformer is not satisfied. }\end{array}$ \\
\hline 4. & ADMS & MGC provides high and low limits for reactive power at PCC (PCC_Q_HI, PCC_Q_LO). \\
\hline 5. & ADMS & $\begin{array}{l}\text { VVWO uses reactive power limits provided by MGC to calculate new optimal value of } \\
\text { reactive power at PCC. }\end{array}$ \\
\hline 6. & ADMS & VVWO sends new reactive power setpoint to MGC (PCC_Q_SET). \\
\hline 7. & MGC & $\begin{array}{l}\text { MGC engages reactive power resources within microgrid to provide desired value of } \\
\text { reactive power at PCC. }\end{array}$ \\
\hline 8. & MGC & Measured value at PCC becomes equal to the setpoint. \\
\hline 9. & ADMS & ADMS receives measured value of reactive power in PCC (PCC_Q). \\
\hline 10. & ADMS & $\begin{array}{l}\text { ADMS detects that power factor constraints are satisfied after VVWO sent new reactive } \\
\text { power setpoint or provides information in VVWO execution report if power factor } \\
\text { constraint remains unsatisfied. }\end{array}$ \\
\hline \multicolumn{3}{|c|}{ Other Requirements } \\
\hline 1. & ADMS & ADMS enables coloring of the sections according to their relative load. \\
\hline
\end{tabular}

The screenshots created during the execution of these scenarios are shown in the following sections.

\section{E.3.1. Scenarios 1 and 2 - Ability to Manage Power Flow Across PCC}

This scenario shows how an operator can manually change the active power of the microgrid at the PCC. It is expected that the operator will manually send a desired value of active power to the MGC. After that, the MGC will engage its resources to maintain the desired level of active power at the PCC. 
This scenario has four steps. In the first step, the system operator sends a desired active power setpoint to the microgrid controller. The setpoint must be between the high and low limits shown in DMD. High and low limits are shown in Figure 64. It is possible to schedule the setpoint of batteries in two ways. First, it is possible to send setpoint to the MGC. Second, it is possible to create the schedule of active power setpoints in the next time period. In this case, DERMS will use the information about setpoints from the schedule and it will automatically dispatch the batteries using the scheduled values. This is shown in Figure 65.

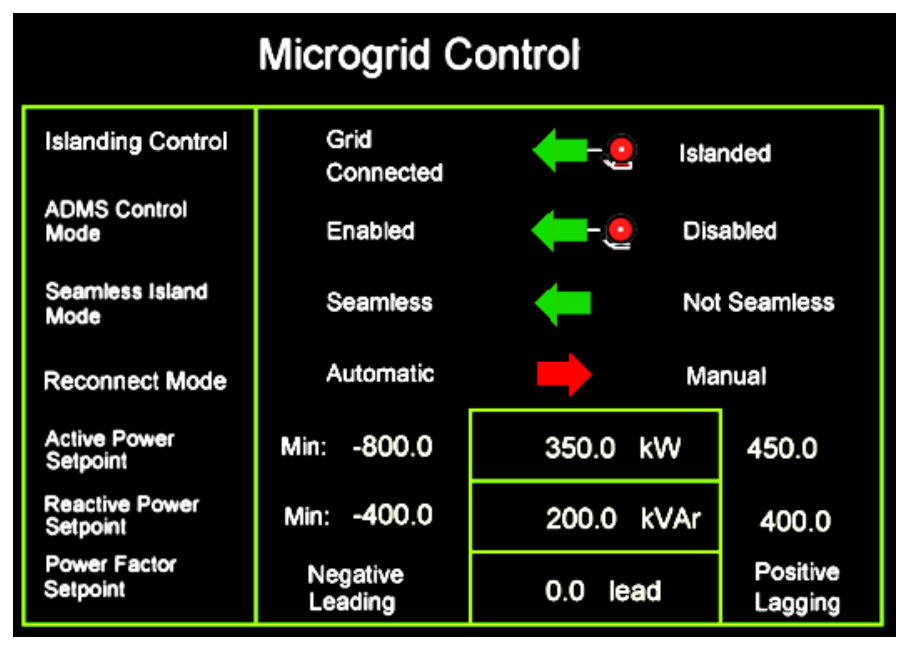

FIGURE 64 High and low limits 


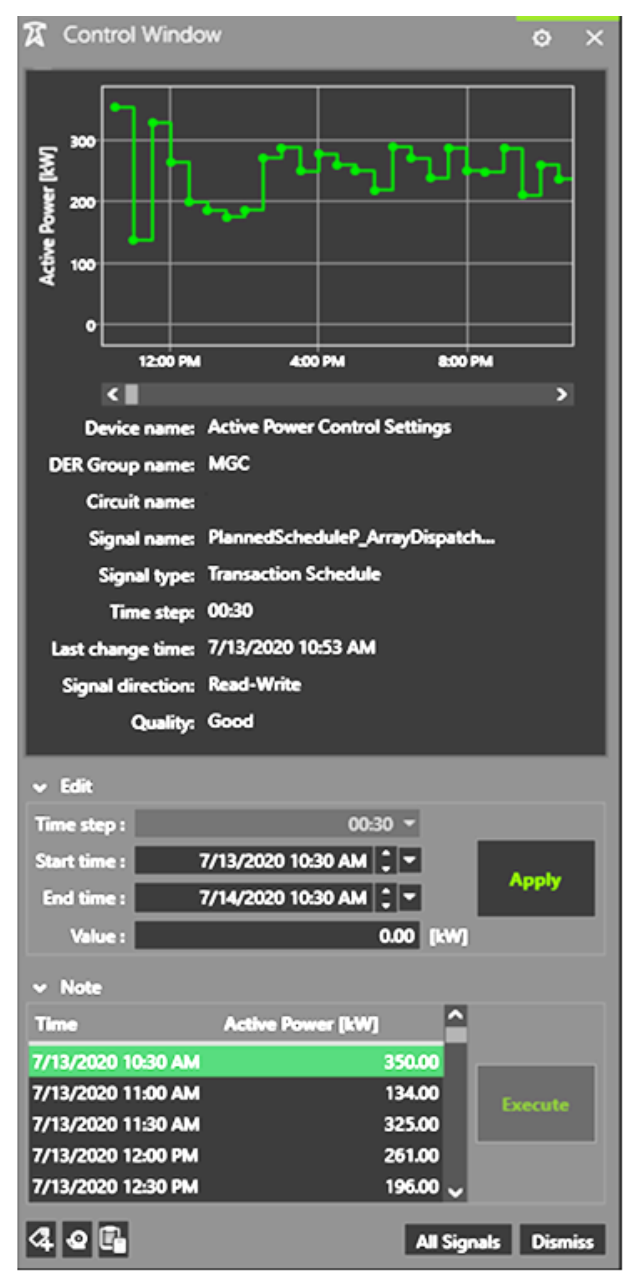

FIGURE 65 Microgrid operation schedule

\section{E.3.2. Scenario 3 - Microgrid Setpoint Is Determined Using Load Relief}

In this scenario, LR detects an overload problem in the system and tries to resolve it using the microgrid as a resource. Before Step 1, it is necessary to run LR in closed loop. LR can be run for the whole substation. Standby status is obtained as no violation is detected in the system. In the first step, ADMS estimates that overload is detected in the section upstream from the microgrid. An ADMS alarm is triggered, which then triggers LR, as shown in Figure 66 and Figure 67. Then the MGC would provide high and low limits for active power at the PCC, as in the previous scenario, and those limits would be used by DERMS. After successful execution of LR, the ADMS sends a new setpoint of active power to the microgrid. In Figure 68, LR execution was successful and all violations are resolved. 


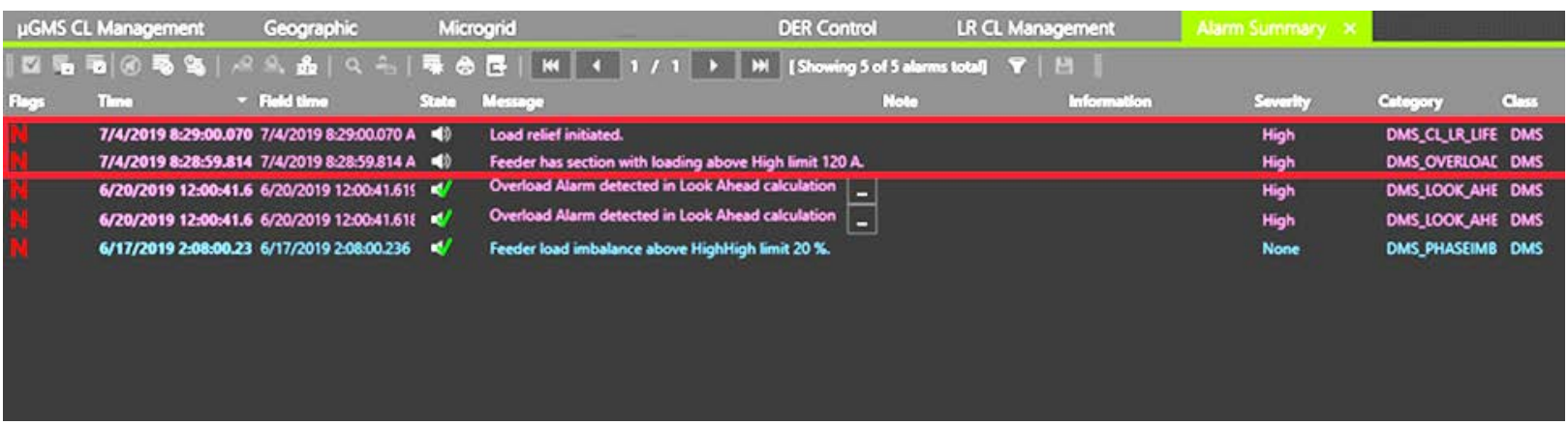

FIGURE 66 Alarm summary when LR is triggered (summary and alarm summary)

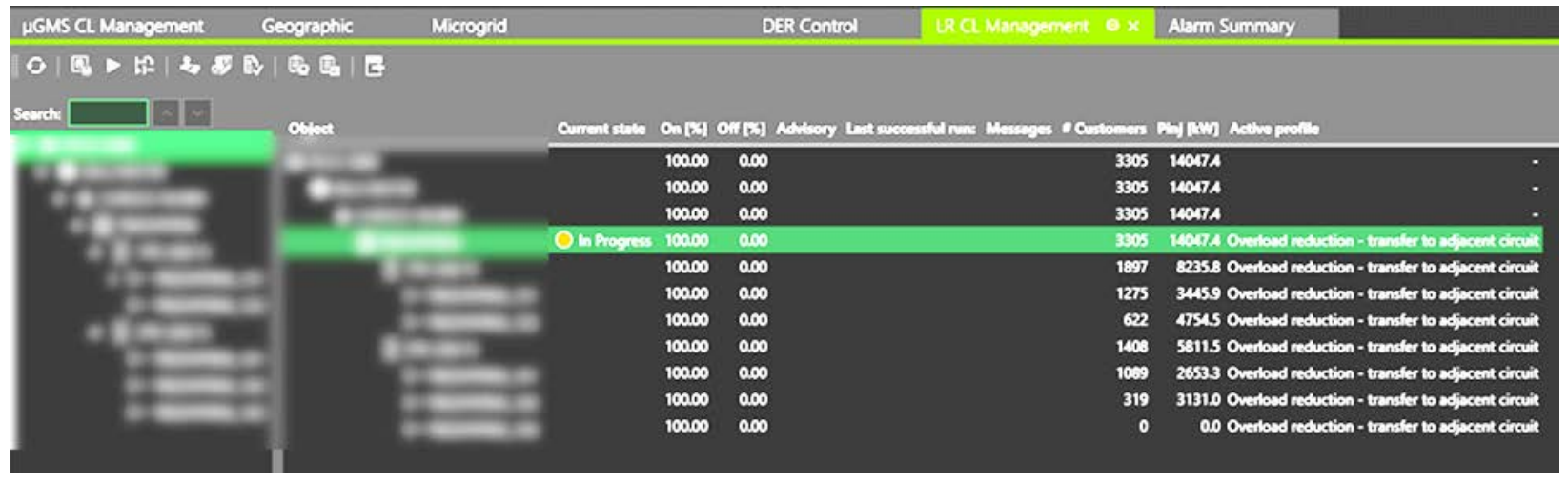

FIGURE 67 LR is triggered and calculates optimal setpoint (core apps and LR closed loop)

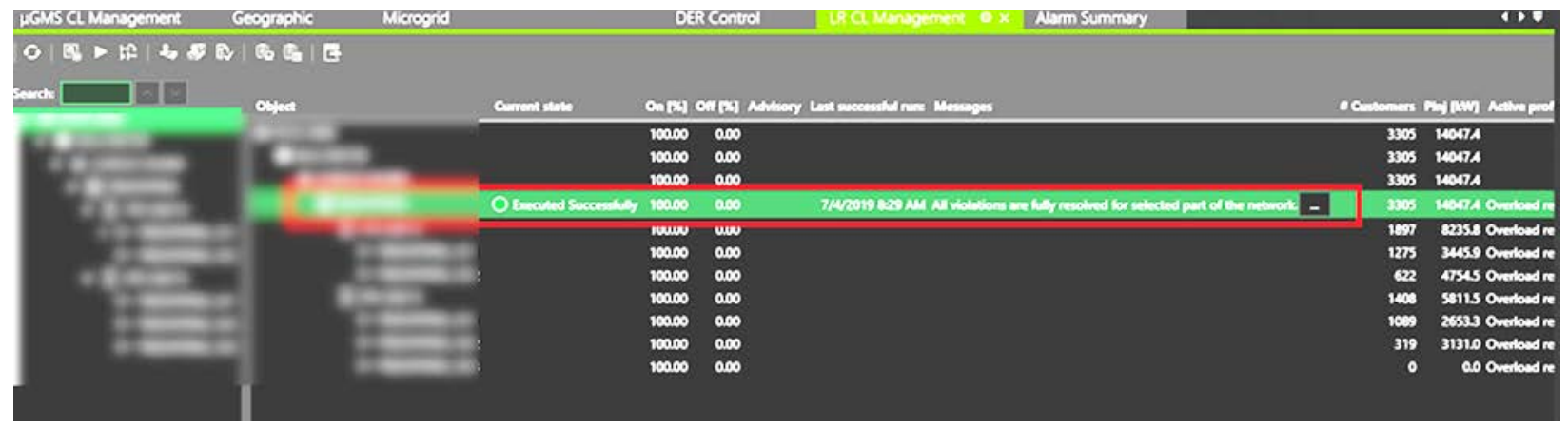

FIGURE 68 LR execution is successful (core apps and LR closed loop) 


\section{E.4 USE CASE 4 - UTILITY VOLTAGE SUPPORT USING MICROGRID BY ADMS}

\section{TABLE 15 Use Case 4}

\begin{tabular}{|c|c|c|}
\hline Step & Actor & Description \\
\hline \multicolumn{3}{|c|}{ Scenario 1 - Regulate Active and/or Reactive Power from VVWO } \\
\hline 1. & MGC & $\begin{array}{l}\text { ADMS control of microgrid is enabled from MGC HMI. ADMS receives indication that } \\
\text { ADMS_CONTROL_MODE signal is } 1 \text { (enabled). } \\
\text { Note: This step can be considered a precondition. If it is already satisfied, it does not need } \\
\text { to be executed. }\end{array}$ \\
\hline 2. & ADMS & $\begin{array}{l}\text { Operator sets constant active and reactive power mode control from ADMS by sending } \\
\text { value } 1 \text { (enabled) to signals PCC_P_MODE_CMD and PCC_Q_MODE_CMD. } \\
\text { Note: This step can be considered a precondition. If it is already satisfied, it does not need } \\
\text { to be executed. }\end{array}$ \\
\hline 3. & ADMS & $\begin{array}{l}\text { VVWO is manually turned on and monitors the system according to predefined VVWO } \\
\text { profile. }\end{array}$ \\
\hline 4. & MGC & $\begin{array}{l}\text { MGC provides high and low active and/or reactive power limits for microgrid } \\
\text { (PCC_P_HI, PCC_P_LO, PCC_Q_HI, PCC_Q_LO). }\end{array}$ \\
\hline 5. & ADMS & $\begin{array}{l}\text { VVWO uses high and low limits obtained from microgrid controller to calculate new } \\
\text { optimal values of active and/or reactive power setpoints at PCC (PCC_P_SET, } \\
\text { PCC_Q_SET). }\end{array}$ \\
\hline 6. & ADMS & ADMS sends new setpoint(s) of active and/or reactive power assigned to microgrid PCC. \\
\hline 7. & MGC & $\begin{array}{l}\text { Microgrid controller receives desired power setpoint(s) and uses it to control DER } \\
\text { resources within microgrid. }\end{array}$ \\
\hline 8. & MGC & Measured values at PCC become equal to the setpoints. \\
\hline 9. & ADMS & $\begin{array}{l}\text { ADMS receives measured values of active and/or reactive power at PCC (PCC_P, } \\
\text { PCC_Q). }\end{array}$ \\
\hline \multicolumn{3}{|c|}{ Other Requirements } \\
\hline 1. & ADMS & ADMS enables coloring of the sections according to their relative voltages. \\
\hline
\end{tabular}

\section{E.4.1. Scenario 1 - Regulate Active and/or Reactive Power from VVWO}

This scenario shows how the ADMS would try to resolve a problem with voltages using the microgrid active and/or reactive power. In the first step, VVWO in closed loop must be turned on.

After VVWO in closed loop is started, ADMS would use high and low limits of the MGC to calculate a new optimal active power setpoint. The new optimal setpoint is sent to the MGC, and the MGC engages resources to obtain the desired value of active power at the PCC. Figure 69 shows the microgrid view after the execution of VVWO. The measured value of active power in PCC is marked with a number 1 . The microgrid is producing energy, which is the expected result 
as it was needed to increase the voltages. In the trending window, the voltage at the PCC is changed over time. This is marked with 2 . After the execution of VVWO, the voltage value at the PCC is no longer below 120 volts. Since the microgrid is connected very close to the supplied line, it is necessary to export more than $1 \mathrm{MW}$ of active power across the PCC in order to demonstrate VVWO functionality.

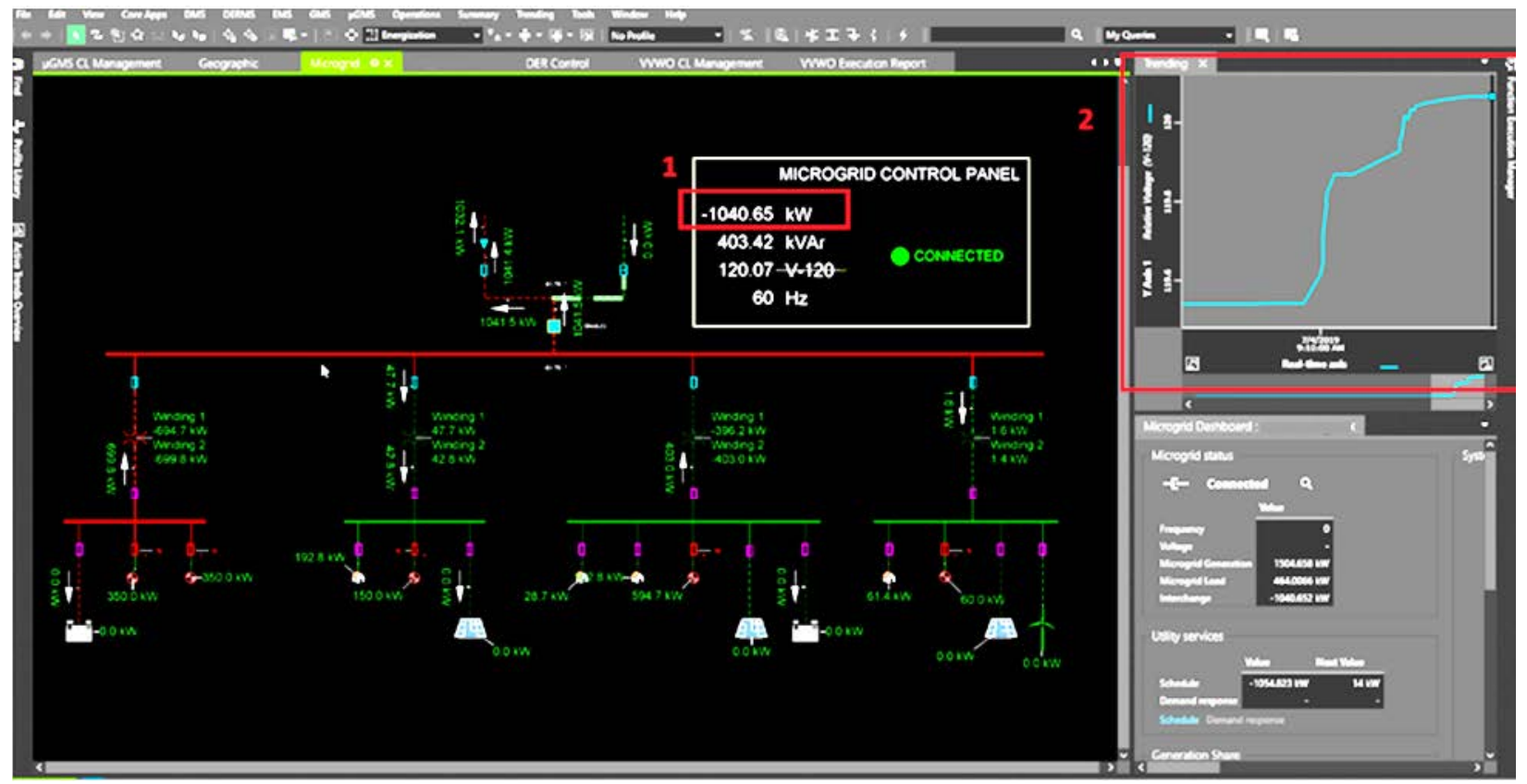

FIGURE 69 Microgrid view after execution of VVWO

\section{E.4.2. Scenario 2 - Autonomous Power Factor Mitigation}

In this scenario, VVWO is used to resolve a power factor violation on the primary side of the supply transformer. 


\section{Argonne}

\section{Energy Systems Division}

Argonne National Laboratory

9700 South Cass Avenue, BIdg. 362

Lemont, IL 60439-4832

www.anl.gov 